NBER WORKING PAPER SERIES

\title{
MIND THE GAP! CONSUMER PERCEPTIONS AND CHOICES OF MEDICARE PART D PRESCRIPTION DRUG PLANS
}

\author{
Florian Heiss \\ Daniel McFadden \\ Joachim Winter \\ Working Paper 13627 \\ http://www.nber.org/papers/w13627 \\ NATIONAL BUREAU OF ECONOMIC RESEARCH \\ 1050 Massachusetts Avenue \\ Cambridge, MA 02138 \\ November 2007
}

\begin{abstract}
We thank Abby Block, Carol Kelly, and Audrey McDowell of CMS, Dana Goldman of RAND, and Richard Suzman of NIA for information and comments. Helpful comments were also obtained from Amy Finkelstein and Arie Kapteyn; from conference participants at the AEA Annual Meeting in Chicago, IL (January 2007), the NBER Conference on the Economics of Aging, Carefree, AZ (May 2007), the Workshop on the Economics of Aging at Collegio Carlo Alberto, Turin (May 2007), and from seminar participants at the University of Mannheim and the ifo Institute, Munich. Dedicated research assistance was provided by Byung-hill Jun, Carlos Noton, and Gregor Tannhof. This research was supported by the Behavioral and Social Research program of the National Institute on Aging (grants P01 AG 05842-18 and R56 AG026622-01A1), with additional support from the E. Morris Cox Fund at the University of California, Berkeley. The authors are solely responsible for the results and conclusions offered in this paper. The views expressed herein are those of the author(s) and do not necessarily reflect the views of the National Bureau of Economic Research.

(C) 2007 by Florian Heiss, Daniel McFadden, and Joachim Winter. All rights reserved. Short sections of text, not to exceed two paragraphs, may be quoted without explicit permission provided that full credit, including $\odot$ notice, is given to the source.
\end{abstract}


Mind the Gap! Consumer Perceptions and Choices of Medicare Part D Prescription Drug Plans Florian Heiss, Daniel McFadden, and Joachim Winter

NBER Working Paper No. 13627

November 2007

JEL No. C25,C61,C81,D12,D91,H51,I10,I12,I18

\begin{abstract}
$\underline{\text { ABSTRACT }}$
Medicare Part D provides prescription drug coverage through Medicare approved plans offered by private insurance companies and HMOs. In this paper, we study the role of current prescription drug use and health risks, related expectations, and subjective factors in the demand for prescription drug insurance. To characterize rational behavior in the complex Part D environment, we develop an intertemporal optimization model of enrollment decisions. We generally find that seniors' choices respond to the incentives provided by their own health status and the market environment as predicted by the optimization model. The proportion of individuals who do not attain the optimal choice is small, but the margin for error is also small since enrollment is transparently optimal for most eligible seniors. Further, there is also evidence that seniors over-react to some salient features of the choice situation, do not take full account of the future benefit and cost consequences of their decisions, or the expected net benefits and risk properties of alternative plans.
\end{abstract}

Florian Heiss

Department of Economics

University of Munich

Ludwigstr. 28 (RG)

D-80539 Munich

Germany

florian.heiss@lrz.uni-muenchen.de

Daniel McFadden

University of California, Berkeley

Department of Economics

549 Evans Hall \#3880

Berkeley, CA 94707-3880

and NBER

mcfadden@econ.berkeley.edu
Joachim Winter

Department of Economics

University of Munich

Ludwigstr. 28 (RG)

D-80539 Munich

Germany

joachim.winter@1rz.uni-muenchen.de 


\section{Introduction}

Medicare Part D provides prescription drug coverage through Medicare-approved plans sponsored by private insurance companies and HMOs. This new program is part of the current trend towards consumer-directed health care. However, making optimal, or even just reasonable, decisions in the Part $\mathrm{D}$ market is difficult for seniors. They face uncertainty with respect to their future health status and drug costs, and a rather complicated benefit schedule with a coverage gap and other peculiar institutional features of the Part D program, as well as a large number of available plans with features that vary along several dimensions. How seniors decide whether to enroll in Medicare Part D, and what plans they select, is therefore not only of crucial importance for public policy, but also an informative experiment on how consumers behave in real-world decision situations with a complex, ambiguous structure and high stakes.

In the week before Medicare Part D enrollment began in November 2005, we conducted a survey of Americans aged 65 and above, termed the Retirement Perspectives Survey (RPS) to study information, perceptions, and preferences regarding prescription drug use, cost, and insurance. After the initial enrollment period closed on May 15, 2006, we re-interviewed the same respondents to elicit their actual Medicare Part D decisions for 2006. In addition, we presented hypothetical choice tasks with experimental variation of plan features. In a third wave of our survey, we re-interviewed our respondents in March and April 2007 to collect data about their experiences in the first year of Medicare Part D and their choices for 2007. ${ }^{2}$

We found in our first interview of eligible seniors in November 2005 that despite the complexity of the program's competing plans, which can differ in premiums and coverage, a majority of the Medicare population had at least some knowledge of Part D and intended to enroll. However, lowincome, less educated elderly with poor health or some cognitive impairment were significantly less informed, and we concluded at that time that they might fail to take advantage of the new program; see Winter et al (2006). In our May 2006 survey following the initial enrollment period, we confirmed that Medicare has met its target of $90 \%$ coverage in the Medicare-eligible population; see Heiss, McFadden, and Winter (2006). However, we also found that sizable numbers of elderly people remain uncovered.

\footnotetext{
${ }^{2}$ In what follows, the three waves of the Retirement Perspectives Survey are referred to as RPS-2005, RPS-2006, and RPS-2007, respectively.
} 
Consumer opinions about Part D were mixed just after the initial enrollment period in May 2006. Majorities were troubled by the deductible and gap provisions of Standard Part D coverage, and found it difficult to determine the current and future formularies of the plans they evaluated. Asked the question "Does your experience with Medicare Part D leave you more satisfied or less satisfied with the Medicare program?", $58.1 \%$ said they were less satisfied. Asked the question "Does your experience with Medicare Part D leave you more satisfied or less satisfied with the political process in Washington that produced this program?", $74.7 \%$ said they were less satisfied. These responses indicated substantial dissatisfaction with the design and administration of the program at that point in time. This raises a more general issue: Consumers are often skeptical about markets, and suspicious of their organizers (McFadden, 2006). This may lead consumers to question market solutions to public good allocation problems despite the attractions of consumer-directed choice. This seems to have been the case for Part D. We did not re-ask general opinion questions regarding Part D in 2007, but surveys by the Kaiser Family Foundation find that levels of dissatisfaction with the Part D program have fallen from 55\% at its inception to $34 \%$ at the end of 2006, with remaining dissatisfaction focused on the complexity of the program, formularies, the gap, and tedious appeals procedures.

In this paper, we study the actual enrollment decisions made in the initial enrollment period for the Medicare Part D program. In most of our analysis, we concentrate on "active deciders", the eligible individuals in our sample who did not have prescription drug coverage in November 2005 that was automatically converted to Part D coverage or equivalent in 2006 (e.g., automatic coverage through their current or former employer's health program, the Veterans Administration, or Medicaid). The first part of our analysis is descriptive; its intention is to study whether choices were related to the salient features of the program and the economic incentives they generated. We look at whether active deciders enrolled in Part D or not, at the timing of enrollment, and at the choice of plans. We stress the role of 2005 prescription drug use, health risks, related expectations, and subjective factors in the demand for prescription drug insurance.

In the second part, we develop a stylized intertemporal optimization problem faced by an individual without other prescription drug coverage during the initial enrollment period. We calibrate, solve and simulate this model using data on the dynamics of health status and chronic conditions as well as drug use and expenditure taken from the Medicare Current Beneficiary Survey (MCBS). This normative analysis allows us to characterize optimal intertemporal decision-making rules in the presence of risk. We then 
combine these results with our own data to study the rationality of decisions in the Medicare Part D initial enrollment period.

We generally find that seniors' choices respond to the incentives provided by their own health status and the market environment as predicted by our intertemporal optimization model. However, there is also evidence that seniors over-reacted to some of the salient features of the choice situation, particularly 2006 costs and benefits, and were insufficiently sensitive to future cost and benefit consequences of their current decisions. We find that the proportion of individuals who do not attain the optimal choice is relatively small, but some of this is due to the fact that enrollment was clearly immediately beneficial for $81.7 \%$ of the population, and was intertemporally optimal for $97.5 \%$. Given these program features, there was limited opportunity for error. Consumers were less consistently rational in their choices among plans, often selecting inexpensive plans in circumstances where plans with more expensive and comprehensive coverage were actuarially favorable.

The remainder of this paper is structured as follows. In section 2, we describe the new Medicare Part D prescription drug benefit and the plans offered by private insurers during the initial enrollment period from November 2005 through May 2006. The existing literature on Medicare Part D, and on the demand for health insurance plans more generally, is reviewed briefly in section 3 . We then introduce our primary source of data, the Retirement Perspectives Survey (section 4). Section 5 contains our descriptive analysis of decisions in the initial enrollment period. In section 6, we develop, calibrate, and simulate an intertemporal optimization model of the Medicare Part D enrollment decision, and we evaluate the rationality of observed decisions. Section 7 takes a preliminary look at the data from the final wave of our survey to characterize first-year experiences with Part D. Section 8 contains some concluding remarks.

\section{The Medicare Part D prescription drug benefit}

The Centers for Medicare and Medicaid Services (CMS) within the U.S. Department of Health and Human Services administer health insurance coverage for older Americans via the Medicare program. The Medicare Modernization Act of 2003 (MMA) was enacted to extend coverage for prescription drugs to the Medicare population. Beginning in 2006, the new Medicare Part D benefit reduced the financial burden of prescription drug spending for beneficiaries, especially those with low incomes or extraordinarily high ("catastrophic") out-of-pocket drug expenses. CMS administers this program, subsidizing outpatient prescription drug coverage offered by private sponsors of drug plans that give 
beneficiaries access to a standard prescription drug benefit. ${ }^{3}$ Critical parameters in determining Standard plan benefits are the plan formulary, the beneficiary's annual pharmacy bill for drugs in the plan formulary, the beneficiary's true out-of-pocket (TrOOP) payments for these covered drugs and threshold for catastrophic coverage, and the average monthly premium. In the benefits formula, expenditures for drugs not in the plan formulary are not counted in the pharmacy bill or in TrOOP payments. Part D premiums are also excluded from TrOOP payments. The Standard Medicare Part D plan had the following benefit schedule in 2006 :

- The beneficiary has an annual deductible of $\$ 250$.

- The beneficiary pays $25 \%$ of drug costs above $\$ 250$ and up to $\$ 2,250$. The TrOOP payment is then $\$ 750$ for a beneficiary whose pharmacy bill has reached $\$ 2,250$.

- The beneficiary pays $100 \%$ of drug costs above $\$ 2,250$ and up to a TrOOP payment of $\$ 3,600$; this is referred to as the coverage gap or doughnut hole. The TrOOP threshold of $\$ 3,600$ is attained at a drug bill of $\$ 5,100$.

- The beneficiary pays 5\% of drug costs above a drug cost threshold of $\$ 5,100$ at which the TrOOP threshold level is achieved; this is referred to as catastrophic coverage.

- Monthly premiums vary with plan sponsor and area, but a national average premium determined by CMS (and used in determining its subsidy) is a publically available indicator of plan cost to beneficiaries.

Figure 1 shows the 2006 benefit schedule as a function mapping the total yearly drug bill into TrOOP cost. Standard plan coverage in 2007 and 2008 has the same structure, with Table 1 showing the adjustments of plan parameters to reflect market base premiums and inflation in drug prices. Section 5.3 provides a calculation of the actuarial value of Standard plan benefits, based on a projection by CMS in 2005 of the distribution of 2006 drug costs for the full Medicare-eligible population. This calculation shows that the 2006 expected drug cost in this population was $\$ 245.03$ per month. If enrollment in the Part D Standard plan had been universal, the expected benefit would have been $\$ 128.02$ per month, or $\$ 91.13$ net of the monthly average premium of $\$ 37$ anticipated in 2005 , and the expected TrOOP cost would have been $\$ 117.01$ per month. The actual monthly average premium of $\$ 32.20$ in 2006 was lower than anticipated; we interpret this as the result of lower drug costs arising from pharmacy benefit management and drug

\footnotetext{
${ }^{3}$ See http://www.medicare.gov/medicarereform/drugbenefit.asp.
} 
price negotiations by sponsors, resulting in 2006 average drug cost of $\$ 215.85$ per month, an expected benefit of $\$ 111.74$ per month, or $\$ 79.55$ net of the premium, and TrOOP cost of $\$ 104.11$ per month.

The Medicare Part D plans sponsored by private insurance firms may differ from the Standard plan in their premiums and other plan features, provided that their benefits for any drug cost are on average at least as high as those of the Standard plan. Enhancements may include coverage for the $\$ 250$ deductible and for the gap in the standard plan. CMS classifies the stand-alone prescription plans that are available under Medicare Part D in four categories, see Bach and McClellan (2006, p. 2313):

- The "standard benefit" is a plan with the statutorily defined coverage, deductible, gap, and cost sharing.

- An "actuarially equivalent" plan is one that has the same deductible and gap as the standard plan, but has different cost sharing (such as copayment tiers for preferred drugs and generic drugs rather than a percentage copayment). Actuarial equivalence to the standard plan may be achieved through restrictions in plan formularies, but all approved plans must have formularies that include at least two drugs in each therapeutic category.

- A "basic alternative" plan is actuarially equivalent to the statutorily defined benefit, but both the deductible and cost sharing can be altered. (Most of these plans have no deductible.)

- An "enhanced alternative" plan exceeds the defined standard coverage - for example, by offering coverage in the gap for generic drugs only, or both generic and branded drugs.

One important feature of Medicare Part D is the penalty for late enrollment. Individuals who enroll after May 15, 2006 and do not have creditable coverage from another source face a late enrollment penalty fee of $1 \%$ a month for every month that they wait to join. The penalty is computed based on the average monthly premium of Part $\mathrm{D}$ standard plans in a given year. This rule was put in place to reduce adverse selection, and as our analysis in Section 6 confirms, it provides a strong incentive for eligible consumers to enroll in 2006 rather than wait to join when health problems develop and drug costs rise.

Section 5.3 describes the market for alternative plans: the CMS subsidy program and its impact on pricing, and the composition of plans offered in 2006 through 2008, and chosen in 2006 and 2007. More details on the Medicare part D prescription drug benefit can be found on the CMS website and in Bach and McClellan (2005). The political controversy surrounding its introduction is reflected in two back-toback papers in the New England Journal of Medicine, Bach and McClellan (2006) and Slaughter (2006). 


\section{Related literature}

The new Medicare Part D prescription drug benefit, and choice of health plans more generally, have been studied by numerous authors. In this section, we briefly review those papers that are more directly related to our analysis.

Hall (2004) provides an empirical analysis of how much Medicare beneficiaries value prescription drug benefits. Using a nested logit specification and data from the Medicare HMO program, she estimates parameters of demand for drug benefits and calculate estimates of consumer surplus and marginal cost. The premium elasticity is estimated to be -0.15 to -0.32 . Further, her results indicate that Medicare beneficiaries are willing to pay about $\$ 20$ per month on average for prescription drug benefits and are willing to pay $\$ 28$ to increase their brand-name coverage by $\$ 100$. Her study also provides empirical evidence for adverse selection and moral hazard effects. She finds that adding a prescription drug benefit raises HMO costs by $\$ 146$ per person per month, and raising brand-name coverage by $\$ 100$ costs $\$ 100$. These cost estimates are higher than the corresponding welfare estimates. Hall argues that this discrepancy is probably due to either the HMOs experiencing adverse selection or regulation of the HMOs that lead them to offer benefits inefficiently combined with moral hazard on the part of beneficiaries.

Huskamp, et al $(2003,2005)$ provide empirical analysis of the effects of three-tier prescription drug formularies which have been adopted by health plans and employers in an effort to control rising prescription drug costs. Huskamp et al (2003) examine the impact of changes in two employer-sponsored health plans on the use of three specific drugs. They find that different changes in formulary administration may have dramatically different effects on drug use and spending; in some cases patients even discontinue therapy. Huskamp et al (2005) estimate econometric models of the probability of selecting drugs assigned to the third tier (with the highest co-payment requirement) of a three-tier plan and compute changes in out-of-pocket spending. They find that implementation of the three-tier formulary resulted in some shifting of costs from the plan to patients. They argue that the savings from increased bargaining power from plans may well be substantial.

Joyce et al (2002) analyze the impact of pharmacy benefit changes implemented by employers and health insurance providers, using data on a large cross-section of employers with different pharmacy benefit designs. Joyce et al find that moving from a two-tier to a three-tier formulary, increasing existing co-payments or coinsurance rates, and requiring mandatory generic substitution, all would result in a 
reduction in plan payments and total pharmacy spending. Goldman et al (2004) investigate the effects of such plan changes on the demand for specific drug classes. They find that a doubling of co-payments was associated with reductions in the use of eight classes. The largest decreases occurred for non-steroidal anti-inflammatory drugs and antihistamines which are both often used intermittently to treat symptoms. The reduction in use of medications for individuals in ongoing care was more modest.

Moran and Simon (2006) estimate how retirees' use of prescription medications responds to changes in their incomes. They find that lower-income retirees exhibit considerable income sensitivity in their use of prescription drugs, using data from the 1993 wave of the Study of Asset and Health Dynamics Among the Oldest Old (AHEAD). Their estimates indicate that a $\$ 1000$ increase in post-retirement income (in 1993 dollars) for those in the low-education and lower-income group would increase the number of prescription medications used in a typical month by approximately 0.55 prescriptions per household. Yang et al (2004) investigate how insurance affects medical care utilization, and subsequently, health outcomes over time. They develop a dynamic model of these variables, and use longitudinal individuallevel data from the 1992-1998 Medicare Current Beneficiary Survey provide to estimate these effects. Their simulations indicate that over five years, expanding prescription drug coverage would increase drug expenditures by between $12 \%$ and $17 \%$. However, other health care expenditures would only increase slightly, and their results suggest that the mortality rate would decrease. Several studies look at the economic incentives provided by the new Medicare Part D prescription drug benefit, including Lucarelli (2006) and McAdams and Schwarz (2006). Frakt and Pizer (2006) and Simon and Lucarelli (2006) describe the plans that were available in 2006. The latter paper also contains a hedonic regression that relates plan premiums to plan features.

There are also several papers that discuss whether Medicare Part D provides sufficient coverage to all older Americans, and in particular the effect of the coverage gap. Stuart et al (2005) argue that discontinuities in the drug benefit will affect people with greater-than-average medical need disproportionately (which by itself is not surprising). More interestingly, they argue that those affected by the coverage gap will reduce their medication use and spending. Donohue (2006) discusses the potential impact of Medicare Part D on the demand for drugs that are used persistently at high expected cost, such as certain psychotropic medications. Her study stresses the close relation between known chronic conditions (and the medications taken for them) and plan choice. 
We are aware of only a few empirical studies of individuals' actual behavior during the Part D initial enrollment period. ${ }^{4}$ The Health and Retirement Study (HRS) contained questions on prescription drug use, expenditure, and Part D decisions in several of its surveys in 2005 and 2006, but results are not yet available. Hurd et al (2007) conducted hypothetical choice experiments with a sample of individuals from the American Life Panel. ${ }^{5}$ They obtain the ranking of several hypothetical prescription drug plans with varying cost and payment schedules. Using data on the respondent's actual drug expenditure, they can also calculate the expected out-of-pocket costs for each of the hypothetical plans. They find that the correspondence between the preference and cost rankings is low. They speculate that respondents do not know the full cost of their drugs and so cannot know what the out-of-pocket cost would be. Another explanation they give for the stated preferences is that respondents anticipate that with some probability their prescription drug requirements will change and take into account the insurance aspects of the plans. Another important issue that we do not address in the current version of this paper is potential moral hazard following enrollment in Medicare Part D.

Another recent study of demand for Medicare Part D plans that uses official CMS data is Cubanski and Neuman (2006). Neuman et al (2007) report results from a national survey that was conducted in 2006 to investigate Part D coverage, but that paper has a more narrow scope than the present paper. Where comparable, their results seem to be in line with ours.

Finally, several recent empirical studies address adverse selection and/or moral hazard in health insurance markets and the difficult problem of how to distinguish among these two effects in observed market data, in particular, Abbring et al (2003), Bajari et al (2006), Fang et al (2006). A particularly interesting empirical study by Shang and Goldman (2007) uses data from the Medicare Current Beneficiary Survey (MCBS) to show that exogenous variations in prescription drug coverage are associated with differences in prescription drug use: Those with prescription drug coverage use more drugs but spend less on other health-care services, indicating that there is a substitution effect between prescription drugs and other health services.

\footnotetext{
${ }^{4}$ Health insurance and health plan choices have of course been studied in many other situations. Buchmueller (2006) presents estimated the premium (price) elasticity of health plan demand and reviews other papers on the effect of price on health plan choice.

${ }^{5}$ The American Life Panel, an internet panel maintained by RAND, Santa Monica, is in many respects similar to the Knowledge Networks Panel we used to collect the data for the Retirement Perspectives Survey.
} 


\section{The Retirement Perspectives Survey (RPS)}

The Retirement Perspectives Survey is a research project conducted by the authors and collaborators ${ }^{6}$ to study the feasibility of using internet survey designs in elderly populations, and using treatments embedded in surveys to detect and mitigate survey response errors. Beginning in 2005, the continuing methodological research objectives have been combined with a substantive focus on consumer choices and experience in the Medicare Part D prescription drug program.

The three waves of the Retirement Perspectives Survey in 2005, 2006, and 2007 used a panel of individuals maintained by Knowledge Networks (KN), a commercial survey firm. The members of the KN Panel are enrolled using random-digit-dialing sampling to obtain a pool that is representative of the U.S. non-institutionalized population in terms of demographics and socioeconomic status. Participants are provided with web TV hardware to use to respond to periodic survey elicitations with content from both commercial and academic clients. KN Panel members are compensated for participation. The RPS respondents are somewhat younger, more educated, healthier, and computerliterate than the underlying population. ${ }^{7}$ For example, about half the panel members use the internet, compared with about a third in the corresponding population. Sample weighting is used to adjust for attrition in the recruitment and retention process, and for nonresponse to specific surveys.

The first wave of our study, RPS-2005, was conducted in November 2005, just before the initial enrollment period for the new Medicare Part D prescription drug benefit began. This survey focused on prescription drug use and intentions to enroll in the new Medicare Part D program. Additional questions focused on long-term care, and a sequence of questions was designed to obtain simple measures of respondents' risk attitudes. The RPS-2005 questionnaire also contained some embedded experiments on information processing and response behavior in consumer surveys (see McFadden, Schwarz, and Winter, 2006, for a discussion of these experiments). In May 2006, after the initial enrollment period had ended, we administered the second wave (RPS-2006). For this survey, we re-

\footnotetext{
${ }^{6}$ Other study investigators are Rowilma Balza, Frank Caro, Byung-hill Jun, Rosa Matzkin, and Teck Ho.

${ }^{7}$ Dennis (2005) details the RPS-2005 sampling protocol and weighting. The initial RDD sample was drawn using U.S. Government standards, with about $50 \%$ of drawn numbers linkable to an address and selected for further sampling. An extended effort was made to contact selected numbers and solicit participation; an overall participation rate of $56 \%$ using supplied web TV's was attained among address-linked numbers. The resulting KN panel was representative of the U.S. population except for some oversampling of the four largest States, the cities of Chicago and Los Angeles, and minority households. In addition, rural households not covered by MSN TV (about 8\%) were not sampled. One adult per household was sampled, independently of household size.
} 
contacted the Medicare eligible respondents of RPS-2005 and elicited their prescription drug insurance status as well as their Part D decisions, including plan choice. RPS-2007 was conducted in March and April 2007; its sample consisted of re-interviews of earlier RPS respondents plus refreshment cases. The RPS interviews required about 30 minutes for completion in 2005 and 2007, and about 20 minutes in 2006. Most socioeconomic and demographic variables were provided by Knowledge Networks as background on panel members, and were not requested again in the RPS questionnaires.

Table 2 contains sample sizes and participation rates for the various RPS waves and segments. Participation rates from the KN panel were generally rather high. For the first wave (RPS-2005), we contacted almost $6000 \mathrm{KN}$ Panel members aged 50 and older, and $80.6 \%$ of those invited to participate completed the questionnaire. For RPS-2006, we contacted only KN members who had completed RPS-2005 and were aged 63 years or older at the time of the interview (or in a few cases were younger but already on Medicare). The participation rate was again rather high at $82.3 \%$. Finally, for RPS-2007 we used two samples: re-interviews of earlier RPS respondents (i. e., those who had completed either RPS-2005 only or both RPS-2005 and RPS-2006), and a refreshment sample of KN Panel members who had not participated in any prior RPS wave. The participation rate among these groups was the highest for those who had completed both RPS-2005 and RPS-2006 (89.6\%) and slightly below the other rates for those who had completed RPS-2005 but missed RPS-2006 (76.6\%). The participation rate for the refreshment sample was $81.5 \%$ and thus well in line with that in the comparable RPS-2005 sample. In private correspondence, $\mathrm{KN}$ indicated that the participation rates that were achieved for the RPS surveys were slightly above those typically observed in other studies that use the KN Panel; this is attributed to the highly topical subject of the surveys.

In sections 5 and 6, we use data from the RPS-2006 "core sample". This sample consists of 1573 respondents who were 65 or older in May 2006, eligible for Part D, interviewed in both RPS-2005 and RPS-2006, and had no item nonresponse on key variables. Item nonresponse rates are generally very low in the KN Panel (less than 5\% for most questions considered in this paper.) Most variables used in our analysis are based directly on the corresponding survey question. The key pharmacy bill variables for 2005, 2006, and 2007, measures of what the annual out-of-pocket drug costs would be for a person without any prescription drug insurance, are constructed using procedures described later.

Descriptive statistics of key variables in the RPS samples are reported in Tables $3 \mathrm{a}$ and $3 \mathrm{~b}$, along 
with corresponding statistics from the 2004 wave of the Health and Retirement Study (HRS). ${ }^{8}$ We present both unweighted and weighted statistics. The RPS samples shown in this table are the 2005 full sample, the 2005/06 core sample, and the 2007 full sample. Table 3a compares the RPS-2005 full sample, which is based on a random selection of KN panel members aged 50 and older, with the full HRS 2004 sample. The weighted RPS-2005 full sample is very similar to the weighted HRS sample with respect to key demographic variables. This is an expected result of the weighting protocols used in each survey. ${ }^{9}$ The distribution of self-rated health in the RPS-2005 full sample is comparable to HRS-2004; but more compressed with fewer responses in the extreme categories. This difference may arise from both response effects and sampling issues. The HRS uses an auditory format (CATI) and RPS is a visual format, and both auditory sequence and visual range have small but predictable effects on response. ${ }^{10}$ Sample selection is a factor, as the KN population is non-institutionalized and sufficiently functional to follow the web TV protocol, while the HRS follows its panel subjects even when they are disabled or institutionalized. Third, the impact of weighting on the marginal distributions of key demographic variables is much stronger in HRS than in RPS; this is due to the complicated multi-cohort sample design of HRS. For an extended discussion of the role of weighting in the analysis of RPS data, see McFadden, Heiss, Jun, and Winter (2006). Table $3 b$ contains descriptive statistics for the 2005/06 core sample and the 2007 full sample, and the comparable HRS 2004 population aged $65+$. The core sample contains all RPS respondents who participated in both RPS-2005 and 2006 and who were older than 65 and on Medicare in 2005, while RPS-2007 contains all continuing RPS participants age 65+, refreshed with a new sample of KN panelists age 65+. This table shows that there are only minor variations in the distributions of key demographic variables across the three RPS sub-samples.

The RPS data has been augmented with three other sources of data. First, the Medicare Current Beneficiary Study (MCBS) provides data on pharmacy bills for a four-year rolling panel with about 10,000 beneficiaries per year; we use the year 2000 to 2003 surveys. MCBS data are currently

\footnotetext{
${ }^{8}$ We use the RAND version F of the HRS data.

${ }^{9}$ RPS sample responses were weighted by raking iteratively to age interacted with the following demographic variables: gender, race/ethnicity, education, Census region, Income, and Internet Access.

${ }^{10}$ Auditory respondents are slightly biased tow ard the last category mentioned, and visual respondents are slightly biased against the extremes of a range.
} 
available only through 2004, but CMS provided an early release in 2005 of projected pharmacy bills in 2005 and 2006, adjusted for drug prices and for sample undercounting. Providers of Part D plans used this information for actuarial calculations of the expected cost of alternative plans, and we do as well. Second, we assembled data on median retail prices of about 100 of the most heavily used drugs in 2006, and 200 of the most heavily used drugs in 2007, primarily from secondary sources such as the AARP website. We used these data to estimate the pharmacy bill of each RPS respondent, based on the inventory of drugs that they report taking, and imputing the cost of drugs with missing prices. We mapped respondent estimates obtained in this way into the 2006 MCBS distribution of pharmacy bills by matching the empirical distribution of RPS bills to quantiles of the MCBS distribution. We followed the same procedure in 2007, with an adjustment for drug price levels. Details on our construction of pharmacy bills can be found in Winter et al (2006). Third, we use U.S. standard life tables, classified by gender, but not by race, to predict mortality.

\section{Consumers' decisions in the initial enrollment period}

In this section, we describe the enrollment decisions of the "active deciders" among the RPS-2006 respondents, the RPS-2006 core respondents who were not automatically enrolled in a Part D plan because of prior coverage by a provider that coordinated with Medicare, such as an employer health plan or a Medicare Advantage plan, or because of Medicaid, military, or veteran status. We look at three aspects of these respondents' decisions: Whether they enrolled, when they enrolled, and what plan they chose. This analysis is descriptive, but it nevertheless sheds light on how consumer's behavior responds to the economic incentives in the Medicare Part D market.

\subsection{Features of respondents}

In the RPS-2006 core sample of 1569 respondents, 443 respondents are classified as active deciders: Among those, 349 (78.6\%) enrolled in a Part D stand-alone plan; 94 (21.4\%) remain uncovered. Table 4 summarizes the enrollment status of all 1569 core respondents, along with breakdowns along various demographic dimensions as well as year 2005 drug use and expenditure. Of the 349 active deciders who enrolled, 319 provided the exact name of their plan, allowing us to determine plan features such as premium and gap coverage from the landscape of plans provided by CMS. 


\subsection{Enrollment and enrollment timing}

The expected payoff of enrolling in a Part D stand-alone plan consists of two components, the expected current value CV (defined as expected 2006 benefits less 2006 premiums) and the expected present value PV of the benefit of avoiding premium penalties in case of future enrollment. The PV component involves future events and choices, and is difficult to evaluate. However, a positive CV is already a sufficient condition for enrollment for risk-neutral or risk-averse consumers, so it is useful to see whether enrollment reacts to factors that influence CV.

As noted before, the initial enrollment period began on November 15, 2005 and ended on May 15, 2006. Coverage in the initial enrollment period began in the month after enrollment (in January 2006 if already enrolled in 2005). Thus, decisions in the initial enrollment period have a second dimension - consumers not only had to decide whether to sign up for a Part D stand-alone plan, they had to choose when to sign up. To characterize the timing dimension, we consider a stylized description of the decision problem.

An individual decides at the beginning of the enrollment period whether to enroll early (Nov/Dec 2005), late (May 2006), or not at all. Let $p$ denote the yearly premium and PV the expected present value of the option of avoiding a premium penalty for enrollment in Part D after 2006. We leave PV unspecified for the purpose of the current descriptive analysis, and specify it fully in the intertemporal optimization model presented in Section 6. Let $\mathrm{c}_{\mathrm{y}}$ denote the pharmacy bill in year y. For the current analysis, assume that these bills have a normal random-effects stochastic structure, with censoring below at zero; i.e., there is a latent bill $\mathrm{c}_{\mathrm{y}}^{*}=\mu+\eta \lambda+\zeta_{\mathrm{y}} \gamma$, where $\mu$ is a mean, $\eta$ is a persistent individual standard normal random effect, the $\zeta_{\mathrm{y}}$ are independent i.i.d. standard normal disturbances, $\lambda$ and $\gamma$ are standard deviations, and $\mathrm{c}_{\mathrm{y}}=\max \left\{0, \mathrm{c}_{\mathrm{y}}^{*}\right\}$. We fit this model by maximum likelihood to 2005 and 2006 RPS pharmacy bills, with top-censoring of bills at $\$ 12,000$ to reduce the influence of extreme outliers that may be mismeasured, and estimate $\mu=2027.7, \lambda=2672.5$, and $\gamma=1759.9$. In a Monte Carlo simulation of 8000 bills for 2005 and 2006, $\mathrm{c}_{\mathrm{y}}$ has mean \$2,548, standard deviation $\$ 2,469$, and a correlation of 0.61 between 2005 and 2006 bills. The probability of a zero bill is 0.26 in the simulation, higher than the observed probability of 0.15 , with conditional probabilities of 0.61 of a zero bill in 2006 given a zero bill in 2005, and of 0.12 of a zero bill in 2006 given a positive bill in 2005. 
Assume that to first order, individuals cannot control the timing of drug bills during the year. Suppose latent monthly bills satisfy $\mathrm{c}^{*}{ }_{\mathrm{yt}}=(\mu+\eta \lambda) / 12+\zeta_{\mathrm{yt}} \gamma /(12)^{1 / 2}$, where the $\zeta_{\mathrm{yt}}$ are i.i.d. standard normal monthly disturbances. Then the sum of latent monthly bills over 12 months gives the model above for the annual latent bill, $\mathrm{c}_{\mathrm{y}}^{*}=\mu+\eta \lambda+\zeta_{\mathrm{y}} \gamma$. Similarly, the latent bill for the last seven months of 2006 is $\mathrm{c}_{6-12: 06}^{*}=7(\mu+\eta \lambda) / 12+\zeta_{6-12: 06} \gamma^{*}$, where $\zeta_{6-12: 06}$ is standard normal and $\gamma^{*}=\gamma(7 / 12)^{1 / 2}=$ 1344.0. Assume that the realized bill for this seven month period is again censored, $\mathrm{c}_{6-12: 06}=$ $\max \left\{0, c^{*}{ }_{6-12: 06}\right\}$. The sum of left-censored latent variables is at least as large as the left-censored sum of latent variables, so that the assumption that both the full year and the seven-month bills can be represented as left-censored normals is an approximation.

Assume that consumers know the persistent component of their latent annual bill, $c^{\#}=\mu+\eta \lambda$.

The expected annual bill given $\mathrm{c}^{\#}$ is then $\mathrm{E} \mathrm{c}_{\mathrm{y}}=\int_{0}^{\infty} \mathrm{c} \varphi\left(\left(\mathrm{c}-\mathrm{c}^{\sharp}\right) / \gamma\right) \mathrm{dc} / \gamma=\mathrm{c}^{\sharp} \Phi\left(\mathrm{c}^{\sharp} / \gamma\right)+\gamma \varphi\left(\mathrm{c}^{\sharp} / \gamma\right)$. Under the

Medicare Part D Standard plan in 2006, the benefits formula is

$$
\mathrm{B}(\mathrm{c})=0.75 \cdot \min \{2000, \max (0, \mathrm{c}-250)\}+0.95 \cdot \max (0, \mathrm{c}-5100),
$$

where $\mathrm{c}$ is the pharmacy bill covered by the plan. The expected current benefit from enrollment for the full year, given $\mathrm{c}^{\sharp}$, is

$$
\begin{aligned}
\mathrm{CV}_{12}= & \mathbf{E} \mathrm{B}\left(\mathrm{c}_{06}\right)-12 \mathrm{p}=0.75 \int_{250}^{2250}(\mathrm{c}-250) \varphi\left(\left(\mathrm{c}-\mathrm{c}^{\sharp}\right) / \gamma\right) \mathrm{dc} / \gamma+1500 \cdot \Phi\left(\left(\mathrm{c}^{\#}-2250\right) / \gamma\right) \\
& +0.95 \int_{5100}^{\infty}(\mathrm{c}-5100) \varphi\left(\left(\mathrm{c}-\mathrm{c}^{\sharp}\right) / \gamma\right) \mathrm{dc} / \gamma-12 \mathrm{p} \\
= & -12 \mathrm{p}+0.75\left(\mathrm{c}^{\sharp}-250\right)\left[\Phi\left(\left(\mathrm{c}^{\#}-250\right) / \gamma\right)-\Phi\left(\left(\mathrm{c}^{\#}-2250\right) / \gamma\right)\right]+1500 \cdot \Phi\left(\left(\mathrm{c}^{\#}-2250\right) / \gamma\right) \\
& +0.75 \gamma\left[\varphi\left(\left(\mathrm{c}^{\#}-250\right) / \gamma\right)-\varphi\left(\left(\mathrm{c}^{\#}-2250\right) / \gamma\right)\right]+0.95\left(\mathrm{c}^{\#}-5100\right) \Phi\left(\left(\mathrm{c}^{\sharp}-5100\right) / \gamma\right)+0.95 \gamma \varphi\left(\left(\mathrm{c}^{\#}-5100\right) / \gamma\right) .
\end{aligned}
$$

Let $\mathrm{c}^{\%}=7 \mathrm{c}^{\# / 12}$. The expected current benefit from enrollment for the last seven months is 


$$
\begin{aligned}
& \mathrm{CV}_{7}=\mathbf{E ~ B}\left(\mathrm{c}_{6-12: 06}\right)-7 \mathrm{p}= 0.75 \int_{250}^{2250}(\mathrm{c}-250) \varphi\left(\left(\mathrm{c}-\mathrm{c}^{\%}\right) / \gamma^{*}\right) \mathrm{dc}+1500 \cdot \Phi\left(\left(\mathrm{c}^{\%}-2250\right) / \gamma^{*}\right) \\
&+0.95 \int_{5100}^{\infty}(\mathrm{c}-5100) \varphi\left(\left(\mathrm{c}-\mathrm{c}^{\%}\right) / \gamma^{*}\right) \mathrm{dc}-7 \mathrm{p} \\
&=-7 \mathrm{p}+0.75\left(\mathrm{c}^{\%}-250\right)\left[\Phi\left(\left(\mathrm{c}^{\%}-250\right) / \gamma^{*}\right)-\Phi\left(\left(\mathrm{c}^{\%}-2250\right) / \gamma^{*}\right)\right]+1500 \cdot \Phi\left(\left(\mathrm{c}^{\%}-2250\right) / \gamma^{*}\right) \\
&+0.75 \gamma^{*}\left[\varphi\left(\left(\mathrm{c}^{\%}-250\right) / \gamma^{*}\right)-\varphi\left(\left(\mathrm{c}^{\%}-2250\right) / \gamma^{*}\right)\right]+0.95\left(\mathrm{c}^{\%}-5100\right) \Phi\left(\left(\mathrm{c}^{\%}-5100\right) / \gamma^{*}\right)+0.95 \gamma^{*} \varphi\left(\left(\mathrm{c}^{\%}-5100\right) / \gamma^{*}\right) .
\end{aligned}
$$

Figure 2 gives the values of $\mathrm{CV}_{12}$ and $\mathrm{CV}_{7}$ plotted against 2006 expected pharmacy bill. Empirically, we find that if $\mathrm{CV}_{12}>\mathrm{CV}_{7}$, which occurs at expected 2006 pharmacy bills above $\$ 950$, then $\mathrm{CV}_{12}>$ 0 and early enrollment is optimal. However, if $\mathrm{CV}_{7}>\mathrm{CV}_{12}$, then there is a more complicated decision on whether to enroll late or not at all, depending on whether $\mathrm{CV}_{7}+\mathrm{PV}$ is positive. A myopic consumer who ignores PV will not enroll at an expected pharmacy bill below $\$ 300$; increasing PV would lower this threshold.

When allowing individuals to decide month by month whether to enroll or delay enrollment, new information may make enrollment beneficial in the middle of the enrollment period. However, the probability of significant new information within a few months is low, so one would expect peaks of enrollment at the beginning of the enrollment period (for people who immediately benefit) and at the end where avoiding the penalty becomes relevant. The distribution of months in which the sample of RPS respondents enrolled is shown in Figure 3. As expected, there are peaks at the beginning and at the end of the initial enrollment period (even though Nov 2005 and May 2006 each had only 15 “enrollment days").

For further analysis, the sample is split into four groups of respondents. Details can be found in Table 5. As argued above, individuals with high drug costs should sign up early, those with intermediate drug costs or high present value of the penalty should sign up late and for the others, it might be rational not to sign up at all. The distribution of drug costs differs significantly between the four groups. Conditional means, medians, 10th and 90th percentiles are also presented in Table 5. The empirical CDFs are given in Figure 4; pairwise Kolmogorov-Smirnov tests confirm that they are statistically significantly different from each other (all pairwise $p$-values are smaller than 0.01 except for "early" vs. "intermediate" which has $p=0.07$ ). Current drug costs appear to have a strong impact 
on enrollment, especially on early enrollment by December 2005 and additional enrollment by March 2006. Additional late enrollment in April or May does not seem to strongly depend on 2005 drug costs.

Next, we present results from logit models for enrollment with dummies for categories of drug costs. A specification with splines and a semiparametric specification with an additive non-parametric function of drug costs give essentially the same results. A few socio-economic variables are added. Odds ratios for enrollment are presented in the first column of Table $6 .{ }^{11}$ Drug costs in 2005 are very strong predictors of enrollment. Younger seniors (under 70 years of age) are more likely to enroll. As might be expected, those in "excellent" SRHS are less likely to enroll, even controlling for drug costs. Poor or fair SRHS also decreases the enrollment probability relative to the intermediate SRHS category, which may indicate that those in poor health had more difficulty in evaluating the program and completing the enrollment process.

The table also shows results from logit models of enrollment timing. As argued above, the rational decision whether to enroll early mainly depends on whether the individual expects immediate benefits in 2006, since delaying enrollment until the deadline in May did not cause a premium penalty. Then, the decision to enroll early should depend primarily on expected drug costs in 2006, which are highly correlated with drug costs in 2005. The second column of Table 6 shows logit results for early enrollment (defined as being enrolled by March 2006). The results are as expected for rational individuals: Drug costs in 2005 are a very strong predictor of early enrollment while the sociodemographic variables have no significant impact. Late enrollment within the initial enrollment period is rational for individuals who do not expect immediate benefits in 2006 but want to avoid the penalty. The present value of avoiding the penalty depends on the whole trajectory of future drug costs. Those are also correlated with 2005 drug costs but weaker than 2006 costs. In addition to that, individual expectations, tastes, and the understanding of the penalty and its expected present value drive the decision whether to enroll late or not at all, given that early enrollment is not beneficial.

The final column of Table 6 shows logit results for whether individuals enroll late (April or May 2006), given that they did not enroll early (by March 2006). Note that this is not a structural

\footnotetext{
${ }^{11}$ Consider a binomial logit model $\mathrm{P}=1 /\left(1+\exp \left(-\beta_{0}-\beta_{1} \mathrm{D}\right)\right)$, where $\mathrm{D}$ is a dummy variable with coefficient $\beta_{1}$, and $\beta_{0}$ summarizes the effect of other covariates. Then, $\mathrm{P} /(1-\mathrm{P})=\exp \left(\beta_{0}+\beta_{1} \mathrm{D}\right)$ is called the odds, and the ratio of the odds when $\mathrm{D}=1$ and $\mathrm{D}=0$, equal to $\exp \left(\beta_{1}\right)$, is called the odds ratio.
} 
behavioral model since it ignores self-selection. The results show that among those not enrolled early, 2005 drug costs do predict late enrollment, but only weakly. On the other hand, socio-economic variables become important predictors. They may reflect health and other expectations, information, and/or tastes. Taken together, the models in Table 6 show that the strong predictive power of drug costs for total enrollment (column 1) is mainly driven by early enrollers (column 2), while the enrollment differentials by socio-economic variables are mainly driven by late enrollers (column 3). This is consistent with a view that most individuals understood at least the gross attributes of the initial enrollment alternatives and the incentives they faced.

\subsection{The CMS Subsidy, and Enhanced Plan Features and Premiums}

The mechanism used by CMS to subsidize Part D plan sponsors determines the premiums for the Standard plan, and affects the cost to sponsors of offering enhanced plans. Key features of the mechanism are established in the Medicare Prescription Drug Improvement and Modernization Act (MMA) of 2003. Descriptions of the mechanism are given in CBO (2004), CMS (2005), Medpac (2006), and Simon and Lucarelli (2007). The essential features of the benefit formulas and subsidy mechanism are summarized here for completeness.

The CMS subsidy of plan sponsors has two components, a direct subsidy, paid prospectively, and reinsurance of a share of catastrophic benefits, paid retrospectively. The prospective payments include risk adjustments for the sponsor's enrollee mix that are intended to neutralize adverse selection, and premium subsidies for qualified low-income enrollees. A key feature of the subsidy mechanism is that sponsors submit bids annually to CMS for their anticipated costs of providing benefits to a representative Part D enrollee, including administrative costs and return on capital, but excluding reinsurance of catastrophic benefits. CMS then processes these bids to produce a national base premium that covers 25.5 percent of the prospective national average total benefits and administrative cost of a representative Part D enrollee (including reinsurance cost), and an associated base direct subsidy equal to the national average bid less the base premium. Premiums for individual plans are then set to the plan's bid less the base direct subsidy. As a consequence, each plan has a premium that when added to the base direct subsidy equals the plan's bid, and the plan bid determines its premium. The principle behind the Part D market design is that competition for enrollees should limit the ability 
of plan sponsors to profit from increasing their bids, encourage cost-saving, and drive bids toward actual long-run cost. ${ }^{12}$

The following notation for Standard plan benefits will be used in giving details of the subsidy mechanism:

\begin{tabular}{|c|c|c|}
\hline \multicolumn{3}{|c|}{ STANDARD PLAN BENEFITS } \\
\hline NOTATION & DESCRIPTION & COMMENTS \\
\hline $\mathrm{APB}$ & annual pharmacy bill & enrollee characteristic \\
\hline TrOOP & true out-of-pocket cost of enrollee & enrollee characteristic \\
\hline DED & deductible (\$250 in 2006) & Part D parameter \\
\hline GTH & gap threshold (\$2250 in 2006) & Part D parameter \\
\hline TTH & $\begin{array}{l}\text { TrOOP threshold for catastrophic benefits } \\
\text { (\$3600 in 2006) }\end{array}$ & Part D parameter \\
\hline $\mathrm{BB}$ & $\begin{array}{l}\text { basic benefit, } 75 \% \text { of APB above DED, up } \\
\text { to GTH }\end{array}$ & $\mathrm{BB}=0.75 \cdot \max \{0, \min \{\mathrm{APB}, \mathrm{GTH}\}-\mathrm{DED}\}$ \\
\hline $\mathrm{CTH}$ & $\begin{array}{l}\text { catastrophic pharmacy bill threshold } \\
(\$ 5100 \text { in } 2006)\end{array}$ & $\mathrm{CTH}=\mathrm{TTH}+0.75 \cdot(\mathrm{GTH}-\mathrm{DED})$ \\
\hline $\mathrm{CPB}$ & catastrophic pharmacy bill & $\mathrm{CPB}=\max \{0, \mathrm{APB}-\mathrm{CTH}\}$ \\
\hline $\mathrm{CB}$ & catastrophic benefit, $95 \%$ of $\mathrm{CPB}$ & $\mathrm{CB}=0.95 \cdot \mathrm{CPB}$ \\
\hline
\end{tabular}

As indicated by these formulas, if an enrollee has an annual pharmacy bill APB, then she will receive a basic benefit BB equal to 75 percent of the APB above a deductible of DED, up to GTH. ${ }^{13}$ In the gap above this threshold, the enrollee pays all pharmacy costs until her APB reaches the catastrophic pharmacy bill threshold CTH at which her true out-of-pocket (TrOOP) cost reaches TTH,

\footnotetext{
${ }^{12}$ Two phenomena may lead to outcomes that are not strictly competitive. First, the Part D market is dominated by two firms, Humana and United Healthcare (AARP), with a fringe of smaller rivals. These firms have sufficient market power to influence the national average bid, and the consequent CMS direct subsidy. Second, the churn rate for enrollees is low, and this created incentives for sponsors to offer low initial premiums to establish large enrollee bases whose relative immobility might later be exploited to shelter their plans from competition.

${ }^{13}$ Actuarially equivalent plans have the same DED and GTH, and alternative cost sharing arrangements (e.g., co-payment tiers for generic, preferred branded, and non-preferred branded drugs, rather than a percentage co-payment) that yield the same expected BB. Basic alternative plans also yield the same expected BB, but can alter both the deductible and cost-sharing arrangements; they typically have a zero deductible.
} 
after which she is entitled to a catastrophic benefit $\mathrm{CB}$, equal to 95 percent of the APB above CTH. ${ }^{14}$ The TrOOP formula is $\mathrm{TrOOP}=\min \{\mathrm{TTH}, \mathrm{APB}-\mathrm{BB}\}+0.05 \cdot \mathrm{CPB}$. Classes of drugs excluded from Part D coverage, and drugs not in the plan formulary, are not counted in the APB used in the TrOOP calculation. Part D premiums are also excluded from TrOOP. The plan sponsor can influence the APB and benefits under this schedule through its formulary, through incentives to physicians and pharmacies to substitute generic for branded drugs, and through the prices of covered drugs it negotiates with pharmaceutical companies. ${ }^{15}$

\begin{tabular}{|c|l|l|l|}
\hline \multicolumn{4}{|c|}{ CMS SUBSIDY PER ENROLLEE } \\
\hline NOTATION & \multicolumn{1}{|c|}{ DESCRIPTION } & COMMENTS & $\begin{array}{l}\text { NATIONAL } \\
\text { AVERAGE }\end{array}$ \\
\hline ADM & $\begin{array}{l}\text { administrative costs (overhead plus return on } \\
\text { capital })\end{array}$ & $\begin{array}{l}\text { Industry standard: } 15 \% \text { of } \\
\text { benefits }\end{array}$ & \\
\hline TC & $\begin{array}{l}\text { total benefit and administrative cost, } \\
\text { including reinsurance }\end{array}$ & TC $=$ BB + CB + ADM & NTC \\
\hline RI & $\begin{array}{l}\text { Federal catastrophic reinsurance } \\
\text { (r = 0.27 in 2006) }\end{array}$ & RI $=0.8 \cdot \mathrm{CPB}$ & NRI $=\mathrm{r} \cdot \mathrm{NTC}$ \\
\hline BID & $\begin{array}{l}\text { sponsor bid to CMS for expected benefit } \\
\text { payments plus administrative costs, } \\
\text { excluding reinsurance }\end{array}$ & $\begin{array}{l}\text { BID }=\mathrm{TC}-\mathrm{RI} \\
=\mathrm{BB}+0.15 \cdot \mathrm{CPB}+\mathrm{ADM}\end{array}$ & NBID \\
\hline BAP & base annual premium & BAP $=0.255 \cdot \mathrm{NTC}=0.255 \cdot \mathrm{NBID} /(1-\mathrm{r})$ \\
\hline BDS & base direct subsidy & BDS $=(0.745-\mathrm{r}) \cdot \mathrm{NTC}=(0.745-\mathrm{r}) \cdot \mathrm{NBID} /(1-\mathrm{r})$ \\
\hline APR & plan annual premium & APR $=$ max $\{0, \mathrm{BAP}+\mathrm{BID}-\mathrm{NBID}\}$ \\
\hline PDS & plan direct subsidy & base direct subsidy, risk-adjusted for case mix \\
\hline SPR & supplementary premium & \multicolumn{2}{|c|}{ supplement for extended plans } \\
\hline
\end{tabular}

\footnotetext{
${ }^{14}$ Enrollees in the gap are entitled to the established prices for formulary drugs.

${ }^{15} \mathrm{CMS}$ requires that each sponsor appoint a Pharmacy and Therapeutics (P\&T) Committee of physicians and pharmacists to determine its formulary, requires that "formularies must include drug categories and classes that cover all disease states", stipulates that "each category or class must include at least two drugs (unless only one drug is available for a particular category or class, or only 2 drugs are available but 1 drug is clinically superior to the other for a particular category or class), regardless of the classification system that is utilized", and reviews compliance with these requirements and additional conditions to ensure that the formulary does not substantially discourage enrollment in the plan by beneficiaries with certain disease states; see CMS (2006), Chapter 6: Part D Drugs and Formulary Requirements.
} 
The notation above will be used to detail the subsidy mechanism. The key steps by CMS in determining the direct subsidy are the averaging of sponsor bids for standard and actuarially equivalent plans to form the national average bid NBID, an estimate by CMS of the proportion $r$ of catastrophic reinsurance in total benefit and administrative cost, and from this an estimate of national average total cost $\mathrm{NTC}=\mathrm{NBID} /(1-\mathrm{r})$. The base annual premium BAP is mandated to equal 25.5 percent of NTC. The base direct subsidy then equals $74.5 \%$ of NTC, less the expected catastrophic reinsurance. If a plan bid equals NBID, then its premium equals BAP. More generally, the plan annual premium APR equals the base annual premium plus the difference between the plan bid and the national average bid, $\mathrm{APR}=\mathrm{BAP}+\mathrm{BID}-\mathrm{NBID}$, or zero if this expression is negative. The quantities NBID and BAP are unknown to the sponsor at the time bids are submitted, and are largely outside the sponsor's influence. By construction, when APR is positive, the prospective revenue, base direct subsidy plus the plan average premium, satisfies BDS $+\mathrm{APR}=(0.745-\mathrm{r}) \cdot \mathrm{NBID} /(1-\mathrm{r})+\mathrm{BAP}+\mathrm{BID}-\mathrm{NBID}=\mathrm{BID}$. If $\mathrm{APR}$ $=0$, then prospective revenue exceeds the plan bid. Then, the sponsor's bid determines its premium, and its position in the competition for enrollees, and prospectively it expects revenue to be at least as large as its bid.

The actual direct subsidy to a plan sponsor is determined by adjusting its bid for the case mix of its enrollees, with the objective of neutralizing adverse selection. Each member of the population of prospective enrollees (submitted by the sponsor) is given a risk weight, using a prescription drug hierarchical condition category (RxHCC) specified by CMS that depends on diagnoses, sex, age, and disabled status. There are averaged to obtain a RxHCC weight, which then multiplies the plan's bid. Other enrollee mix factors are applied to account for low-income and institutionalized status. The result is a case-mix adjusted plan bid. The actual plan direct subsidy PDS then equals the case-mix adjusted plan bid less the enrollee premium,

$\mathrm{PDS}=\mathrm{BID} \cdot[\mathrm{RxHCC}$ weight $] \cdot[$ Low-income and institutionalized-status weight $]$ - APR.

If the plan has a nationally representative case mix, then the adjustment weights are one, and PDS equals BDS. More generally, to the extent that the case-mix weights accurately capture differences in benefit costs attributable to observable patient characteristics, the weighting will neutralize adverse selection, removing the incentive for the sponsor to selectively discourage enrollment or re-enrollment 
by patients with observed characteristics that are associated with high benefit costs. The RxHCC classification system and risk factor models are described in Robst, Levy, and Ingber (2007). ${ }^{16}$

There are additional adjustments to CMS subsidies that provide prospective payments for lowincome premium subsidies and catastrophic reinsurance, with reconciliation after the end of each year. Finally, there are "symmetric risk corridors" that reduced risk to sponsors via a profit-sharing arrangement in the initial years of operation of the new Part D market; this feature is designed to disappear over time.

Next consider enhanced alternative plans that provide gap coverage, and the CMS subsidies they receive. Three coverage levels have been offered by these plans, all formulary drugs, more restrictively generic drugs, and even more restrictively "preferred" generic drugs. These plans extend the basic coverage co-payment terms into the gap. These plans are affected by a feature of the MMA that specifies a TrOOP threshold for catastrophic benefits, and excludes supplemental premium payments from the calculation of TrOOP. Then, enhanced coverage that lowers TrOOP increases the pharmacy bill threshold CTH for catastrophic benefits, and reduces the reinsurance component of the CMS subsidy. Consequently, there is in effect a tax on gap coverage that partly offsets the CMS subsidy. Recognizing this disincentive to enhanced plans, CMS established a Part D payment demonstration to "allow private sector plans maximum flexibility to design alternative prescription drug coverage". This demonstration allows some classes of sponsors of enhanced plans to select a "capitated option" and receive an "actuarially equivalent" capitated payment for catastrophic coverage in leu of catastrophic reinsurance. Excluded from the demonstration are PACE and employersubsidized plans. The capitated payment is determined by calculating the case-mix adjusted reinsurance payments expected for enrollees in the extended plan if they had instead been enrolled in the standard plan.

\footnotetext{
${ }^{16}$ Risk adjustment weights are effective in neutralizing adverse selection incentives if each observationally distinguishable patient group has the same risk-weight deflated expected benefit cost to the sponsor. They will not be completely effective if the sponsor finds groups that in interaction with its formulary and benefit schedule have higher or lower deflated expected benefit cost. The models used to obtain risk weights explain a relatively low proportion of the variance in annual pharmacy bills. This is not in itself a barrier to effective neutralization, but it leaves opportunities for data mining that may identify groups for whom deflation is imperfect. In particular, risk adjustment weights tuned to neutralize adverse selection for universal Standard plan benefits are unlikely to neutralize adverse selection incentives in extended plan benefits, or even in Standard plan benefits once non-enrollment and selection among plans makes Standard plan benefits non-universal. Sponsors seeking to profit from imperfect neutralization are likely to look for diagnostic interactions that are not captured by the RxHCC classification, higher-order interactions that are omitted from the essentially linear additive models used by CMS to calculate the risk weights, and statistical inaccuracies.
} 
Sponsors electing capitation have Flexible Capitation and Fixed Capitation options. Under the flexible option, catastrophic coverage does not commence until TrOOP reaches TTH. Then there is a range of APB above the standard plan CTH (\$5100 in 2006) where TrOOP is below TTH, and the beneficiary co-payment is the same as in the basic benefit range, 25 percent, rather than the catastrophic co-payment rate of 5 percent. This reduces the value of the extended benefit relative to the standard plan, but increases the pool of revenue the sponsor can use to reduce the supplementary premium for extended benefits. Under the fixed capitation option, catastrophic coverage commences at the standard plan threshold $\mathrm{CTH}$, and the TrOOP threshold is ignored.

To evaluate extended plans offering generic coverage, it is necessary to determine the share of generic drugs in the APB. Utilizing 1833 observations on specific drugs used by respondents in RPS2007, their generic classification, and their average market prices, we regress the share of generics in drug expenditures on the reciprocal of APB for APB satisfying $\$ 1<\mathrm{APB}<\$ 10,000$ and obtain an intercept of $0.341(\mathrm{SE}=0.009)$ and a slope coefficient of $3.183(\mathrm{SE}=0.560)$. Then, the estimated generic expenditure share is over $50 \%$ for low APB, but in the gap where this allocation affects extended benefits and TrOOP, it is near 34\%. Our generic expenditure shares are similar in pattern but somewhat higher than those found several years earlier by Dana Goldman in a sample of age 65+ retirees from a large firm. ${ }^{17}$ We cannot determine whether this is due to the limitations of the drug information collected in RPS-2007, or is the result of recent generic competition in several popular drug categories, and incentives to physicians and pharmacists from Part D sponsors to dispense generics.

\subsection{Plan choice}

Next, we turn to plan choice of those core respondents who enrolled in a Medicare Part D standalone plan. We examine both choice across different types of plans, and choice of sponsor within plans of a given type. We do not consider choices of Medicare Advantage (MA) plans, which involve broader health care decisions, including choice of HMO or fee-for-service care. Table 7 reproduces summary information from a CMS website for consumers that provides a landscape of alternative stand-alone plans. This website contains a "plan finder" for consumers that identifies plans with

\footnotetext{
${ }^{17}$ Private communication.
} 
formularies that include the consumer's current drugs, and for each of these plans estimate the consumer's expected TrOOP in the coming year. ${ }^{18}$ The average number of distinct plans available in a State was 42.5 in 2006, 54.7 in 2007, and 53.4 in 2008. In 2006, the number of plans available in the various States ranged from 17 to 52. Between 2006 and 2008, the share of Standard or actuarially equivalent plans available has remained around one-third, the share of basic alternative plans that eliminate the deductible has fallen from $51 \%$ to $38 \%$, the share of enhanced plans that offer gap coverage for generics has risen from $13 \%$ to $29 \%$, and the share of enhanced plans that offer gap coverage for all formulary drugs has fallen from $2.5 \%$ to near zero. Average monthly premiums have decreased slightly from 2006 for Standard and actuarially equivalent plans, and enhanced plans that cover the deductible, and have increased substantially for enhanced plans offering gap coverage for generics. ${ }^{19}$ The average premium for enhanced plans with full gap coverage shows a major increase between 2006 and 2007, and in 2008 this coverage was unavailable except for one plan in Florida. One interpretation of these observations is that providers of plans with full coverage experienced higher than expected drug bills in 2006 due to adverse selection and/or moral hazard, and adjusted their plans accordingly.

We asked the RPS Part D enrollees what plan they chose using a two-stage procedure during which they were first presented with a list of plan providers active in their state, and then with a list of plans offered by that firm. Information on all available plans' features comes from a database available on the CMS website. Because of variations in plan formularies as well as plan features such as copay and tier arrangements, deductible, and gap coverage for generics or for all drugs, individuals face a complex set of alternatives. However, plans can be switched annually with no cost other than the time and bother. Unless individuals choose plans strategically to reduce the burden of future switching, plan choice should depend only on expected benefits in 2006.

For 316 of the 349 respondents with individual stand-alone insurance (92\%) in 2006, the information that subjects provide in RPS is sufficient to identify the specific plan they chose. Table

\footnotetext{
${ }^{18}$ The plan finder is a useful tool for consumers, but by concentrating on current drug use, it facilitates myopic choice in which the consumer ignores the risks of altered drug requirements in the future.

${ }^{19}$ There is an actuarial relationship between the average Standard plan premium calculated and posted by CMS as part of their determination of the subsidy to plan sponsors, and averages calculated from posted premiums on the CMS website. However, due to features of the CMS calculation, particularly adjustments for health risk in the projected population of beneficiaries of a plan, the averages are not identical.
} 
8 shows the distribution of drug costs by enrollment status and plan features. "Cheapest plan" indicates whether the individual enrolled in the plan with the lowest premium available in her state.

Figure 5a shows the distribution of the premiums of all 2166 plans that were available for 2006, stratified into four coverage classes: standard plans, actuarially equivalent plans, and two types of enhanced plans (one with gap coverage only for generic drugs, the other with gap coverage for generic and brand drugs). As expected, premiums are higher for the enhanced plans. More importantly, there is considerable variation in plan premiums in each coverage class. Figure $5 \mathrm{~b}$ shows similar distributions for those plans that were chosen by the RPS respondents. A comparison of the two figures shows that RPS respondents tended to choose cheaper plans in each of the categories, and also to concentrate on a few plans in each category, in particular among the equivalent plans. The plan that was in highest demand in this group was the United Healthcare plan endorsed by AARP, which had a 30\% share among RPS respondents who enrolled in a stand-alone plan; see Table 9. The market shares we obtained from RPS-2006 data are well in line with those computed using official CMS data by Cubanski and Neuman (2006, Table 1).

Table 10 shows results from OLS and quantile regressions for chosen plan premiums, using the same covariates as in Table 6. Higher pharmacy bills substantially increase chosen plan premiums, especially in the lower part of the APB distribution. The socio-economic variables have almost zero explanatory power. Table 11 presents odds ratios from logit regressions where the dependent variables are various classifications of choice among "cheap" or "bare-bones" plans versus the remainder: A cheap plan is defined in the first column as one with a premium less than $\$ 10 /$ month, in the second column as the cheapest of all available plans in the respondent's State, and the third column as a Part D standard plan (with no deductible or gap coverage). A high ABP substantially decreases the probability of enrolling in a cheap or "bare-bones" plan. Tables 10 and 11 support the proposition that individuals who enroll in order to avoid the penalty but do not expect immediate benefits rationally choose cheap or "bare-bones" plans since there is no monetary cost to switching plans in future years.

Table 12 reports market shares and average premiums for those plans that were chosen by RPS respondents in 2006 and 2007. The changes between 2006 and 2007 are similar to those observed on the supply side (Table 7). In particular, demand for plans with full gap coverage almost vanished in our sample. 
To analyze the impact of the CMS subsidy mechanism on premiums and the value of alternative plans to beneficiaries, we utilize the distribution of 2006 APB estimated by CMS from the Medicare Current Beneficiary Study (MCBS). Table 13 gives this distribution of the eligible population, and gives the benefits at selected APB for the Standard plan and alternatives. The second panel of the table gives the calculation of the Standard plan premium when the national average bid is based on this distribution and includes an allowance of 13 percent of benefits paid to cover administrative costs. It also gives the catastrophic reinsurance payments, direct subsidy, base and annual premiums, and net expected benefits from the Standard plan and alternatives. These calculations assume that the premiums on each plan are set to cover sponsor benefit payments and administrative costs if the full eligible population enrolled in this plan.

Using the MCBS distribution yields a expected annual pharmacy cost of \$2,940 and Standard plan benefits of $\$ 1,536$. The Standard plan monthly premium is near $\$ 37$, the number anticipated by CMS in 2005. The expected benefit net of premiums for the Standard plan is then $\$ 1,094$, the implied Medicare subsidy of Part D. The net expected benefits of extended plan alternatives are all less than that for the Standard plan, to be expected since the extended benefits and administrative overhead must be covered by the supplementary premiums. Of course, these plans may still be preferred by consumers who are risk averse or who have information on their prospective drug use that the sponsor does not know or cannot use. Full deductible and gap coverage has a substantially lower net expected benefit, due to the implicit tax imposed by the delay in catastrophic coverage until the TrOOP threshold is reached. Generic gap coverage without capitation is also affected by this implicit tax, but the impact is smaller because $100 \%$ co-payment for branded drugs increases TrOOP rapidly in the gap.

The actual experience in 2006 was a national average Standard plan premium of $\$ 32.20$ rather than $\$ 36.89$, indicating that in some combination, sponsors anticipated lowering APB's through formulary control, incentives to use generic drugs, and lower drug prices obtained by negotiation with pharmaceutical companies, and were willing to accept below normal recovery of administrative costs in order to recruit large enrollment bases. To reflect this, Table 14 adjusts the MCBS APB distribution to reproduce the 2006 observed Standard plan premium. This is done by first approximating the MCBS cumulative distribution function by a log normal distribution with a point mass at zero, $\mathrm{F}_{\mathrm{MCBS}}(\mathrm{APB})=0.1456+0.8544 \cdot \Phi((\log (\mathrm{APB})-\mu) / \sigma)$, with parameters $\mu=7.87$ and $\sigma=0.77$ obtained by matching the $50 \%$ and $90 \%$ quantiles. Then, $\mu$ is adjusted (to $\mu=7.70$ ) to yield the Standard plan 
premium of $\$ \$ 32.20$. The overall levels of net benefits are lower in Table 14 than Table 13, as are supplementary premiums, but the comparisons between plans are essentially the same.

The expected benefit and premium calculations in Tables 13 and 14 assumed that the entire eligible population enrolled in the plan being examined. In fact, consumers will choose among plans given their information on prospective APB. This creates the potential for adverse selection in which people with low APB in 2005 do not enroll, and those with high APB choose plans with extended gap coverage. This selection increases the sponsor cost of enrolled extended plan beneficiaries, and lowers the sponsor cost of enrolled Standard plan beneficiaries if the diversion of high APB enrollees to extended plans offsets the loss of low-APB non-enrollees. To assess the impact of plan selection, we assume that enrollees faced the plan, premium, and benefit schedules in Table 14. We make a computationally convenient rough approximation to the conditional distribution of an enrollee's 2006 APB given her 2005 APB: With probability $0.61, \mathrm{APB}_{2006}=\mathrm{APB}_{2005}$, and with probability 0.39, $\mathrm{APB}_{2006}$ has the distribution of the full Part $\mathrm{D}$ eligible population. This implies a correlation of 0.61 between $\mathrm{APB}_{2005}$ and $\mathrm{APB}_{2006}$, corresponding to our estimate from Section 3 of this paper of the correlation between RPS-2005 and RPS-2006 APB. With this distributional assumption, the expected benefit to an enrollee in a specified plan equals 0.61 times the net benefit if $\mathrm{APB}_{2006}=\mathrm{APB}_{2005}$, plus 0.39 times the expected net benefit for the full Medicare-eligible population. We assume that the enrollee chooses the plan that maximizes her conditional expected net benefit. Table 15 gives the calculated premiums and plan shares, and for comparison RPS active decider enrollment shares in 2006. In this table, the observed average Standard plan premium is lower than the national average; this reflects selection in which enrollees choose low-premium plans. The calculated and observed premiums for generic gap coverage are comparable. However, the observed premium for full gap coverage is substantially below the calculated break-even level. An important factor is that in 2006, many sponsors did not offer generic gap coverage plans, a supply constraint that limited demand for these plans.

Despite the fact that observed premium for extended coverage was substantially below the calculated premium, the calculated shares in Table 15 underestimate the observed Standard plan share, and overestimate the observed extended plan shares. For generic gap coverage, availability of plans was an factor. There may also have been confusion on the part of enrollees regarding the added benefits of extended coverage, and a tendency in the face of ambiguity to choose low-price "bargains". 
The pattern of calculated choice among plans leads to substantial adverse selection. People with $\mathrm{APB}_{2005}$ below $\$ 250$ do not enroll. Those with $\mathrm{APB}_{20005}$ between $\$ 250$ and $\$ 3000$ enroll in the Standard plan. Those with $\mathrm{APB}_{2005}$ between $\$ 3000$ and $\$ 5000$ enroll in generic gap coverage with flexible capitation, those between $\$ 5000$ and $\$ 7800$ enroll in full deductible and gap coverage, and those above $\$ 7800$ enroll in generic gap coverage with fixed capitation. Generic gap coverage without capitation is never chosen. As a result of the diversion of high APB enrollees to enhanced plans, Standard plans save more on the sponsor share of catastrophic benefits than they lose on low-APB non-enrollees, and are calculated to earn positive profits. In contrast, extended plans are selected by people who on the basis of $\mathrm{APB}_{2005}$ predict that they will gain more from benefits than the premium cost, despite the loading produced by administrative costs and the implicit tax on non-capitated extended coverage. While a major fraction of the actual benefits paid to high-APB enrollees is recaptured by sponsors through case-mix adjustments to the prospective capitated payment by CMS in leu of reinsurance, the $15 \%$ sponsor share of catastrophic pharmacy bills is not fully captured by risk-adjusted prospective direct subsidies, since the risk adjustment weights do not depend on historical pharmacy bills and therefore cannot capture all the information used by enrollees in selecting among plans. Calculation shows that if consumers allocate themselves among plans as described above, then the Standard plan would show a profit of about \$17 per enrollee per month, full deductible and gap coverage and generic coverage with flexible capitation would both show a loss of about $\$ 12$ per enrollee per month, and generic coverage with fixed capitation would break even.

One would expect the Part D market to adjust to the success and profitability of alternative plans. In particular, if consumer plan choice follows the calculations above, then one would expect unprofitable or unpopular plans such as full gap coverage, and generic gap coverage with no capitation or flexible capitation to raise premiums substantially or exit the market. In particular, full gap coverage appears to be in a death spiral in which increasingly expensive plans would be demanded by a shrinking fraction of the population who can expect to benefit at the high added premium, and falling share will lead to its extinction. Generic gap coverage may also face a death spiral. The forces acting against extinction are that extended plans offer insurance to risk-averse consumers, and some aid in managing personal budgets through the calendar year, and that sponsors may recognize some benefit in managing their case-mix through separating equilibria in which there is some cross-subsidization 
across plans, but these may be insufficient to overcome adverse selection when sponsors are prohibited from discriminating among potential enrollees on the basis of past APB.

The market penetration and profitability of plans is very sensitive to plan mix and the workings of selection. Table 16 gives calculated plan shares and profitability with various mixes of plans in the market. If the unprofitable full gap coverage plans becomes extinct, or all unprofitable extended plans become extinct, then generic gap coverage with fixed capitation becomes unprofitable, and may then begin its own adverse selection death spiral.

\subsection{Market hedonics of Part D plans}

The evolution of the Part D market can be pictured as a sequential hedonic equilibrium in which sponsors announce the features and premiums of the plans they will provide in the coming year, consumers then choose among the available plans to maximize their preferences, and the process repeats itself in following years, with sponsors having additional information on market shares and profit history of offered plans and on the strategies of rivals. Anderson et al (1996) discuss the economic theory and econometrics of oligopolistic markets with products that are differentiated in hedonic space, and Heckman et al (2003) analyze equilibrium in such markets, and the econometric issues of identifying and estimating market structure. The Part D market has several characteristics that simplify hedonic analysis. First, CMS rules fix the schedule for offering plans, and substantially restrict the range of plans that can be offered. As a result, sponsors do not have significant opportunities to revise offerings in response to the plans offered by rivals, or in response to current consumer behavior, but they can learn from history. A feature that the Part D market shares with many markets where consumers must renew or switch contracts is the prospect for substantial consumer inertia, which creates incentives for sponsors to capture market share with "loss-leader" prices, and then profit from price increases later that will not induce much switching; see Jenkins et al (2005). Opportunities for sponsors to conduct limited-time, limited-area offers to test plans experimentally are precluded by CMS regulations, although national sponsors may learn about price response from State by State pricing. The Part D market has a few large sponsors, with a fringe of smaller ones. We anticipate that this market will approach an equilibrium with some price leadership, but sufficient impact of the fringe to attain roughly competitive pricing, with frontier plans priced near their marginal cost, and inefficient plans losing market share or migrating toward the frontier in successive years. 
It is conceivable that in 2006 many sponsors offered plans inside the efficiency frontier because consumer hedonic values and rival strategies were unknown. We observe that in the 2007 , there was less variety and less price variation across comparable plans, and anticipate that the tradeoffs in features of frontier plans will move toward tradeoffs in consumer side hedonic values.

For a more detailed look at the features of chosen plans, we present estimates of both the implicit price and the willingness to pay for those features in 2006 and in 2007. The attributes we study are:

- No deductible: Plan offers benefits without the $\$ 250$ deductible of the standard plan.

- Gap coverage (generics): Generic drugs are covered in the coverage gap of the standard plan.

- Gap coverage (brand-name drugs): In addition to generics, brand-name drugs are also covered in the coverage gap.

- Top 100 drugs uncovered: Number of top 100 drugs missing in the formulary (available in 2006 only).

- Top 100 with authorization: Number of top 100 drugs only covered after authorization or step therapy (available in 2006 only).

- Drug tiers: Plan divides drugs into tiers with differing co-pays.

We first estimate the implicit supply prices of these attributes based on a hedonic regression for the 2166 plans offered in the 51 states in $2006 .{ }^{20}$ For state s, company c, and plan $\mathrm{p}$, the premium pr $\mathrm{scp}_{\mathrm{s}}$ is specified as

$$
\mathrm{pr}_{\mathrm{scp}}=\alpha_{\mathrm{sc}}+\mathbf{x}_{\mathrm{scp}} \boldsymbol{\beta}+\mathrm{u}_{\mathrm{spp}}
$$

with $\mathrm{x}_{\mathrm{scp}}$ denoting the vector of plan attributes listed above. The regression includes fixed effects for state/company combinations so that the implicit prices $\beta$ are identified by plans with different features offered by the same company in the same state. Results for 2006 plans are reported in the first column of Table 17. Sponsors priced coverage (of $75 \%$ of the cost of covered drugs, or equivalent) of the $\$ 250$ deductible at $\$ 7.42$ per month, generic gap coverage at $\$ 8.29$ per month, and full (generic and

\footnotetext{
${ }^{20}$ Simon and Lucarelli (2006) present a hedonic analysis of Part D plans that uses a database they collected that includes various plan characteristics that are not part of the publicly available CMS database we use.
} 
branded drugs) gap coverage at $\$ 31.09$ per month. From Table 14, the actuarial added cost of deductible coverage is approximately $\$ 11.40$ per month, of generic gap coverage with flexible capitation is $\$ 10.01$ per month, and of full gap coverage is $\$ 79.78$ per month. ${ }^{21}$ To the extent that adverse selection led consumers to choose deductible or gap coverage only if they were likely to benefit from it, these figures underestimate actuarial costs. We conclude that extended deductible and generic gap coverage were priced below their actuarial costs to sponsors, although perhaps within a range where formulary control, negotiated drug prices, and low marginal administrative costs might be sufficient to break even. On the other hand, full gap coverage was apparently substantially underpriced by sponsors.

The price of a large formulary was 95 cents per additional drug from the top 100. Sponsors charge $\$ 6.63$ per month for plans that place drugs on tiers, which have the ambiguous effect of reducing copayments for generic drugs, and increasing copayments for non-preferred branded drugs. Finally, sponsors do not reduce premiums for plans requiring prior authorization for some drugs. The attributes in Table 17 explain $74 \%$ of the variance of the premium within companies and states. The variance of the company/state fixed effects is more than three times the variance of the remaining i.i.d. error. Interestingly, the correlation between these fixed effects and the explained premiums is negative, so plans offered by "expensive" companies in "expensive" states tend to have inferior measured attributes.

Consider the demand side of the hedonic market for plans, and willingness to pay (WTP) for plan attributes. Table 12 shows that deductible coverage was popular with consumers, but gap coverage was not, despite full gap coverage being offered at premiums substantially below break even levels for sponsors. Even if full gap coverage had been offered with fixed capitation to avoid the implicit tax from a delayed catastrophic threshold, it would still have had a break even monthly supplementary premium above $\$ 50$, well above the observed hedonic supply price. Thus, the lack of interest by consumers in this coverage indicates that capitation to reduce premiums would have been insufficient to make full gap coverage viable. RPS data shows that consumers who selected gap coverage tended

\footnotetext{
${ }^{21}$ A representative consumer has a $85.3 \%$ change of an APB above $\$ 250$, and a $12.3 \%$ chance of an APB above $\$ 5100$. Then, a benefit of $75 \%$ of the deductible, or $\$ 187.50$, will be realized with probability $85.3 \%$, and this benefit will be recovered by the sponsor due to delay in reaching the TrOOP threshold with probability $12.3 \%$. Then, the expected value of deductible coverage is $\$ 11.40$ per month.
} 
to have large pharmacy bills that increased once they were enrolled. Thus, adverse selection and moral hazard both appear to be working to make extended plans with gap coverage unprofitable for sponsors.

To determine consumer WTP for plan attributes, we assume that the utility to consumer $i$ of plans $\mathrm{j}=1, \ldots, \mathrm{J}$ available in her state depends on plan attributes and the premium,

$$
\mathrm{U}_{\mathrm{ij}}=\mathbf{x}_{\mathrm{j}} \gamma+\mathrm{pr}_{\mathrm{j}} \delta+\varepsilon_{\mathrm{ij}}
$$

The error terms $\varepsilon_{\mathrm{ij}}$ are specified as i.i.d. Extreme Value Type 1 random variables, leading to a multinomial logit model of choice. ${ }^{22}$ The WTP is defined as the amount of premium increase that exactly offsets the increase of an attribute by one unit, so that the total utility (and therefore the choice probability) remains unaffected. ${ }^{23}$ This model is first estimated for the sample of the 316 individuals for whom we can identify the chosen plan assuming identical WTP. Then, the same model is estimated adding full interactions between the attributes and an indicator for respondent 2005 drug costs above the median. These models can be interpreted as allowing values to vary with expected need. Consumers with low drug costs may be more sensitive to premium, and less sensitive to extended features of the plans, than consumers with high drug costs. The results for the WTP and implicit price estimates are shown in the last three columns in Table 17.

For all respondents without value differentiation by pharmacy cost, the WTP for deductible coverage is $\$ 14.13$ per month. Limited gap coverage is valued at $\$ 2.72$ per month, and full gap coverage is valued at $\$ 20.25$ per month. For each of the top 100 drugs not in the formulary, the value of a plan is decreased by $\$ 1.40$. Requiring authorization or step therapy for a drug decreases the value of a plan by $\$ 1.01$. Consumers dislike drug tiers, valuing them at $-\$ 11.21$ per month. In the last two columns of Table 17, comparing consumers with low and high drug costs in 2005, we find that those with high drug costs place a higher values on limited gap coverage and an expansive formulary, and are less deterred by drug tiers.

\footnotetext{
${ }^{22}$ See McFadden (1984), McFadden and Train (2000). It would be preferable to implement a flexible mixed multinomial logit choice model of taste heterogeneity, which could be used to study the development of the hedonic market, including possible separating equilibria with clusters of plans competing for different segments of consumers. Data limitations preclude this generalization.

${ }^{23}$ The WTP for the $\mathrm{k}^{\text {th }}$ component of $\mathrm{x}$ is calculated as $-\gamma_{\mathrm{k}} / \delta$.
} 
Compare supply side hedonic prices in 2006 and the corresponding demand side WTP. For coverage of the $\$ 250$ deductible, price $(\$ 7.42)$ was below cost $(\$ 11.40)$, which was below value (\$14.13). Then, consumers should view this coverage favorably and choose it, while sponsors push price increases for deductible coverage to cover their costs. What we see instead in Table 7 is some exit of plans offering deductible coverage, and relatively stable prices. For generic gap coverage, value $(\$ 2.72)$ was below price $(\$ 8.29)$, which was below cost $(\$ 10.01)$. For full gap coverage, value (\$20.25) was below price (\$31.09), which was below cost (\$79.78). Then, many consumers should view this coverage unfavorably, with the possible exception of consumers with moderately high APB who can benefit from full gap coverage, but are unlikely to reach APB levels where the delayed catastrophic threshold taxes these benefits away, or consumers with very high APB who can benefit from plans with fixed capitation. There groups created adverse selection that made full gap coverage actuarially more costly, and this coverage even more unprofitable for sponsors. Then, in 2007 one would expect declining supply, reduced demand, and increased prices for full gap coverage.

For generic gap coverage, average WTP is below the hedonic price, but for consumers with high drug costs, WTP is near the hedonic supply price. Thus, there may be substantial demand for generic gap coverage by high APB users. As noted in the discussion of Table 16, the presence of full gap coverage plans in the market may mask the potential unprofitability of generic gap plans with fixed capitation, but with the extinction of full gap plans, sponsors are likely to experience losses from their generic gap plans.

Other plan features where there are substantial discrepancies between price and value are drug tiers and authorization requirements. Unless sponsors find cost savings that allow significant reductions in the prices of these features, one would expect most plans to drop these features.

For comparability across the 2006 and 2007 plan years, we repeat the hedonic analysis of plans and of WTP, with a restricted set of plan attributes that are measured in both periods. The results are given in Table 18. There are only minor changes in the estimated values of the retained attributes of 2006 plans when those attributes not available for 2007 are omitted. The only dramatic shifts between 2006 and 2007 are substantial increases in the prices of generic gap coverage from $\$ 8.99$ to $\$ 18.23$ and full gap coverage from $\$ 31.10$ to $\$ 38.76$. Then, full gap coverage remained priced well below cost, while generic gap coverage price rose above cost levels before adjustment for adverse selection. In 
contrast, WTP for generic or full gap coverage changed little from 2006 to 2007, and remain well below the hedonic prices for these features.

To investigate further how WTP for gap coverage varies with current drug expenditure, we estimated additional models with an interaction between splines of current drug bills and the gap coverage dummies. The estimated parameters are omitted here; instead we show implied WTPs for 2006 and 2007 as functions of 2005 and 2006 drug bill in Figures 6a and 6b, respectively. Figure 6a shows that there is a strong effect of 2005 drug expenditure on WTP for gap coverage in the plan choices for 2006. In particular, once the current drug bill exceeds about \$3000, WTP is significantly positive. This finding matches well with the location of the coverage gap (which starts at \$2250). We conclude that gap coverage will attract a limited sub-population with high drug bills, which may result in escalating prices and further adverse selection. The effect of drug expenditure on WTP is much weaker in the choices for 2007; one explanation is that few consumers in our data considered switching plans for 2007 and even fewer actually switched (we will come back to this issue in Section 7 below). Thus it is not surprising that plan attributes do not explain 2007 plan choices well.

Important questions are the impact of drug use on enrollment and plan choices, and consequent adverse selection, and the impact of prescription drug insurance on drug use. Table 19 gives the mean and median pharmacy bills of RPS respondents classified by their prescription drug insurance status in 2006, and the change in pharmacy bills from 2005 to 2006 classified by insurance status. The 2005 pharmacy bills were substantially lower for consumers who chose no coverage in 2006 than for covered consumers. Consumers with automatic, private, or Part D stand-alone coverage have comparable 2005 pharmacy bills. Because the share of non-enrollees is quite low, the effect of adverse selection in enrollment is small. Pharmacy bills rise in 2006 compared with 2005 for enrollees in all types of Part D plans, and strikingly for those enrolling in plans with gap coverage, and those with automatic enrollment which often incorporates gap coverage. This is strong evidence of a moral hazard in which gap coverage induces additional drug use. This puts pressure on the profitability of current plans offering gap coverage. Whether this induced drug use is productive in lowering other medical costs and promoting health cannot be assessed yet in the RPS population, although there is other evidence that at least selective promotion of drug use can lower overall medical costs; see Goldman and Philipson (2007). Table 19 shows that for consumers without drug coverage, median pharmacy bills do not change from 2005 to 2006. However, their mean pharmacy bills increase 
significantly, indicating that a tail of this group experienced health problems and significant drug needs in 2006. This underscores the risks and the value of Part D insurance even for this healthy group.

\section{The utility option value of enrolling in Medicare Part D}

In this section, we consider the dynamic stochastic programming problem faced by an individual with the option of enrolling now in a Medicare Part D prescription drug plan, or delaying enrollment. An individual who enrolls now gains current insurance coverage, and preserves the option value of later coverage at a non-penalized premium. An individual who delays has no current insurance coverage, and faces a premium penalty if he or she enrolls later, but if current drug use is sufficiently low, may still come out ahead by waiting until health conditions warrant. We ask whether observed enrollment decisions are "rational" in the sense of consistency with optimization of a dynamic stochastic program that minimizes the expected present value of lifetime out-of-pocket and insurance premium expenditures, noting that genuine "irrationalities" may result if the individual fails to act in her self-interest given her beliefs, or if she fails to have "rational expectations" regarding future events, but spurious claims of irrationality could result if we misspecify her dynamic programming problem.

Medicare Part D embeds a substantial government subsidy, so that at market premiums it is actuarially favorable for most seniors. As a consequence, all risk-averse seniors with significant current prescription drug costs will find delayed enrollment "out of the money". Seniors meeting this criterion are clearly irrational if they fail to enroll. ${ }^{24}$ However, healthy seniors with sufficiently low current drug costs face a more difficult choice, weighing the expected net cost of immediate enrollment against the likelihood of future health problems and drug needs, and the expected present value of penalized premiums from delayed enrollment. A saving remnant in the difficulty of the choice facing healthy seniors is that the expected cost of a mistake is low, so that these consumers may justifiably give the choice limited attention, and making a casual or default choice. Elements of a rational decision on enrollment for these individuals will be socioeconomic status, age, gender, the degree of risk aversion, their

\footnotetext{
${ }^{24} \mathrm{We}$ classify rejection of actuarially favorable insurance as "irrational" behavior. In principle, an individual could be risk-loving and rationally decline actuarially favorable insurance. We have not formally tested this possibility, but believe that as an explanation of Part D enrollment choices it would be inconsistent with other behavior and with stated preferences among hypothetical lotteries.
} 
discount rates, and their beliefs about future health, mortality, and prescription drug needs and costs, given current health.

An individual who enrolls in Part D may also face choices among alternative plans that differ in premiums, coverage, and degree of risk protection. It is possible to embed the Part D enrollment decision in a more general framework for modeling dynamic decisions on health, including decisions on the use of optional preventative or palliative drugs, and the effects of drug use on health outcomes. We will outline of this modeling framework, but will not implement all its elements in our current analysis.

The major pieces of our analysis are a dynamic stochastic programming model for the enrollment decision, and an econometric hidden Markov model for the dynamics of health and drug use status. Section 6.1 provides a general framework for studying consumers' life-cycle economic and health decisions. Section 6.2 describes the hidden Markov model we specify and estimate for health and drug cost dynamics. In section 6.3, we describe the dynamic programming model we use to study Part D enrollment decisions, and present the results of a simulation study of rational decisions. Section 6.4 contrasts rational and observed Part D enrollment decisions of RPS respondents.

\subsection{Modeling consumer lifetime health and economic dynamics}

The life-cycle of a consumer can be described as a series of periods (e.g., years) at which economic and health states are realized, and economic and health choices are made. Broadly, the consumers' problem is to make these choices to maximize well-being, subject to the impact of choices on the evolution of economic and health states. In general, economic and health choices influence both current satisfaction and the evolution of the individual's state.

In general form, a model of health dynamics may specify a vector of health states and indicators, as well as economic state variables, a decision set that includes economic alternatives on consumption, saving, and insurance, and health alternatives including use of preventative and palliative drugs, equations of motion that determine the evolution of economic and health states as functions of medical technology, and health care and life-style choices. We describe the dynamics of health in terms of latent "health capital" whose evolution depends on the technology for health maintenance, stochastic health risks, behavior, and inputs of resources that treat or prevent problems. The concept of health capital was introduced by Grossman (1972). His model with a depreciation rate that increases with age captures some of the life-cycle dynamics of health, but McFadden (2004) suggests that health capital may be 
more like the stock of water in a reservoir, so that (1) early in life the body's self-repair and replenishment mechanisms are usually adequate to maintain the stock near capacity, (2) with age natural replenishment diminishes and more budgeted investment is needed to maintain the stock, and (3) the technology of depreciation may induce losses that are not proportional to stock, and are relatively larger when the stock is small, old, and worn. This analogy provides a simple explanation as to why health expenditures can be low when we are young and health capital is high, and can rise sharply as we age and the remaining stock of health capital diminishes.

This paper models health capital as one-dimensional, with self-rated health status (SRHS), a five-point semantic differential from "poor" to "excellent", as an indicator. More generally, health capital may be fundamentally multi-dimensional (e.g., cardio-vascular, gastro-intestinal, crystalized and fluid mental, respiratory, and skeletal-muscular capital), with multiple indicators such as health conditions, biomarkers, ADL's, and IADL's. This approach to describing health raises a number of interesting questions for future research: Are different types of health capital complements or substitutes? Can consumers re-balance their portfolios of health capital stocks through the life cycle to minimize health problems? Can individuals report self-rated cardio-vascular or respiratory health status more reliably than a single overall self-rated health status? How predictive are various health capital levels for incidence of health problems or death?

A preliminary question for our analysis is the reliability of SRHS as an indicator of health capital. Adams et al (2003) find in an analysis of AHEAD data that Poor/Fair SRHS is predictive of future incidence of health conditions and of mortality, but the Good/Very Good/Excellent gradient is not predictive. This may be a reporting effect, or if SRHS is a good indicator of health capital, may reflect sharply diminishing productivity of health capital above a threshold. This paper also finds that Poor/Fair SRHS is strongly associated with clinical depression, and strongly associated with a dwelling rated Poor/Fair, even with statistical control for overall socioeconomic status. This suggests that reporting effects may influence SRHS. SRHS may also be susceptible to justification effects; see Baker et al (2004). Our treatment of SRHS can tolerate some reporting effects, but it does not attempt to identify and remove them.

The evidence from Heiss (2006) is that persistent unobserved components are present in the evolution of health capital. There may be heterogeneity across individuals in the technologies available for health maintenance and in initial endowments of health capital; these individual 
differences reflect what is often designated the latent "robustness" or "frailty" of the individual. In the current model, we assume that all such differences are captured by our dynamic specification for latent health capital. More critically, in this paper we assume that the evolution of health capital is not influenced by feedbacks from consumer choices on heath insurance, prescription drug use, or other economic or health-relevant decisions. We believe this is reasonable for the analysis of insurance and drug use over a two-year period, but future research that looks more broadly at questions of interactions and feedbacks between health outcomes and consumer behavior, particularly between prescription drug use and incidence of health problems, will have to look closely at the determination of health capital.

A general model of the life-cycle well-being of consumers requires specification of a felicity function of current consumption and health status that incorporates risk preferences. In general, some consumption expenditures and health states enter felicity directly, and others are inputs to the technology that determines the evolution of health. For example, palliative drugs to relieve the effects of specific health conditions such as arthritis or depression will enter felicity, while therapeutic drugs to treat health conditions such as diabetes and preventative drugs to treat conditions such as hypertension will enter the equation of motion for health capital. A future research question is whether insurance programs such as Part $\mathrm{D}$ will selectively encourage the use of preventative drugs, and improve compliance with therapeutic regimens. A research challenge is to determine how felicity is influenced by health conditions, and the extent to which individuals rationally manage the risks of future health conditions. Behavioral research suggests that humans do poorly in anticipating the disutility of health impairments and pain, and adapt to these impairments when they occur (the "hedonic treadmill"), so that it will be challenging to construct predictive models of health risk management that assume rational planning; see Kahneman and Snell (1990) and Gilbert et al (1998).

Our analysis of Part D enrollment decisions isolates a single component of overall felicity, the pharmacy out-of-pocket cost and drug insurance premium cost, and assumes that consumers seek to minimize the expected present value of this cost. We assume that consumers are risk-neutral, but this assumption can be relaxed within our model framework. 


\subsection{A hidden Markov model for health dynamics}

We model health dynamics as an annual process with the timing convention that events for a survivor at the end of the old year unfold in the following sequence: (1) If the individual has not previously enrolled in Part $\mathrm{D}$, an enrollment decision is made. If there are plan choices, the individual decides whether to switch to a new plan. (2) A new year health capital state is determined. (3) Survivor status, SRHS, and pharmacy bill are determined for the year, but part-year SRHS and pharmacy bills are discarded for individuals who do not survive the entire year. ${ }^{25}$ (4) Net out-of-pocket pharmacy costs are calculated taking into account insurance coverage and plan. (5) Finally, felicity for the new year, equal to the negative of the current value of Part $\mathrm{D}$ premiums plus out-of-pocket pharmacy costs, is determined. We initialize the dynamics at age 64 , so that all consumers who reach age 65 and become eligible for Medicare have a prior year health capital state.

We adapt the econometric specification of Heiss $(2006,2007)$ for the dynamics of health capital; see Heiss et al (2006) for a similar model. Let $\mathrm{R} *(\mathrm{n}, \mathrm{t})$ denote the latent "robustness" of respondent $\mathrm{n}$ in year $\mathrm{t}$, and $\mathrm{H}^{*}(\mathrm{n}, \mathrm{t})$ denote the latent health capital of this respondent. Assume that robustness follows a stationary $\mathrm{AR}(1)$ process, and that latent health capital is determined by robustness plus an exogenous drift,

$$
R^{*}(n, t)=\rho R^{*}(n, t-1)+\left(1-\rho^{2}\right)^{1 / 2} u_{0}(n, t) \text { and } H^{*}(n, t)=\alpha_{0} x(n, t)+R^{*}(n, t)
$$

where $x(n, t)$ is a vector of exogenous variables such as age and gender, and the $\mathrm{u}_{0}(\mathrm{n}, \mathrm{t})$ are i.i.d. standard normal. ${ }^{26}$ Robustness is assumed to be standard normal at age 64 . Then, $\mathrm{R} *(\mathrm{n}, \mathrm{t})$ is a stationary process, and if one directly observed $\mathrm{R}^{*}$ in two or more periods without censoring, its offdiagonal covariances identify the parameter $\rho$. However, because mortality depends on $\mathrm{R}^{*}$, the density of $\mathrm{R}^{*}$ conditioned on survival is influenced by selection at ages greater than 64 .

19. Lack of monthly data, and inconsistent reporting in year of death due to the discrete timing of surveys and limited proxy information, make it impractical to implement a monthly dynamic model.

20. This modeling choice specifies the form of depreciation of health capital and excludes feedbacks from health care and behavior to health capital depreciation or restoration. In light of the previous discussion of the forms that health capital might take, and interesting research question is whether alternative specifications of health capital dynamics give better fits to observed health dynamics. 
Suppose that one observes mortality/morbidity status $d(n, t)$ in year $t$, and for survivors with $d(n, t)=1$, one observes SRHS in five categories from "poor" to "excellent", and pharmacy bills (PB) in 12 categories. These satisfy the mappings,

$$
\begin{aligned}
& \mathrm{d}(\mathrm{n}, \mathrm{t})=\mathbf{1}\left(\mathrm{x}(\mathrm{n}, \mathrm{t}) \alpha_{1}+\gamma_{1} \mathrm{H}^{*}(\mathrm{n}, \mathrm{t})+\mathrm{u}_{1}(\mathrm{n}, \mathrm{t})>0\right), \\
& \operatorname{SRHS}(\mathrm{n}, \mathrm{t})=\mathrm{m}_{2} \text { if } \theta_{2, \mathrm{~m}-1} \leq \gamma_{2} \mathrm{H}^{*}(\mathrm{n}, \mathrm{t})+\mathrm{u}_{2}(\mathrm{n}, \mathrm{t})<\theta_{2, \mathrm{~m}} \quad \text { for } \mathrm{m}_{2}=1, \ldots, 5, \\
& \operatorname{PB}(\mathrm{n}, \mathrm{t})=\mathrm{m}_{3} \text { if } \theta_{3, \mathrm{~m}-1} \leq \mathrm{x}(\mathrm{n}, \mathrm{t}) \alpha_{3}+\gamma_{3} \mathrm{H}^{*}(\mathrm{n}, \mathrm{t})+\mathrm{u}_{3}(\mathrm{n}, \mathrm{t})<\theta_{3, \mathrm{~m}} \quad \text { for } \mathrm{m}_{3}=1, \ldots, 12,
\end{aligned}
$$

where the $u_{j}(n, t)$ are i.i.d. logistic disturbances, and the threshold parameters satisfy $\theta_{2,0}=\theta_{3,0}=-\infty$, and $\theta_{2,5}=\theta_{3,12}=+\infty$. Equation (6) requires one additional normalization of the location relative to the thresholds, which is accomplished for example by imposing $\theta_{2,3}=0$, or equivalently by requiring that the sample mean of $\mathrm{H}^{*}$ at age 64 be zero. We continue to assume that the vector $x(n, t)$ is exogenous, but note that the model could be extended to accommodate predetermined variables in $\mathrm{x}$ such as previous year's pharmacy bill. We assume there is no autocorrelation in the disturbances entering the equations for SRHS and PB. This is a strong restriction that forces latent health capital to account for all persistence random effects, such as persistent random reporting effects in SRHS. One limitation of the current model specification is that it cannot account for feedbacks from prescription drug use to health outcomes. These are potentially important, but are unlikely to be observed in a short panel.

The model (4)-(7) can be estimated by maximum likelihood or generalized method of moments. Note that as specified these equations of motion do not depend on behavior such as the Part D enrollment choice, so that issues of endogeneity do not arise. While would be possible to carry out simulated maximum likelihood estimation directly in our short panel, a more practical and stable method that also works in long panels is a sequential algorithm similar to the Kalman filter; see Heiss (2007).

Given the value of $H^{*}(n, t)$, the outcome $d(n, t)$ has a binomial logit probability. Further, the independence of $u_{j}(n, t)$ implies that given $H^{*}(n, t)$, mortality occurs "at random", so that conditioned on survival, SRHS and PB are independent and their probabilities are ordered logit. Let $y(n, t)$ denote the observed events " $d(n, t)=0$ " in the case of mortality and " $d(n, t)=1$, SRHS $=m_{2}, P B=m_{3}$ " in the case of survival and observations $m_{2}$ and $m_{3}$ for SRHS and PB, respectively, and let $\operatorname{Pr}\left(\mathbf{y}(n, t) \mid H^{*}(n, t)\right)$ denote 
the conditional probability of $y(n, t)$ given $H^{*}(n, t)$. The likelihood contribution of individual $n$ can then be expressed as

$$
L(n)=\int \ldots \int \prod_{t=1}^{T} \operatorname{Pr}\left(y(n, t) \mid H^{*}(n, t)\right) f_{1 \ldots T}\left(H^{*}(n, 1), \ldots, H^{*}(n, T)\right) d H^{*}(n, 1) \cdots d H^{*}(n, T)
$$

where $f_{1 \ldots T}$ is the density of $\left(H^{*}(n, 1), \ldots, H^{*}(n, T)\right)$. Absent mortality, this density would be multivariate normal density with mean vector $\left(\alpha_{0} \mathrm{x}(\mathrm{n}, 1), \ldots, \alpha_{0} \mathrm{x}(\mathrm{n}, \mathrm{T})\right)$ and covariance matrix $\Sigma$ with elements $\Sigma_{\mathrm{ij}}=\rho^{|\mathrm{i}-\mathrm{j}|}$, However, mortality causes it to be modified by selection. As discussed by Heiss (2007), the structure of such models allows us to write this likelihood contribution as the product of conditional likelihoods,

$$
\begin{aligned}
L(\mathrm{n})=\int \operatorname{Pr}\left(\mathbf{y}(\mathrm{n}, 1) \mid \mathrm{H}^{*}(\mathrm{n}, 1)\right) \mathrm{f}_{1}\left(\mathrm{H}^{*}(\mathrm{n}, 1)\right) \mathrm{dH}^{*}(\mathrm{n}, 1) \\
\quad \times \prod_{t=2}^{T} \int \operatorname{Pr}\left(\mathbf{y}(\mathrm{n}, \mathrm{t}) \mid \mathrm{H}^{*}(\mathrm{n}, \mathrm{t})\right) \mathrm{f}_{\mathrm{t} \mid 1, \ldots, \mathrm{t}-1}\left(\mathrm{H}^{*}(\mathrm{n}, \mathrm{t}) \mid \mathbf{y}(\mathrm{n}, 1), \ldots, \mathbf{y}(\mathrm{n}, \mathrm{t}-1)\right) \mathrm{d} H^{*}(\mathrm{n}, \mathrm{t}),
\end{aligned}
$$

where $f_{1 \ldots .}$ is the marginal density for the first period, and $f_{t \mid 1, \ldots, t-1}$ is the conditional density for period $t$ given observed outcomes prior to t. These densities would be normal if there were no selection and the conditioning was on past values of $\mathrm{H}^{*}$, but are modified from this specification by selection and by conditioning on observed events. Equation (9) allows a sequential approximation of the likelihood contribution in the spirit of the Kalman filter. Start with the outcome probability of the first period. The conditional density $\mathrm{f}_{2 \mid 1}$ needed for the second period is approximated in two steps: First account for the information $\mathbf{y}(n, 1)$ contains on $H^{*}(n, 1)$ using the model for $\operatorname{Pr}\left(\mathbf{y}(n, t) \mid H^{*}(n, t)\right)$ and Bayes' rule. In the second step, account for the shocks $\mathrm{u}_{0}$ using the transition model (4). This procedure is repeated recursively until all T observations are included. Heiss (2007) discusses this approach and the sequential Gaussian quadrature algorithm used for the estimation of our model in more detail

\subsection{Data and Estimation Results.}

The data used to estimate the model of health and drug expenditure dynamics come from the Medicare Current Beneficiary Survey (MCBS) collected by CMS, in particular, the Cost and Use files 
for years 2000 to 2003. The MCBS is is a rotating panel based on a stratified random sample of about 12,000 Medicare beneficiaries in each cohort. An individual is observed for at most three years (together with a preliminary interview, resulting in at most four observations). The MCBS includes information on demographics, socioeconomic status, health status, and utilization as well as cost of medical care (including physician services, inpatient hospital services, and prescription drugs). Self-reported events are validated by Medicare claims. A study by Poisal (2003) suggests that there is some underreporting in self-reported prescription drug expenditure in the MCBS. We do not address this issue here.

Table 20 shows the maximum likelihood parameter estimates of the full model. It includes age splines, a dummy variable for high education (more than high school) and a dummy variable for noncaucasian respondents in all equations. The model is estimated separately by gender. Ceteris paribus, non-white females use less drugs than white females. Independent of gender, highly educated respondents use less drugs and report better self-rated health. The latent component enters all equations significantly and its correlation from one year to the next is high (.97 for males and .96 for females), but the null hypothesis of time-constant latent "robustness" is clearly rejected by a likelihood ratio test $(\mathrm{p}<0.001)$.

\subsection{Simulation of health trajectories}

Since the model parameters are difficult to interpret directly, a few simulations of the trajectories help to understand the model and its implications. All results are for white males with a high school degree or less unless stated otherwise.

Figure 7 illustrates the dynamic features of the latent robustness $\mathrm{R}^{*}$. It shows its mean for the surviving population given starting values at the median, the 10th, and 90th percentile. While the three lines tend to converge, they remain distinct. Technically, this is due to the high serial correlation in $\mathrm{R}^{*}$, and to the differential effects of mortality. Intuitively it means that someone who is very healthy at age 65 will be still be relatively healthy at age 90 compared to someone who was in worse health at 65 . Selection due to mortality shifts the distribution markedly at higher ages.

Figure 8 shows survival probabilities for the same hypothetical individuals with initial latent health at the mean, the 25 th, and 75 th percentile. The differences are strong. While only half of the unhealthy survive past age 70 , half of the average individuals survive to age 80 and almost half of the very healthy survive to age 90 . 
Figure 9 shows the average drug bill by age. The thick black line represents cross-sectional averages in the MCBS sample. If anything, the average drug bills decreases with age, as those with health conditions requiring high drug use are selected out by mortality. The thin black line shows the simulation results from the estimated model. It represents the average simulated drug bill for the surviving population. The decline over time appears mostly as a selection effect: The healthy use less drugs and are more likely to survive to a higher age. This effect is illustrated by the thin lines. They show the simulated drug bill of the population surving to age $70,75,80,85,90$, and 95 . Those who survive to a high age are also likely to have used fewer drugs when they were 65 than the average population alive at 65 .

\subsection{The consumer's dynamic stochastic program}

Consumers face an open enrollment period for prescription drug insurance at the end of each year. If they are not currently enrolled, they may decide to enroll, or default to continued non-enrollment. (About sixty percent of seniors are automatically enrolled through employer or union, VA, military, Federal employee, or Medicaid programs.) If consumers are currently enrolled, they may switch plans, or by default continue in their current plan. This decision structure allows us to simulate an optimal enrollment decision strategy in a relatively straightforward way. We ignore plan choice in analyzing enrollment strategies, assuming the only options of a consumer are no prescription drug insurance or a Part D standard plan with a market average premium. This simplification may understate the option

value of Part D enrollment, but the effect will be small. Since the consumer can switch plans annually, plan choice conditioned on current enrollment and health capital does not require strategic preparation. Since the added features of extended plans are not subsidized, they will be actuarially unfair to their enrollees in market equilibrium once administrative overhead costs are added. Then, the possibility is remote that a risk-neutral consumer will in the future encounter circumstances where extended plans offered at market premiums are substantially better values than the standard plan, and these additional plans will add little to the option value of enrollment for healthy consumers.

Let $\mathrm{t}=1, \ldots, \mathrm{T}$ denote years past age 64 , so that at $\mathrm{T}=35$, an individual is age 100 , which we assume is the maximum attainable age. Let $H^{*}(n, t), d(n, t), \operatorname{SRHS}(n, t)$, and $\operatorname{PB}(n, t)$ denote , respectively, latent health capital, a survival indicator, self-rated health status, and pharmacy bill for consumer $\mathrm{n}$ in year $\mathrm{t}$, 
and assume that they are determined by $(4)-(7)$. Let $E(n, t)$ be an indicator for enrollment in a Part D plan in year $\mathrm{t}$, and let

$$
\mathrm{CNE}(\mathrm{n}, \mathrm{t})=\sum_{s=1}^{t}(1-\mathrm{E}(\mathrm{n}, \mathrm{s}))
$$

denote the cumulative years of non-enrollment at the end of year t. (All consumers age 64+ start with zero CNE in 2005 when the Part D market first opened.) The current net benefit from Part D standard plan enrollment, from (1), is

$$
\begin{aligned}
\mathrm{CV}(\mathrm{n}, \mathrm{t})=0.75 \cdot \min \{2000, \max \{\mathrm{PB}(\mathrm{n}, \mathrm{t})-250,0\}\}+0.95 \cdot \max (\mathrm{PB}(\mathrm{n}, \mathrm{t})-5100,0\} \\
-(1+0.12 \cdot \mathrm{CNE}(\mathrm{n}, \mathrm{t})) \cdot 12 \mathrm{p}
\end{aligned}
$$

where $\mathrm{p}$ is the monthly premium and the factor $(1+0.12 \cdot \mathrm{CNE}(\mathrm{n}, \mathrm{t}))$ is the premium penalty for delayed enrollment. We assume that the standard plan benefit schedule and premium remain fixed in real terms into the future. We assume that at the time of an enrollment decision at the end of year $\mathrm{t}-1$, consumers know $H^{*}(\mathrm{n}, \mathrm{t}-1)$, SRHS(n,t-1), PB(n,t-1), and CNE(n,t-1), and can predict perfectly all future values of exogenous variables $\mathrm{x}$, but do not know the future shocks that determine health capital, health status, pharmacy bills, and survival in year $t$ and beyond.

The objective of the risk-neutral consumer of age $\tau-1$ in 2005 is to choose an enrollment strategy to maximize the expected present value of the future stream of current net benefits,

$$
\mathbf{E}_{\tau-1} \sum_{t=\tau}^{T}\left[\prod_{s=\tau}^{t} d(n, s)\right] \mathrm{E}(\mathrm{n}, \mathrm{t}) \cdot \mathrm{CV}(\mathrm{n}, \mathrm{t}),
$$

subject to the known initial conditions $H^{*}(\mathrm{n}, \tau-1), \operatorname{SRHS}(\mathrm{n}, \tau-1), \operatorname{PB}(\mathrm{n}, \tau-1)$, and $\mathrm{CNE}(\mathrm{n}, \tau-1)=0$, and to the equations (4)-(7), (10), and (11). Let $\mathrm{V}\left(\mathrm{H}^{*}, \mathrm{CNE}, \mathrm{x}, \mathrm{t}\right)$ denote a valuation function giving the optimized expected present value of the future stream of current net benefits from age $t$ on, starting from state variables $\mathrm{H}^{*}$ and $\mathrm{CNE}$ and the exogenous variables $\mathrm{x}$. Then, $\mathrm{V}$ is defined by backward recursion, with

$$
\mathrm{V}\left(\mathrm{H}^{*}(\mathrm{n}, \mathrm{T}-1), \mathrm{CNE}(\mathrm{n}, \mathrm{T}-1), \mathrm{x}, \mathrm{T}\right)=\max _{\mathrm{E}(\mathrm{n}, \mathrm{T})=0,1} \mathbf{E}_{\mathrm{T}-1} \mathrm{~d}(\mathrm{n}, \mathrm{T}) \cdot \mathrm{E}(\mathrm{n}, \mathrm{T}) \cdot \mathrm{CV}(\mathrm{n}, \mathrm{T}),
$$


and

$$
\begin{aligned}
& \mathrm{V}\left(\mathrm{H}^{*}(\mathrm{n}, \mathrm{t}-1), \mathrm{CNE}(\mathrm{n}, \mathrm{t}-1), \mathrm{x}, \mathrm{t}\right) \\
& \quad=\max _{\mathrm{E}(\mathrm{n}, \mathrm{t})=0,1} \mathbf{E}_{\mathrm{t}-1} \mathrm{~d}(\mathrm{n}, \mathrm{t})\left\{\mathrm{E}(\mathrm{n}, \mathrm{t}) \cdot \mathrm{CV}(\mathrm{n}, \mathrm{t})+\beta \cdot \mathrm{V}\left(\mathrm{H}^{*}(\mathrm{n}, \mathrm{t}), \mathrm{CNE}(\mathrm{n}, \mathrm{t}), \mathrm{x}, \mathrm{t}\right)\right\},
\end{aligned}
$$

where $d(n, t)$ and $C V(n, t)$ are given by (4)-(7), (10), and (11), and $\beta<1$ is a rate of time impatience.

Discretize the distribution of the health state with $\mathrm{K}$ nodes, so $\mathrm{H}^{*}(\mathrm{n}, \mathrm{t}) \in\left\{\mathrm{h}_{1}, \ldots, \mathrm{h}_{\mathrm{K}}\right\}$. These nodes can be thought of as draws from the marginal distribution of $\mathrm{H}^{*}$. Equation (4) then translates into transition probabilities $\mathrm{P}_{\mathrm{jk}}=\operatorname{Pr}\left(\mathrm{H}^{*}(\mathrm{n}, \mathrm{t})=\mathrm{h}_{\mathrm{j}} \mid \mathrm{H}^{*}(\mathrm{n}, \mathrm{t}-1)=\mathrm{h}_{\mathrm{k}}\right)$ for any $\mathrm{j}, \mathrm{k}=1, \ldots, \mathrm{K}$.

The decision problem is now solved using backward induction from $\mathrm{T}=100$. For each possible configuration $\mathrm{CNE}(\mathrm{n}, \mathrm{T}-1) \in\{0, \ldots, 34\}$ and $\mathrm{H}^{*}(\mathrm{n}, \mathrm{T}-1) \in\left\{\mathrm{h}_{1}, \ldots, \mathrm{h}_{\mathrm{K}}\right\}$, and $\mathrm{x}$, solve (13). Then, recursively, given the previously obtained valuation function $\mathrm{V}\left(\mathrm{H}^{*}(\mathrm{n}, \mathrm{t}), \mathrm{CNE}(\mathrm{n}, \mathrm{t}), \mathrm{x}, \mathrm{t}\right)$ and each possible configuration $\mathrm{CNE}(\mathrm{n}, \mathrm{t}-1) \in\{0, \ldots, \mathrm{t}-1\}$ and $\mathrm{H}^{*}(\mathrm{n}, \mathrm{T}-1) \in\left\{\mathrm{h}_{1}, \ldots, \mathrm{h}_{\mathrm{K}}\right\}$, and $\mathrm{x}$, solve (14). The final result is a table of optimal strategies for individuals age $64+$ for each possible configuration of state variables and exogenous variables they may face. An optimal strategy is obtained for an individual of age $\tau-1$ in 2005 with health capital $H^{*}(n, \tau-1)$ by look-up for these state variables and $\mathrm{CNE}(\mathrm{n}, \tau-1)=0$.

We give simulations from this dynamic stochastic program for illustrative combinations of socioeconomic characteristics. Figure 10a shows net benefits of enrollment for 65 year old white males with a high school degree or less who are choosing whether to enroll into a standard plan which costs $\$ 240$ a year. The discount rate is set to $5 \%$ per year. The abscissa represents the relative value of $\mathrm{H}^{*}$. The very healthy are located on the left, and the very unhealthy on the right. The thin solid upward sloping line shows the expected immediate net benefit of enrollment. It is negative for the healthiest $14 \%$ of this population. The dotted line shows the expected present value of penalty savings. It is driven by two effects: worse health increases the probability of future enrollment and decreases further life expectancy. These two effects have offsetting effects regarding the expected present value of penalty savings.

In the simulation, the extremely healthy have a low present value of future penalty savings because they have a good chance never to enroll. Present value of penalty savings increases as health gets worse. The 10th percentile already has a very high probability of future enrollment. However, as health worsens further, life expectancy and therefore also the present value of penalty savings decreases markedly. The 
top thick solid line is the total net benefit of enrollment, the sum of the other two lines. It is positive for all but the healthiest two percent. Then, according to our model, $98 \%$ of this population should enroll.

Figure 10b shows the same graph as Figure 10a for the same population but with the additional restriction that in the previous year, the individual did not use any drugs. This population only has an 8 percent chance that they will end up with a drug bill that makes enrollment immediately beneficial. But at the same time, the further life expectancy is quite high for this group and there is a good chance that they will eventually end up with a sizable drug bill, the expected present value of the penalty savings is high enough to make enrollment beneficial for more than $80 \%$.

Figure 10c shows the simulation results for the same population as Figure 10a, but for the age 80 instead of 65 . The expected immediate benefits are similar to those of the 65 years old, but due to the lower further life expectancy, the present value of future benefit savings is lower, resulting in a rational enrollment rate of only $60 \%$.

\subsection{Predicted and observed Part D enrollment decisions of RPS respondents}

We have run the same simulation presented for illustrative individuals in section 6.5 for all active deciders in RPS. The result is a probability that enrollment is rational according to our model which represents the share of people with the same age, previous year's drug bill, SRHS, and demographics who have a positive net benefit. Furthermore, we impute the enrollment share if individuals only look at the next year's outcome and the expected benefit of enrollment, split into the immediate benefit and the present value of saved penalties.

Table 21 shows the overall descriptive statistics of these values. In total, $97.5 \%$ should enroll if they are fully rational, and for $81.7 \%$ this is even immediately beneficial. On average, the immediate benefit is $\$ 1116$ and the present value of future benefit savings is $\$ 299$. In Table 22, these averages are classified by the actual enrollment decisions of the RPS respondents. (For this table, enrollment is defined as either a Part D stand-alone plan or a Medicare Advantage plan with Part D prescription drug coverage.) Respondents who have a larger probability that enrollment is rational do have a higher enrollment rate. But using the fully rational rule given by our model, $93.4 \%$ of those who did not enroll should have enrolled. 
Table 23 shows actual and simulated enrollment by health and socio-demographic and health variables. Only respondents who have not used any drugs in 2005 have a reasonable probability to be better off not enrolling according to the rational model. The myopic decision rule implies only $12.7 \%$ enrollment with a zero previous drug bill. The actual enrollment in this group is with $64.1 \%$ between the rational and the myopic rule. For higher drug bills, the probability that enrollment is rational is essentially one. Higher 2005 drug bills are clearly correlated with both myopically optimal and actual enrollment.

Table 24 compares estimates from reduced-form models of actual and rational enrollment. The previous drug bill is the most important determinant of both. Also, both are lower for respondents with excellent SRHS. The other predictors are hardly significant for actual enrollment. Rational enrollment is lower for the older because of the lower life expectancy over which the present value of avoided penalties accumulate. Highly educated individuals have a higher life expectancy. The same is true for females and they tend to use more drugs. Race does not play any role.

Table 25 shows parameter estimates from more logit models of enrollment. Specification (1) only includes the simulated rational enrollment probability as an explanatory variable. Its coefficient is highly significantly positive - on average, respondents who have a high enrollment probability in our model are more likely to actually enroll. Specification (2) adds the dollar-value of enrollment, split into immediate and future benefits. High immediate benefits increase the enrollment probability, whereas future benefits do not seems to have an effect. Specification (3) also includes the simulated enrollment probability if respondents only care about the immediate benefits. Its coefficient comes out highly significantly and all other variables lose their explanatory power. Adding socio-demographic variables in Specification (4) does not qualitatively change the results. Adding the 2005 drug bill in addition leads to a collinearity problem: the four simulated values and the 2005 drug bill are too highly dependent to statistically decide which of the groups of variables drive the results. While single t-tests of these nine variables do not reject the hypothesis that they are equal to zero, a Wald test of the hypothesis that they are all zero is clearly rejected (a chi-square test statistic with 9 degrees of freedom is 46.94 , giving significance $p<0.0001$ ). Overall, the results indicate that respondents are very well aware of the (simple) fact that enrollment is more beneficial with a higher drug bill, but do not seem to understand the (complicated) consequences of the penalty for late enrollment. 


\section{Plan satisfaction and switching: First results from RPS-2007}

The analysis presented in this paper so far focused mostly on data from RPS-2005 and RPS-2006. As discussed in Section 3, we interviewed the RPS respondents for a third time in April 2007 to ask them about their plan choices for 2007 as well as their satisfaction with their 2006 plan. In this section, we investigate plan satisfaction and switching very briefly. The number of observations is larger than in our earlier analysis since we can also use answers from respondents in the 2007 refreshment sample (for whom we do not have 2005 and 2006 data).

We asked the RPS respondents about their satisfaction with their 2006 Part D stand-alone plans, both overall and with respect to five plan features. Each question was answered on a five-point scale (poor, fair, good, very good, excellent). The results are summarized in Table 26 where we report the proportion of respondents who were dissatisfied ("poor" or "fair" ratings). Overall, 17.6\% are dissatisfied with their plans. The dimension that attracts the most negative ratings is gap coverage $-47.2 \%$ say that they are dissatisfied with this feature. The rating is even worse for those respondents who say that they actually hit the gap; among them, $66.3 \%$ are dissatisfied with having a gap in their coverage. In contrast, customer service does not seem to be a major cause of dissatisfaction.

Table 27 summarizes the Part D enrollment status of those respondents who have a stand-alone plan for 2007. Of these respondents, $91.2 \%$ already had coverage in 2006 . The majority (62\%) did not consider switching, and another $18.4 \%$ considered switching but stayed with their plan. Only $10.7 \%$ switched plans. The fact that only relatively few respondents considered switching, and even fewer actually switched is important since switching is costless and many plans changed one or more of their attributes - not only premiums but also such features as deductibles, gap coverage, formularies, etc. We have not performed a formal analysis, but it is conceivable that switching would have been optimal for more than just about $10 \%$ of consumers. Thus, it seems that there is a lock-in effect, and so it may have been a good strategy for plan providers in this repeated-interaction market to offer cheap plans in the first period and then to increase premiums and/or reduce plan quality over time. (For instance, one plan that was very popular in 2006 has seen a substantial premium increase from 2006 to 2007, which was hotly debated in the popular press). We cannot investigate this issue further, but this is certainly an important area for future research on consumer and firm behavior in "consumer-directed" health care markets.

Finally, we estimated logit models for the dependent variables "considered switching plans" and "switched plans" (Table 28). The number of observations is rather small because these models require 
information on the features of the chosen plans in both 2006 and 2007. Having a plan with no deductible in 2006 has a negative effect on whether a respondent considers switching. Also, an increase in the premium of the 2006 plan in 2007 made respondents consider a switch. When we add plan dissatisfaction, defined as in Table 26, it also has a positive and strong effect on considering a switch. These variables have similar effects on the actual switching decision. Comparing both models, the switching decision appears to be better explained by the variables in our model, and the effects are generally intuitive. Thus, even though arguably too few consumers switch plans, the switching decision itself is well in line with the underlying economics incentives.

\section{Conclusions}

The introduction of Medicare Part D - the most significant expansion of the Medicare program since its inception - had several political goals, most importantly to provide access to affordable drug coverage to all Medicare beneficiaries (in particular to the chronically ill) and to create a "competitive, transparent marketplace offering a wide array of benefits" (Bach and McClellan, 2005). Medicare Part D also exemplifies the trend towards consumer-directed healthcare, giving consumers more choice but also confronting them with difficult decisions. The complexity of the program was a great source of concern before its introduction. Consumers were quite confused about the Part D program before enrollment began, with 40 percent knowing little or nothing about what the program offered (according to our earlier estimates; see Heiss, McFadden, and Winter, 2006).

In this paper, we investigated in great detail how older Americans made their decisions in the enrollment periods for the first two years of the new Medicare Part D prescription drug benefit. We analyzed data from three waves of the Retirement Perspectives Survey (RPS) which we designed specifically to obtain information on older Americans' health status and expenditures, their preferences, and their prescription drug insurance choices before and after the introduction of Medicare Part D. The main purpose of our analysis was to understand how consumers react to the economic incentives embedded in Medicare Part D. This is an important research question that goes much beyond the more pressing public policy issue of how successful the program was in terms of the goals stated above. It is

our view that understanding whether and how consumers react to economic incentives in complex health insurance markets is an important part of the process of optimally designing social insurance programs such as Medicare Part D. This paper can be interpreted as a first step in that direction. 
Our analysis proceeded in several steps. We began by looking at how consumers reacted to the incentives operating in the first year of Part D. Specifically, we asked whether and when eligible consumers without prescription drug coverage from other sources enrolled in Medicare Part D. Given the structure of the program, expected drug costs for the first year should be by far the most important determinant of those decisions. Our analysis confirms this: Enrollment, and particularly early enrollment (i.e., before January 1, 2006) seems to be driven almost entirely by 2005 drug costs (which should be a good predictor of 2006 drug costs) and very little by other variables. Also, those consumers who enrolled late in the initial enrollment period have had lower drug expenditure in 2005 than those who enrolled early. Overall, these results suggest that consumers' choices can be approximated well already by a very simple model with static expectations and myopic decisions in which only current drug costs play a role. That observed choices can be explained by such a simple model may be not surprising since CMS's information campaign as well as advertisements by plan providers stressed exactly those immediate costs and benefits of enrolling in a Part D.

Next, we investigated plan choices of those individuals who enrolled in a Part D standalone plan. While in a full structural model, the enrollment and the plan choice decisions cannot be separated, we believe it is a reasonable approximation of actual choice behavior to consider these decisions separately. Our analysis of plan choices was based on a comparison of the implicit prices of various plan features (estimated using a simple hedonic regression model and CMS data on all plans offered) and consumers' willingness to pay for those features (estimated using a discrete choice model and RPS data on actual plan choices). We found that implicit prices and WTPs match up surprisingly well. In particular, WTP for "coverage in the gap" is significantly positive for those consumers whose 2005 drug bills put them in the coverage gap.

The overall conclusion from this first part of our analysis is that consumers respond to the immediate incentives that are induced by their current health status and drug expenditures combined with the salient, widely publicized features of the Medicare Part D program. However, this is only half of the story since in an attempt to counter potential adverse selection problems, the designers of Medicare Part D introduced a penalty for late enrollment. This feature makes the enrollment decision a dynamic one. In the second part of our analysis, we thus analyze whether consumers also react to the intertemporal incentives provided by Medicare Part D. To this end, we developed a dynamic model of health status and drug expenditure which we estimated using data from the Medicare Current Beneficiary Survey(MCBS) 
and an intertemporal optimization model of Medicare Part D enrollment decisions that could be used to predict optimal enrollment decisions in our sample.

Our model predicts that some consumers for whom enrollment in 2006 did not have positive value should nevertheless have enrolled in order to avoid future penalties. Under the assumptions we made, not enrolling in 2006 would have been rational only for $2.5 \%$ of our sample, according to our simulations. This finding reflects the combined effects of the subsidies to the program and the penalty for signing up after first becoming eligible.

We conclude from our analysis that the Medicare Part D market has been, on the whole, a tactical success. It has achieved high enrollment levels, and through tight control of products in the market has assured that rates of consumer deception and fraud are low. It has led to competition among sponsors that has kept premiums low, and succeeded in applying competitive pressure to lower drug prices and encourage use of generic substitutes. In the annual open enrollment period, consumers can switch away from plans that provide unsatisfactory service, a choice that has option value and influences sponsor behavior even if it is not commonly exercised. However, adverse selection appears to be in the process of extinguishing most of the extended plan alternatives that would offer consumers wide choice. Strategically, it remains to be seen whether this market dominated by two large sponsors will remain vigorously competitive, whether the risk weighting methods used by CMS will be effective in neutralizing adverse selection, particularly for extended plans, and consumers will be sufficiently alert to use their ability to switch to discipline poor service. It is clear that the administrative cost of operating a Medicare prescription drug benefit through a market rather than through a mandatory single-product system (such as Medicare Part A) is higher than the best-run single-payer systems around the world. The question for society is whether the efficiencies of production and the consumer benefits of choice actually achieved in this market are sufficient to justify its higher administrative cost, and if so whether the organization and administration of the Part D market is a good model for other areas of health care.

We end by mentioning directions for future research on Medicare Part D and on consumer-directed health care and insurance markets more generally. One issue that deserves more attention is whether consumers' decision are rational. However, any analysis of this issue, including our attempt in this paper, is necessarily restricted by the need to make strong assumptions about preferences and expectations. Another important aspect of the market for Medicare Part D plans is adverse selection and moral hazard, the extent to which they hinder market efficiency, and the extent to which they can be neutralized 
through mechanism design. We have provided some first insights in this paper on these questions, but more research is needed here as well. Next, market structure and firm behavior are interesting in its own right, and they may also interact with consumer behavior (for instance, the fact that few consumers switched plans between 2006 and 2007 may indicate that a pricing strategy with low premiums in 2006 and then increases for 2007 would have been very effective). Finally, as we already noted above, we hope that the models we developed and estimated in this paper will prove useful in the design of future health insurance reforms, including periodic reappraisal of the Medicare Part D program itself.

\section{References}

Abbring, J. H., P.-A A. Chiappori, J. J. Heckman, and J. Pinquet (2003): Adverse selection and moral hazard in insurance: Can dynamic data help to distinguish? Journal of the European Economic Association, 1(2-3), 512-521.

Adams, P., M. D. Hurd, D. McFadden, A. Merrill, and T. Ribeiro (2003): Healthy, wealthy, and wise? Tests for direct causal paths between health and socioeconomic status. Journal of Econometrics, 112, 3-56.

Anderson, S.; A. De Palma, and J. Thisse (1996) Discrete Choice Theory of Product Differentiation, MIT Press: Cambridge.

Bach, P. B. and M. B. McClellan (2005): A prescription of a modern Medicare program. New England Journal of Medicine, 353, 2733-2735.

Bach, P. B. and M. B. McClellan (2006): The first months of the prescription-drug benefit: A CMS update. New England Journal of Medicine, 354, 2312-2314.

Bajari, P., H. Hong, and A. Khwaja (2006): Moral hazard, adverse selection and health expenditures: A semiparametric analysis. NBER Working Paper No. 12445.

Baker, M., M. Stabile, and C. Deri (2004): What do self-reported, objective, measures of health measure? Journal of Human Resources, 39(4), 1067-1093.

Buchmueller, T. (2006): Price and the health plan choices of retirees. Journal of Public Economics, 25, 81-101.

CMS (2006) Medicare Prescription Drug Benefit Manual, http://www.cms.hhs.gov/PrescriptionDrugCovContra/

CMS (2005) Instructions for the Part D payment demonstration, Centers forMedicare and Medicaid Services, Technical Report.

Congressional Budget Office (2004) A detailed description of CBO's cost estimates for the Medicare prescription drug benefit, Technical Report, CBO.

Cubanski, J. and P. Neuman (2006): Status report on Medicare Part D enrollment in 2006: Analysis of plan-specific market share and coverage. Health Affairs, 26(1), w1-w12.

Dennis, J. M. (2005): Field Report for the Retirement Perspectives Survey. Menlo Park, CA: Knowledge Networks, Inc.

Donohue, J. (2006): Mental health in the Medicare Part D drug benefit: A new regulatory model? Health Affairs, 25(3), 707719.

Fang, H., M. P. Keane, and D. Silverman (2006): Sources of advantageous selection: Evidence from the Medigap insurance market. NBER Working Paper No. 12289.

Frakt, A. B. and S. D. Pizer (2006): A first look at the new Medicare prescription drug plans. Health Affairs, 25 , w252 w261.

Gilbert, D. T., Pinel, E. C., Wilson, T. D., Blumberg, S. J., and Wheatley, T. (1998): Immune neglect: A source of durability bias in affective forecasting. Journal of Personality and Social Psychology, 75, 617-638.

Goldman, D. P., G. F. Joyce, J. J. Escarce, J. E. Pace, M. D. Solomon, M. Laouri, P. B. Landsman, and S. M. Teutsch (2004): Pharmacy benefits and the use of drugs by the chronically ill. Journal of the American Medical Association, 291(19), 2344-2350.

Goldman, D., and T. Philipson (2007) Integrated insurance design in the presence of multiple medical technologies. American Economic Review, Papers and Proceedings, 97(2), 427-32. 
Grossman, M. (1972) On the Concept of Health Capital and the Demand for Health. Journal of Political Economy, 80(2), 223-255.

Hall, A. E. (2004): Estimating the demand for precription drug benefits by Medicare beneficiaries. Unpublished manuscript, MIT and NBER.

Heckman, J., R. Matzkin, and L. Nesheim (2003): Estimation and simulation of nonadditive hedonic models. NBER Working Paper No. 9895.

Heiss, F. (2006): Dynamics of self-rated health and selective mortality. Unpublished manuscript, University of Munich.

Heiss, F. (2007): Sequential numerical integration in nonlinear state-space models for microeconometric panel data. Journal of Applied Econometrics, forthcoming.

Heiss, F., A. Börsch-Supan, M. Hurd, and D. Wise (2006a): Pathways to disability: Predicting health trajectories. In D. Cutler and D. A. Wise (Eds.), Health in Older Ages: The Causes and Consequences of Declining Disability Among the Elderly, Chicago and London: University of Chicago Press, forthcoming.

Heiss, F., D. McFadden, and J. Winter (2006b): Early results: Who failed to enroll in Medicare Part D, and why? Health Affairs, 25, w344-w354.

Hurd, M., A. Kapteyn, S. Rohwedder, and A. van Soest (2007): Knowledge of drug costs and insurance plan choice. Paper presented at the AEA Annual Meeting, Chicago, January.

Huskamp, H. A., P. A. Deverka, A. M. Epstein, R. S. Epstein, K. A. McGuigan, and R. G. Frank (2003): The effect of incentive-based formularies on prescription-drug utilization and spending. New England Journal of Medicine, 349(23), 2224-2232.

Huskamp, H. A., R. G. Frank, K. A. McGuigan, and Y. Zhang (2005): The impact of a three-tier formulary on demand response for prescription drugs. Journal of Economics and Management Strategy, 14(3), 729-753.

Jenkins, M.; P. Liu; R. Matzkin; D. McFadden (2005): The browser war: Econometric analysis of Markov perfect equilibrium in markets with network effects. Unpublished manuscript, University of California, Berkeley.

Joyce, G. F., J. J. Escarce, M. D. Solomon, and D. P. Goldman (2002): Employer drug benefit plans and spending on prescription drugs. Journal of the American Medical Association, 288(14), 1733-1739.

Kahneman, D. and Snell, J. (1990): Predicting utility. In R. Hogarth (Ed.), Insights in Decision Making, 295-310. Chicago: University of Chicago Press.

Lucarelli, C. (2006): An analysis of the Medicare prescription drug benefit. Unpublished manuscript, Cornell University.

McAdams, D. and M. Schwarz (2006): Perverse incentives in the Medicare prescription drug benefit. NBER Working Paper No. 12008.

McFadden, D. (1984): Econometric analysis of qualitative response models. In Z. Griliches and M. D. Iniriligator (Eds.), Handbook of Econometrics, Vol. II, 1395-1457. Amsterdam: North-Holland.

McFadden, D. (2004): Comments on Case-Deaton 'Broken Down by W ork and Sex: How Our Health Declines', in D. Wise (ed.): Analyses in the Economics of Aging. Chicago: University of Chicago Press, 2005.

McFadden, D. (2006): Free markets and fettered consumers. American Economic Review, 96(1), 5-29.

McFadden, D., Heiss, F., Jun, B., Winter, J.(2006): On testing for independence in weighted contingency tables. Medium for Econometric Applications, 14(2), 11-18.

McFadden, D., N. Schwarz, and J. W inter (2006): Measuring perceptions and behavior in household surveys. Unpublished manuscript, University of California, Berkeley.

McFadden, D. and K. Train (2000): Mixed MNL models for discrete response. Journal of Applied Econometrics, 15(5), 447470.

Medpac (2006) "Part D Payment System", www.medpac.gov

Moran, J. R. and K. I. Simon (2006): Income and the use of prescription drugs by the elderly: Evidence from the notch cohorts. Journal of Human Resources, 41(2), 411-432.

Neuman, P., M. K. Strollo, S. Guterman, W. H. Rogers, A. Li, A. M. C. Rodday, and D. G. Safran (2007): Medicare prescription drug benefit progress report: Findings from a 2006 national survey of seniors. Health Affairs, 26(5), w630w643.Poisal, J. A. (2003): Reporting of drug expenditures in the MCBS. Health Care Financing Review, 25(2), 23-36.

Robst, J.; J. Levy; M. Ingber (2007) “Diagnosis-based risk adjustment for medicare prescription drug plan payments,” Health Care Financing Review, 28, 15-30.

Shang, B. and D. P. Goldman (2007): Prescription drug coverage and elderly Medicare spending. NBER Working Paper No. 13358.

Simon, K. I. and C. Lucarelli(2006): What drove first year premiums in stand-alone Medicare drug plans? NBER W orking Paper No. 12595. 
Slaughter, L. M. (2006): Medicare Part D: The product of a broken process. New England Journal of Medicine, 354, 23142315.

Stuart, B., L. Simoni-W astila, and D. Chauncey (2005): Assessing the impact of coverage gaps in the Medicare Part D drug benefit. Health Affairs, w167-w179.

Winter, J., R. Balza, F. Caro, F. Heiss, B. Jun, R. Matzkin, and D. McFadden (2006): Medicare prescription drug coverage: Consumer information and preferences. Proceedings of the National Academy of Sciences of the United States of America, 103(20), 7929-7934.

Yang, Z., D. B. Gilleskie, and E. C. Norton (2004): Prescription drugs, medical care, and health outcomes: A model of elderly health dynamics. NBER Working Paper, No. 10964. 
Table 1: Medicare Part D Standard Plan parameters

\begin{tabular}{lrrr}
\hline & \multicolumn{3}{c}{ Year } \\
& 2006 & 2007 & 2008 \\
\hline Deductible & $\$ 250$ & $\$ 265$ & $\$ 275$ \\
Gap Threshold & $\$ 2,250$ & $\$ 2,400$ & $\$ 2,510$ \\
Catastrophic Coverage TrOOP Threshold & $\$ 3,600$ & $\$ 3,850$ & $\$ 4,050$ \\
National Average Base Premium & $\$ 32.20$ & $\$ 27.35$ & $\$ 27.93$ \\
\hline
\end{tabular}


Table 2: Sample selection criteria and response rates, RPS 2005-2007

\begin{tabular}{|c|c|c|c|c|c|c|}
\hline & RPS 2005 & RPS 2006 & \multicolumn{4}{|c|}{ RPS 2007} \\
\hline Age selection criteria & 50 and older & 63 and older* & \multicolumn{4}{|c|}{64 and older } \\
\hline & & \multirow{3}{*}{ yes** } & \multicolumn{2}{|c|}{ re-interview } & refreshment & total \\
\hline Completed RPS 2005 & & & \multicolumn{2}{|c|}{ yes $^{\star \star}$} & no & \\
\hline Completed RPS 2006 & & & no & yes & no & \\
\hline KN members contacted & 5,879 & 2,598 & 217 & 1,704 & 1,250 & 3,171 \\
\hline Completed interviews & 4,738 & 2,137 & 165 & 1,526 & 1,020 & 2,711 \\
\hline Response rate ra**$^{* *}$ & $80.6 \%$ & $82.3 \%$ & $76.0 \%$ & $89.6 \%$ & $81.6 \%$ & $85.5 \%$ \\
\hline
\end{tabular}

Notes: * In addition, RPS 2005 respondents younger than 63 years were contacted for RPS 2006 if they said that they are on Medicare. ${ }^{* *}$ Completion of RPS 2005 was required for this subsample. ${ }^{* *}$ The cooperation rate is defined as the number of completed interviews as a proportion of the number of KN Panel members contacted. 
Table 3a: Descriptive statistics, HRS 2004 and RPS 2005/06

\begin{tabular}{llrrrr}
\hline & & \multicolumn{2}{c}{$\begin{array}{c}\text { HRS 2004 } \\
\text { (full sample) }\end{array}$} & $\begin{array}{c}\text { RPS 2005 } \\
\text { (full sample) }\end{array}$ \\
\cline { 3 - 6 } & & Unweighted & Weighted & Unweighted & Weighted \\
\hline Gender & Female & $57.6 \%$ & $54.1 \%$ & $53.8 \%$ & $54.0 \%$ \\
& Male & $42.4 \%$ & $45.9 \%$ & $46.2 \%$ & $46.0 \%$ \\
\hline Race & White & $80.9 \%$ & $85.6 \%$ & $80.1 \%$ & $77.9 \%$ \\
& Non-white & $19.1 \%$ & $14.4 \%$ & $19.0 \%$ & $21.3 \%$ \\
\hline Age & $50-60$ & $28.5 \%$ & $44.2 \%$ & $45.3 \%$ & $46.0 \%$ \\
& $61-70$ & $34.4 \%$ & $26.6 \%$ & $30.1 \%$ & $27.7 \%$ \\
& $71-80$ & $23.0 \%$ & $19.2 \%$ & $19.0 \%$ & $19.3 \%$ \\
& $81-90$ & $12.0 \%$ & $8.9 \%$ & $5.3 \%$ & $6.5 \%$ \\
& $>90$ & $2.1 \%$ & $1.0 \%$ & $0.3 \%$ & $0.4 \%$ \\
\hline Education & Less than HS & $27.9 \%$ & $22.8 \%$ & $12.0 \%$ & $17.3 \%$ \\
& High school & $30.9 \%$ & $30.3 \%$ & $35.4 \%$ & $33.8 \%$ \\
& More than HS & $41.2 \%$ & $46.9 \%$ & $52.6 \%$ & $48.8 \%$ \\
\hline Income & $<\$ 20 K$ & $29.6 \%$ & $24.9 \%$ & $19.5 \%$ & $21.0 \%$ \\
& $\$ 20 \mathrm{~K}-\$ 60 \mathrm{~K}$ & $41.5 \%$ & $39.4 \%$ & $48.7 \%$ & $44.9 \%$ \\
& $>$ \$60K & $28.9 \%$ & $35.7 \%$ & $31.8 \%$ & $34.1 \%$ \\
\hline SRHS & excellent & $11.3 \%$ & $13.2 \%$ & $9.4 \%$ & $8.8 \%$ \\
& very good & $27.1 \%$ & $29.3 \%$ & $34.7 \%$ & $33.3 \%$ \\
& good & $31.3 \%$ & $30.9 \%$ & $34.8 \%$ & $35.3 \%$ \\
& fair & $20.8 \%$ & $18.5 \%$ & $16.2 \%$ & $17.4 \%$ \\
& poor & $9.5 \%$ & $8.1 \%$ & $4.9 \%$ & $5.1 \%$ \\
\hline Number of & 19279 & & 4738 & \\
\hline & & & & &
\end{tabular}

Table 3b: Descriptive statistics, HRS 2004, RPS 2005/06, and RPS 2007

\begin{tabular}{|c|c|c|c|c|c|c|c|}
\hline & & \multicolumn{2}{|c|}{$\begin{array}{c}\text { HRS } 2004 \\
\text { (age } 65 \text { and older) }\end{array}$} & \multicolumn{2}{|c|}{$\begin{array}{l}\text { RPS 2005/06 } \\
\text { (core sample) }\end{array}$} & \multicolumn{2}{|c|}{$\begin{array}{c}\text { RPS } 2007 \\
\text { (full sample) } \\
\end{array}$} \\
\hline & & Unweighted & Weighted & Unweighted & Weighted & Unweighted & Weighted \\
\hline \multirow[t]{2}{*}{ Gender } & Female & $57.4 \%$ & $57.1 \%$ & $56.0 \%$ & $57.4 \%$ & $56.6 \%$ & $57.2 \%$ \\
\hline & Male & $42.6 \%$ & $42.9 \%$ & $44.0 \%$ & $42.6 \%$ & $43.4 \%$ & $42.8 \%$ \\
\hline \multirow[t]{2}{*}{ Race } & White & $83.7 \%$ & $89.2 \%$ & $85.8 \%$ & $81.1 \%$ & $86.7 \%$ & $81.7 \%$ \\
\hline & Non-white & $16.3 \%$ & $10.8 \%$ & $12.5 \%$ & $17.1 \%$ & $11.7 \%$ & $16.9 \%$ \\
\hline \multirow[t]{5}{*}{ Age } & $50-60$ & & & & & & \\
\hline & $61-70$ & $35.6 \%$ & $32.9 \%$ & $38.4 \%$ & $35.2 \%$ & $32.3 \%$ & $31.5 \%$ \\
\hline & $71-80$ & $39.9 \%$ & $44.2 \%$ & $47.7 \%$ & $48.4 \%$ & $51.6 \%$ & $49.1 \%$ \\
\hline & $81-90$ & $20.9 \%$ & $20.6 \%$ & $13.1 \%$ & $15.2 \%$ & $15.0 \%$ & $18.3 \%$ \\
\hline & $>90$ & $3.6 \%$ & $2.3 \%$ & $0.9 \%$ & $1.1 \%$ & $1.1 \%$ & $1.1 \%$ \\
\hline \multirow[t]{3}{*}{ Education } & Less than $\mathrm{HS}$ & $32.8 \%$ & $29.6 \%$ & $12.6 \%$ & $25.9 \%$ & $12.4 \%$ & $23.5 \%$ \\
\hline & High school & $32.5 \%$ & $33.7 \%$ & $41.7 \%$ & $36.6 \%$ & $42.1 \%$ & $37.6 \%$ \\
\hline & More than HS & $34.7 \%$ & $36.7 \%$ & $45.7 \%$ & $37.4 \%$ & $45.6 \%$ & $38.9 \%$ \\
\hline \multirow[t]{3}{*}{ Income } & $<\$ 20 \mathrm{~K}$ & $36.1 \%$ & $34.0 \%$ & $23.5 \%$ & $28.8 \%$ & $23.5 \%$ & $26.1 \%$ \\
\hline & $\$ 20 K-\$ 60 K$ & $45.6 \%$ & $46.6 \%$ & $58.1 \%$ & $52.4 \%$ & $58.4 \%$ & $53.8 \%$ \\
\hline & $>\$ 60 \mathrm{~K}$ & $18.3 \%$ & $19.4 \%$ & $18.5 \%$ & $18.8 \%$ & $18.1 \%$ & $20.0 \%$ \\
\hline \multirow[t]{5}{*}{ SRHS } & excellent & $8.4 \%$ & $8.9 \%$ & $6.1 \%$ & $5.6 \%$ & $3.5 \%$ & $3.1 \%$ \\
\hline & very good & $25.4 \%$ & $26.8 \%$ & $31.9 \%$ & $27.8 \%$ & $29.7 \%$ & $26.6 \%$ \\
\hline & good & $32.4 \%$ & $33.4 \%$ & $40.0 \%$ & $42.4 \%$ & $42.4 \%$ & $43.3 \%$ \\
\hline & fair & $23.1 \%$ & $21.6 \%$ & $17.9 \%$ & $19.4 \%$ & $19.9 \%$ & $22.0 \%$ \\
\hline & poor & $10.6 \%$ & $9.3 \%$ & $4.1 \%$ & $4.8 \%$ & 0.044 & $5.0 \%$ \\
\hline \multicolumn{2}{|c|}{ Number of observations } & 11113 & & 1569 & & 2711 & \\
\hline
\end{tabular}


Table 4: Prescription drug insurance status after the initial enrollment period

\begin{tabular}{|c|c|c|c|c|c|}
\hline & No coverage & Automatic & Private & Part D & Total \\
\hline Observations & 94 & 827 & 299 & 349 & 1569 \\
\hline$\%$ & 5.99 & 52.71 & 19.06 & 22.2 & 100.0 \\
\hline \multicolumn{6}{|l|}{2005 drug costs (dollars) } \\
\hline Mean & 1411.3 & 2574.2 & 2610.6 & 2766.9 & 2554.3 \\
\hline 1st quartile & 0.0 & 748.0 & 685.4 & 843.9 & 685.4 \\
\hline Median & 93.8 & 1996.5 & 1671.4 & 1981.4 & 1878.8 \\
\hline 3rd quartile & 1492.5 & 3479.6 & 3330.1 & 3333.2 & 3338.4 \\
\hline \multicolumn{6}{|c|}{ Total prescription drug cost in 2005} \\
\hline$\$ 0$ & 39.4 & 10.6 & 12.0 & 9.7 & 12.4 \\
\hline$\$ 1$ to $\$ 250$ & 16.0 & 6.9 & 7.7 & 6.6 & 7.5 \\
\hline$\$ 251$ to $\$ 1000$ & 9.6 & 9.7 & 10.7 & 8.9 & 9.7 \\
\hline$\$ 1001$ to $\$ 2250$ & 20.2 & 27.8 & 29.1 & 32.7 & 28.7 \\
\hline$\$ 2251$ to $\$ 5100$ & 8.5 & 32.4 & 27.8 & 29.2 & 29.4 \\
\hline$\$ 5101$ or more & 6.4 & 12.6 & 12.7 & 12.9 & 12.3 \\
\hline \multicolumn{6}{|c|}{ Total number of prescription drugs taken in 2005} \\
\hline No drugs & 38.3 & 10.5 & 12.0 & 9.7 & 12.3 \\
\hline 1 or 2 drugs & 34.0 & 24.4 & 30.4 & 29.2 & 27.2 \\
\hline 3 or more drugs & 27.7 & 65.1 & 57.5 & 61.0 & 60.5 \\
\hline \multicolumn{6}{|c|}{ Self-reported health status } \\
\hline Excellent & 20.2 & 5.3 & 7.0 & 6.6 & 6.8 \\
\hline Very good or good & 62.8 & 71.7 & 69.9 & 73.0 & 71.1 \\
\hline Poor or fair & 17.0 & 23.0 & 23.1 & 20.4 & 22.1 \\
\hline \multicolumn{6}{|l|}{ Age class } \\
\hline 70 years or younger & 38.3 & 42.3 & 39.1 & 45.9 & 42.3 \\
\hline 71 to 75 years & 37.2 & 27.6 & 27.4 & 24.4 & 27.4 \\
\hline 76 years or more & 24.5 & 30.1 & 33.4 & 29.8 & 30.3 \\
\hline \multicolumn{6}{|l|}{ Sex } \\
\hline Male & 35.1 & 50.1 & 36.5 & 38.7 & 44.0 \\
\hline Female & 64.9 & 49.9 & 63.6 & 61.3 & 56.0 \\
\hline \multicolumn{6}{|l|}{ Education class } \\
\hline More than high school & 38.3 & 49.0 & 42.8 & 42.4 & 45.7 \\
\hline High school or less & 61.7 & 51.0 & 57.2 & 57.6 & 54.3 \\
\hline \multicolumn{6}{|l|}{ Income class } \\
\hline$\$ 20,000$ or less & 30.9 & 20.9 & 31.1 & 28.1 & 25.1 \\
\hline$\$ 20,001$ to $\$ 60,000$ & 58.5 & 58.7 & 51.5 & 56.5 & 56.8 \\
\hline$\$ 60,001$ or more & 10.6 & 20.4 & 17.4 & 15.5 & 18.2 \\
\hline
\end{tabular}

Notes: "Private" includes prescription drug coverage as part of a Medicare Advantage program. "Part D" includes only Part D stand-alone plans. 
Table 5: Distribution of the month of Part D enrollment among active deciders

\begin{tabular}{lrrrrr}
\hline & Nov--Dec & Jan--Mar & Apr--May & Not enrolled & \multicolumn{1}{c}{ Total } \\
\hline Observations & 139 & 106 & 94 & 94 & 433 \\
$\%$ & 32.1 & 24.5 & 21.7 & 21.7 & 100.0 \\
\hline 2005 drug costs (dollars) & & & & & \\
\hline Mean & 3376.8 & 2802.9 & 1887.0 & 1411.3 & 2486.2 \\
1st decile & 685.4 & 142.5 & 0.0 & 0.0 & 0.0 \\
Median & 2364.7 & 1968.0 & 1140.4 & 93.8 & 1614.0 \\
9th decile & 7095.7 & 5477.9 & 5279.8 & 3117.1 & 5477.9 \\
\hline
\end{tabular}

Notes: 10 respondents without information on the enrollment month are excluded. 
Table 6: Logit analysis of the active enrollment decision

\begin{tabular}{|c|c|c|c|}
\hline & Enrollment & Enrollment by March 06 & $\begin{array}{l}\text { Late enrollment given } \\
\text { not enrolled by March } 06\end{array}$ \\
\hline \multicolumn{4}{|c|}{2005 drug costs (reference category is $\$ 0$ ) } \\
\hline$\$ 1$ to $\$ 250$ & 1.5898 & $3.0426^{* *}$ & 1.064 \\
\hline$\$ 251$ to $\$ 1000$ & $4.53^{* * *}$ & $5.84^{* * *}$ & 2.65 * \\
\hline$\$ 1001$ to $\$ 2250$ & $7.33^{\star * *}$ & $13.48^{* * *}$ & 2.42 * \\
\hline$\$ 2251$ to $\$ 5100$ & $16.48^{* * *}$ & $17.12^{* * *}$ & $4.62 * * *$ \\
\hline$\$ 5101$ or more & $9.74^{* * *}$ & $12.47^{* * *}$ & 2.55 \\
\hline $\mathrm{p}$-value for F-test & $(<0.0001)$ & $(<0.0001)$ & $(0.0728)$ \\
\hline \multicolumn{4}{|l|}{ Socio-economic variables } \\
\hline 71 to 75 years & $0.4498^{* \star}$ & 0.8006 & 0.4835 * \\
\hline 76 years or more & 0.72 & 0.89 & 0.78 \\
\hline Female & 0.73 & 1.10 & $0.49 * *$ \\
\hline High school or less & 0.67 & 0.98 & 0.58 \\
\hline Income less than $\$ 30,000$ & 0.88 & 0.97 & 0.78 \\
\hline SRHS excellent & $0.37^{* *}$ & 0.87 & $0.26^{* * *}$ \\
\hline SRHS poor or fair & $0.45^{* *}$ & 0.94 & $0.34^{* *}$ \\
\hline $\mathrm{p}$-value for F-test & $(0.0193)$ & $(0.9933)$ & $(0.0152)$ \\
\hline Observations & 432 & 432 & 188 \\
\hline
\end{tabular}

Notes: Coefficients reported in this table are odds ratios; all covariates are coded as dummy variables.

${ }^{*}$ denotes $p<.1,{ }^{* *}$ denotes $p<.05$, and ${ }^{* * *}$ denotes $p<.01$ for a two-sided t-test. 
Table 7: Types of plans, all plans available (excluding territories)

\begin{tabular}{|c|c|c|c|c|c|c|}
\hline & \multicolumn{3}{|c|}{ Share (\%) } & \multicolumn{3}{|c|}{ Avg Premium $[\$ / \mathrm{mo}]$} \\
\hline & 2006 & 2007 & 2008 & 2006 & 2007 & 2008 \\
\hline Standard or actuarially equivalent benfit & 34.0 & 31.1 & 32.8 & $\$ 30.75$ & $\$ 27.70$ & $\$ 28.41$ \\
\hline No or reduced deductible, no gap coverage & 50.6 & 40.0 & 38.0 & $\$ 37.92$ & $\$ 31.93$ & $\$ 33.12$ \\
\hline Gap coverage for generics & 12.9 & 27.5 & 29.2 & $\$ 48.13$ & $\$ 51.03$ & $\$ 63.34$ \\
\hline Gap coverage for generics \& brand name drugs & 2.5 & 1.4 & 0.0 & $\$ 61.88$ & $\$ 96.92$ & $\$ 49.40$ \\
\hline Total & 100.0 & 100.0 & 100.0 & $\$ 37.36$ & $\$ 36.71$ & $\$ 40.39$ \\
\hline Average number of plans per state & 42.5 & 54.7 & 53.4 & & & \\
\hline
\end{tabular}


Table 8: 2006 Enrollment decisions, plan attributes, and 2005 drug costs

\begin{tabular}{|c|c|c|c|c|}
\hline & \multirow[b]{2}{*}{ Observation } & \multirow[b]{2}{*}{ Column \% } & \multicolumn{2}{|c|}{2005 drug costs } \\
\hline & & & mean & median \\
\hline Total & 1569 & 0.0 & 2554.3 & 1878.8 \\
\hline \multicolumn{5}{|c|}{ Enrollment of active deciders } \\
\hline No & 94 & 21.2 & 1411.3 & $93.8^{* * *}$ \\
\hline Yes & 349 & 78.8 & 2766.9 & 1981.4 \\
\hline \multicolumn{5}{|c|}{ Information on chosen plan } \\
\hline No & 31 & 8.9 & 2801.9 & 2168.9 \\
\hline Yes & 318 & 91.1 & 2763.4 & 1934.5 \\
\hline \multicolumn{5}{|c|}{ Cheapest plan } \\
\hline Yes & 252 & 79.2 & 2882.3 & $2142.5^{* \star}$ \\
\hline No & 66 & 20.8 & 2309.7 & 1497.0 \\
\hline \multicolumn{5}{|c|}{ Monthly premium } \\
\hline$\$ 20$ or less & 93 & 29.2 & 2248.0 & $1492.5^{* \star \star}$ \\
\hline$\$ 21$ to $\$ 30$ & 141 & 44.3 & 2822.0 & 1898.6 \\
\hline$\$ 31$ or more & 84 & 26.4 & 3235.9 & 2544.5 \\
\hline \multicolumn{5}{|l|}{ Deductible } \\
\hline Yes & 117 & 36.8 & 2650.3 & 1878.8 \\
\hline No & 201 & 63.2 & 2829.3 & 2010.8 \\
\hline \multicolumn{5}{|c|}{ Gap coverage } \\
\hline No & 288 & 90.6 & 2679.5 & $1883.5^{\star \star *}$ \\
\hline Yes & 30 & 9.4 & 3569.7 & 3449.9 \\
\hline
\end{tabular}

Note: Stars correspond to tests of equal medians; ${ }^{* *}: p<.01,{ }^{* *}: p<.05$ 
Table 9: Top five plans purchased by RPS 2006 respondents

\begin{tabular}{llcccc}
\hline Rank & Plan name & $\mathrm{N}$ & $\begin{array}{c}\text { Share } \\
(\%)\end{array}$ & $\begin{array}{c}\text { Mean premium } \\
\text { (dollars) }\end{array}$ & Plan type \\
\hline 1 & AARP Medicare Rx Plan & 93 & 29.15 & 25.95 & Equivalent \\
2 & Humana PDP Standard & 66 & 20.69 & 8.96 & Standard \\
3 & Humana PDP Enhanced & 18 & 5.64 & 13.67 & Equivalent \\
4 & Humana PDP Complete & 12 & 3.76 & 53.93 & Enhanced (G \& B) \\
5 & Pacificare Saver Plan & 10 & 3.13 & 24.63 & Equivalent \\
& Other plans & 120 & 37.62 & 33.59 & \\
\hline Total & & 319 & 100 & 25.63 & \\
\hline
\end{tabular}


Table 10: Regression analysis of premiums of chosen Part D plans

\begin{tabular}{|c|c|c|c|c|}
\hline & \multirow[t]{2}{*}{ OLS } & \multicolumn{3}{|c|}{ Quantile Regression: percentiles } \\
\hline & & Median & 20th & 80th \\
\hline \multicolumn{5}{|c|}{2005 drug costs (reference category is $\$ 0$ ) } \\
\hline$\$ 1$ to $\$ 250$ & $7.31^{*}$ & $9.18^{* * *}$ & 3.01 & 2.26 \\
\hline$\$ 251$ to $\$ 1000$ & 1.94 & $4.50 * *$ & 3.95 & -0.16 \\
\hline$\$ 1001$ to $\$ 2250$ & $8.84^{* * *}$ & $9.88^{* * *}$ & $9.58^{* *}$ & 2.63 \\
\hline$\$ 2251$ to $\$ 5100$ & $13.12 * * *$ & $11.65^{* * *}$ & $14.74^{* * *}$ & $12.97^{* * *}$ \\
\hline$\$ 5101$ or more & $10.42^{* * *}$ & $10.97^{* * *}$ & $12.50 * *$ & 2.95 \\
\hline \multicolumn{5}{|l|}{ Socio-economic variables } \\
\hline 71 to 75 years & -0.07 & 0.02 & 4.43 & -2.13 \\
\hline 76 years or more & 0.84 & -1.22 & 4.79 & -1.11 \\
\hline Female & -1.44 & $-1.67 *$ & -1.72 & -1.09 \\
\hline High school or less & -0.45 & 0.15 & -1.42 & 0.94 \\
\hline Income less than $\$ 30,000$ & -1.57 & 0.96 & -0.06 & -1.82 \\
\hline SRHS excellent & 1.97 & 1.98 & 7.95 & 2.82 \\
\hline SRHS poor or fair & -0.15 & 0.63 & -4.64 & 3.07 \\
\hline Constant & $18.51^{* * *}$ & $16.78^{* * *}$ & 5.41 & $29.44^{* * *}$ \\
\hline Observations & 318 & 318 & 318 & 318 \\
\hline
\end{tabular}

${ }^{*} p<.1 ;{ }^{* *} p<.05 ;{ }^{* * *} p<.01$

Notes: All covariates are coded as dummy variables.

${ }^{*}$ denotes $p<.1$, ${ }^{* *}$ denotes $p<.05$, and ${ }^{* * *}$ denotes $p<.01$ for a two-sided t-test. 
Table 11: Logit Odds Ratios of choosing a cheap plan

\begin{tabular}{|c|c|c|c|}
\hline & Low monthly premium $(<\$ 10)$ & Cheapest plan available & Standard plan \\
\hline \multicolumn{4}{|c|}{2005 drug costs (reference category is $\$ 0$ ) } \\
\hline$\$ 1$ to $\$ 250$ & $0.251^{*}$ & 0.452 & 0.312 * \\
\hline$\$ 251$ to $\$ 1000$ & $0.336 *$ & 0.641 & 0.451 \\
\hline$\$ 1001$ to $\$ 2250$ & $0.092 * * *$ & $0.279 * * \star$ & $0.298 * * *$ \\
\hline$\$ 2251$ to $\$ 5100$ & $0.110 * * *$ & $0.122 * * *$ & $0.290 * * *$ \\
\hline$\$ 5101$ or more & $0.211^{* *}$ & $0.219 * *$ & $0.295^{* *}$ \\
\hline \multicolumn{4}{|l|}{ Socio-economic variables } \\
\hline 71 to 75 years & 0.871 & 0.633 & 0.802 \\
\hline 76 years or more & 0.807 & 0.667 & 0.637 \\
\hline Female & 1.368 & 0.965 & 1.149 \\
\hline High school or less & 1.409 & 1.101 & 0.926 \\
\hline Income less than $\$ 30,000$ & 0.748 & 1.109 & 1.249 \\
\hline SRHS excellent & 0.195 & 0.391 & 0.426 \\
\hline SRHS poor or fair & 0.888 & 1.815 & 1.438 \\
\hline Observations & 318 & 318 & 318 \\
\hline Percent "yes" & 11.0 & 20.8 & 35.2 \\
\hline
\end{tabular}

${ }^{*} p<.1 ;{ }^{* \star} p<.05 ;{ }^{\star \star *} p<.01$

Notes: Coefficients reported in this table are odds ratios; all covariates are coded as dummy variables.

${ }^{*}$ denotes $p<.1,{ }^{* *}$ denotes $p<.05$, and ${ }^{* * *}$ denotes $p<.01$ for a two-sided t-test. 
Table 12: Types of plans chosen by RPS respondents

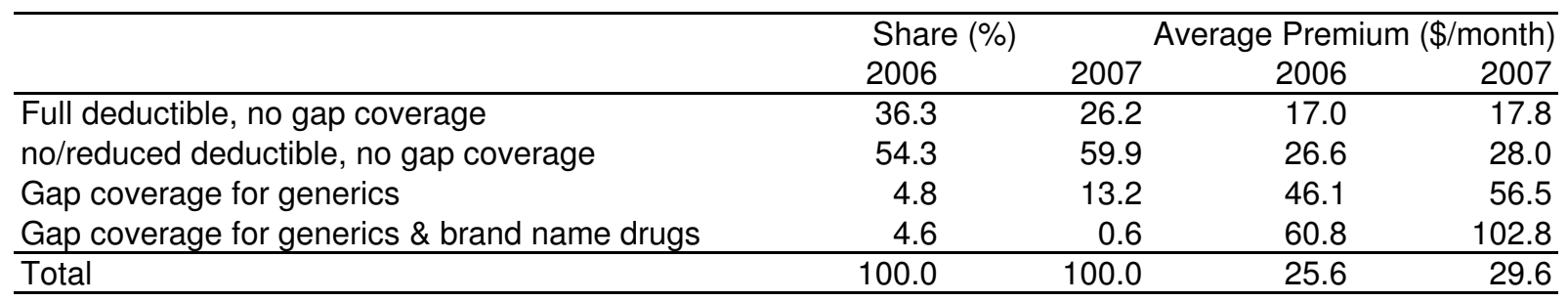


Table 13: Total Benefits for Alternative Plans (MCBS Cost Distribution, 2006)

\begin{tabular}{|c|c|c|c|c|c|c|}
\hline & $\begin{array}{c}\text { CDF for Eligible } \\
\text { Population }\end{array}$ & $\begin{array}{l}\text { Standard } \\
\text { Plan }\end{array}$ & $\begin{array}{c}\text { Full } \\
\text { Deductible } \\
\text { and Gap } \\
\text { Coverage } \\
\end{array}$ & $\begin{array}{c}\text { Generic } \\
\text { Gap } \\
\text { Coverage, } \\
\text { No } \\
\text { Capitation } \\
\end{array}$ & $\begin{array}{l}\text { Generic } \\
\text { Gap } \\
\text { Coverage, } \\
\text { Flexible } \\
\text { Capitation } \\
\end{array}$ & $\begin{array}{c}\text { Generic } \\
\text { Gap } \\
\text { Coverage, } \\
\text { Fixed } \\
\text { Capitation }\end{array}$ \\
\hline \multicolumn{7}{|c|}{ Benefits at Annual Pharmacy Bill (APB, average = $\$ 2,940)$ : } \\
\hline$\$ 0$ & $14.56 \%$ & $\$ 0$ & $\$ 0$ & $\$ 0$ & $\$ 0$ & $\$ 0$ \\
\hline$\$ 250$ & $19.46 \%$ & $\$ 0$ & $\$ 188$ & $\$ 0$ & $\$ 0$ & $\$ 0$ \\
\hline$\$ 2,250$ & $50.65 \%$ & $\$ 1,500$ & $\$ 1,688$ & $\$ 1,500$ & $\$ 1,500$ & $\$ 1,500$ \\
\hline$\$ 5,100$ & $83.70 \%$ & $\$ 1,500$ & $\$ 3,825$ & $\$ 2,229$ & $\$ 2,229$ & $\$ 2,229$ \\
\hline$\$ 6,200$ & $88.77 \%$ & $\$ 2,545$ & $\$ 4,650$ & $\$ 2,594$ & $\$ 2,594$ & $\$ 3,274$ \\
\hline$\$ 15,000$ & $99.09 \%$ & $\$ 10,905$ & $\$ 11,370$ & $\$ 10,954$ & $\$ 10,954$ & $\$ 11,634$ \\
\hline$\$ 40,000$ & $99.95 \%$ & $\$ 34,655$ & $\$ 35,120$ & $\$ 34,704$ & $\$ 34,704$ & $\$ 35,384$ \\
\hline Expected Benefit & EB & $\$ 1,536$ & $\$ 2,222$ & $\$ 1,656$ & $\$ 1,656$ & $\$ 1,751$ \\
\hline \multicolumn{7}{|l|}{ Catastrophic Coverage: } \\
\hline Catastrophic threshold & CTH & $\$ 5,100$ & $\$ 14,400$ & $\$ 6,080$ & $\$ 6,080$ & $\$ 5,100$ \\
\hline Catastrophic pharmacy bill & CPB & $\$ 574$ & $\$ 83$ & $\$ 438$ & $\$ 438$ & $\$ 574$ \\
\hline Reinsurance & $\mathrm{RI}=0.8^{*} \mathrm{CPB}$ & $\$ 459$ & $\$ 66$ & $\$ 350$ & $\$ 459$ & $\$ 459$ \\
\hline \multicolumn{7}{|l|}{ Costs: } \\
\hline Administrative & ADM & $\$ 200$ & $\$ 289$ & $\$ 215$ & $\$ 215$ & $\$ 228$ \\
\hline Sponsor Cost & $S C=E B+A D M-R I$ & $\$ 1,277$ & $\$ 2,445$ & $\$ 1,521$ & $\$ 1,413$ & $\$ 1,519$ \\
\hline Total Cost & $\mathrm{TC}=\mathrm{SC}+\mathrm{RI}$ & $\$ 1,736$ & $\$ 2,511$ & $\$ 1,872$ & $\$ 1,872$ & $\$ 1,978$ \\
\hline \multicolumn{7}{|c|}{ Subsidy, Based on Standard Coverage: } \\
\hline $\mathrm{RI}$ share of total cost & $r=\mathrm{RI} / \mathrm{TC}$ & 0.26 & \multirow{4}{*}{\multicolumn{4}{|c|}{$\begin{array}{l}\text { (same as Standard Plan) } \\
\text { (same as Standard Plan) } \\
\text { (same as Standard Plan) } \\
\text { (same as Standard Plan) }\end{array}$}} \\
\hline Direct Subsidy & $\mathrm{DS}=(0.745-r)^{*} \mathrm{TC}$ & $\$ 834$ & & & & \\
\hline Annual Premium & APR = SC-DS & $\$ 442$ & & & & \\
\hline & APR/month & $\$ 36.89$ & & & & \\
\hline \multicolumn{7}{|c|}{ Total Premium \& Net Benefits: } \\
\hline \multirow[t]{2}{*}{ Supplemental Premium } & $S P R=S C-D S-A P R$ & $\$ 0$ & $\$ 1,168$ & $\$ 244$ & $\$ 136$ & $\$ 242$ \\
\hline & SPR/month & $\$ 0.00$ & $\$ 97.31$ & $\$ 20.37$ & $\$ 11.32$ & $\$ 20.20$ \\
\hline Total Premium & $\mathrm{TPR}=\mathrm{APR}+\mathrm{SPR}$ & $\$ 442$ & $\$ 1,610$ & $\$ 686$ & $\$ 578$ & $\$ 684$ \\
\hline Net Expected Benefit & $=$ EB-TPR & $\$ 1,094$ & $\$ 611$ & $\$ 969$ & $\$ 1,078$ & $\$ 1,066$ \\
\hline
\end{tabular}


Table 14: Total Benefits for Alternative Plans (Modified Approximate Cost Distribution, 2006)

\begin{tabular}{|c|c|c|c|c|c|c|}
\hline & $\begin{array}{c}\text { CDF for Eligible } \\
\text { Population }\end{array}$ & $\begin{array}{l}\text { Standard } \\
\text { Plan }\end{array}$ & $\begin{array}{c}\text { Full } \\
\text { Deductible } \\
\text { and Gap } \\
\text { Coverage } \\
\end{array}$ & $\begin{array}{c}\text { Generic } \\
\text { Gap } \\
\text { Coverage, } \\
\text { No } \\
\text { Capitation } \\
\end{array}$ & $\begin{array}{l}\text { Generic } \\
\text { Gap } \\
\text { Coverage, } \\
\text { Flexible } \\
\text { Capitation } \\
\end{array}$ & $\begin{array}{c}\text { Generic } \\
\text { Gap } \\
\text { Coverage, } \\
\text { Fixed } \\
\text { Capitation }\end{array}$ \\
\hline \multicolumn{7}{|c|}{ Benefits at Annual Pharmacy Bill (APB, average = $\$ 2,590)$ : } \\
\hline$\$ 0$ & $14.56 \%$ & $\$ 0$ & $\$ 0$ & $\$ 0$ & $\$ 0$ & $\$ 0$ \\
\hline$\$ 250$ & $14.75 \%$ & $\$ 0$ & $\$ 188$ & $\$ 0$ & $\$ 0$ & $\$ 0$ \\
\hline$\$ 2,250$ & $57.24 \%$ & $\$ 1,500$ & $\$ 1,688$ & $\$ 1,500$ & $\$ 1,500$ & $\$ 1,500$ \\
\hline$\$ 5,100$ & $87.66 \%$ & $\$ 1,500$ & $\$ 3,825$ & $\$ 2,229$ & $\$ 2,229$ & $\$ 2,229$ \\
\hline$\$ 6,200$ & $91.99 \%$ & $\$ 2,545$ & $\$ 4,650$ & $\$ 2,594$ & $\$ 2,594$ & $\$ 3,274$ \\
\hline$\$ 15,000$ & $99.41 \%$ & $\$ 10,905$ & $\$ 11,370$ & $\$ 10,954$ & $\$ 10,954$ & $\$ 11,634$ \\
\hline$\$ 40,000$ & $99.99 \%$ & $\$ 34,655$ & $\$ 35,120$ & $\$ 34,704$ & $\$ 34,704$ & $\$ 35,384$ \\
\hline Expected Benefit & EB & $\$ 1,341$ & $\$ 1,949$ & $\$ 1,447$ & $\$ 1,447$ & $\$ 1,517$ \\
\hline \multicolumn{7}{|l|}{ Catastrophic Coverage: } \\
\hline Catastrophic threshold & CTH & $\$ 5,100$ & $\$ 14,400$ & $\$ 6,080$ & $\$ 6,080$ & $\$ 5,100$ \\
\hline Catastrophic pharmacy bill & CPB & $\$ 371$ & $\$ 33$ & $\$ 270$ & $\$ 270$ & $\$ 371$ \\
\hline Reinsurance & $\mathrm{RI}=0.8^{*} \mathrm{CPB}$ & $\$ 296$ & $\$ 26$ & $\$ 216$ & $\$ 296$ & $\$ 296$ \\
\hline \multicolumn{7}{|l|}{ Costs: } \\
\hline Administrative & ADM & $\$ 174$ & $\$ 253$ & $\$ 188$ & $\$ 188$ & $\$ 197$ \\
\hline Sponsor Cost & $S C=E B+A D M-R I$ & $\$ 1,219$ & $\$ 2,176$ & $\$ 1,419$ & $\$ 1,339$ & $\$ 1,418$ \\
\hline Total Cost & $\mathrm{TC}=\mathrm{SC}+\mathrm{RI}$ & $\$ 1,515$ & $\$ 2,203$ & $\$ 1,635$ & $\$ 1,635$ & $\$ 1,714$ \\
\hline \multicolumn{7}{|c|}{ Subsidy, Based on Standard Coverage: } \\
\hline $\mathrm{RI}$ share of total cost & $r=\mathrm{RI} / \mathrm{TC}$ & 0.2 & \multirow{4}{*}{\multicolumn{4}{|c|}{$\begin{array}{l}\text { (same as Standard Plan) } \\
\text { (same as Standard Plan) } \\
\text { (same as Standard Plan) } \\
\text { (same as Standard Plan) }\end{array}$}} \\
\hline Direct Subsidy & $\mathrm{DS}=(0.745-r)^{*} \mathrm{TC}$ & $\$ 832$ & & & & \\
\hline Annual Premium & APR = SC-DS & $\$ 386$ & & & & \\
\hline & APR/month & $\$ 32.20$ & & & & \\
\hline \multicolumn{7}{|c|}{ Total Premium \& Net Benefits: } \\
\hline \multirow[t]{2}{*}{ Supplemental Premium } & $S P R=S C-D S-A P R$ & $\$ 0$ & $\$ 957$ & $\$ 200$ & $\$ 120$ & $\$ 199$ \\
\hline & SPR/month & $\$ 0.00$ & $\$ 79.78$ & $\$ 16.70$ & $\$ 10.01$ & $\$ 16.57$ \\
\hline Total Premium & $\mathrm{TPR}=\mathrm{APR}+\mathrm{SPR}$ & $\$ 386$ & $\$ 1,343$ & $\$ 586$ & $\$ 506$ & $\$ 585$ \\
\hline Net Expected Benefit & $=$ EB-TPR & $\$ 955$ & $\$ 606$ & $\$ 860$ & $\$ 941$ & $\$ 932$ \\
\hline
\end{tabular}


Table 15: 2006 Total Monthly Premiums and Plan Shares

\begin{tabular}{|c|c|c|c|c|}
\hline \multirow[t]{2}{*}{ Plan } & \multicolumn{2}{|c|}{ Monthly Premium } & \multicolumn{2}{|c|}{ Plan Share } \\
\hline & Calculated & Observed & Calculated & Observed \\
\hline None & $\$ 0.00$ & $\$ 0.00$ & $14.8 \%$ & $12.7 \%$ \\
\hline Standard \& Actuarially Equivalent & $\$ 32.20$ & $\$ 30.80$ & $55.5 \%$ & $79.1 \%$ \\
\hline Full Deductible \& Gap Coverage & $\$ 111.98$ & $\$ 61.90$ & $7.9 \%$ & $4.0 \%$ \\
\hline Generic Gap Coverage: All & - & $\$ 48.10$ & $21.8 \%$ & $4.2 \%$ \\
\hline No Capitation & $\$ 48.90$ & - & $0.0 \%$ & - \\
\hline Flexible Capitation & $\$ 42.21$ & - & $17.1 \%$ & - \\
\hline Fixed Capitation & $\$ 48.77$ & - & $4.7 \%$ & - \\
\hline
\end{tabular}


Table 16: Plan Shares and Profitability with Alternative Plan Mixes

\begin{tabular}{|c|c|c|c|c|c|c|}
\hline \multirow[t]{2}{*}{ Market Environment } & & \multirow[t]{2}{*}{ Standard } & \multirow[t]{2}{*}{ Full } & \multicolumn{3}{|c|}{ Generic by Type of Capitation } \\
\hline & & & & None & Flexible & Fixed \\
\hline \multicolumn{7}{|l|}{ All present: } \\
\hline & Share: & $55.5 \%$ & $7.9 \%$ & $0.0 \%$ & $17.1 \%$ & $4.7 \%$ \\
\hline & Profit: & $\$ 17$ & $-\$ 12$ & $\$ 0$ & $-\$ 13$ & $\$ 0$ \\
\hline \multicolumn{7}{|l|}{ Full gap plan extinct: } \\
\hline & Share: & $55.5 \%$ & - & $0.0 \%$ & $18.1 \%$ & $11.5 \%$ \\
\hline & Profit: & $\$ 17$ & - & - & $-\$ 13$ & $-\$ 6$ \\
\hline \multicolumn{7}{|c|}{ Full, generic/none, and generic/flexible plans extinct: } \\
\hline & Share: & $76.3 \%$ & - & - & - & $23.7 \%$ \\
\hline & Profit: & $\$ 17$ & - & - & - & $-\$ 17$ \\
\hline
\end{tabular}


Table 17: Implicit prices of, and willingness-to-pay for, Part $D$ stand-alone plan attributes

\begin{tabular}{lcccc}
\hline & Implicit & \multicolumn{3}{c}{ Willingness to pay } \\
& price & all & low costs & high costs \\
\hline No deductible & $7.42^{* * *}$ & $14.13^{* * *}$ & $15.03^{* * *}$ & $13.28^{* * *}$ \\
Gap coverage (generics) & $8.29^{* * *}$ & $2.72^{* *}$ & $-2.58^{* *}$ & $7.18^{* *}$ \\
Gap coverage (brand-name drugs) & $31.09^{* *}$ & $20.25^{* * *}$ & $22.60^{* * *}$ & $19.63^{* * *}$ \\
Drug tiers & $6.63^{* * *}$ & $-11.21^{* *}$ & $-12.02^{* * *}$ & $-9.91^{*}$ \\
Top 100 drugs uncovered & $-0.95^{* * *}$ & $-1.40^{* * *}$ & $-0.90^{* * *}$ & $-2.08^{* * *}$ \\
Top 100 with authorization & $-0.04^{* *}$ & $-1.01^{* * *}$ & $-1.04^{* * *}$ & $-1.08^{* * *}$ \\
Constant & $31.56^{* * *}$ & & & \\
\hline R2 $($ within) & 0.74 & & & \\
Var $(\alpha) / \operatorname{Var}(\alpha+\mathrm{u})$ & 0.76 & & & \\
Corr $(\alpha, \times \beta)$ & -0.42 & & & \\
\hline
\end{tabular}

Notes: See text for definition of plan attributes and explanation of regressions.

${ }^{*}$ denotes $p<.1,{ }^{* *}$ denotes $p<.05$, and ${ }^{* *}$ denotes $p<.01$ for a two-sided t-test.

Table 18: Implicit prices of, and willingness-to-pay for, Part $D$ stand-alone plan attributes

\begin{tabular}{lrrrc}
\hline & \multicolumn{2}{c}{ Implicit price } & \multicolumn{2}{c}{ Willingness to pay (all) } \\
& $2006^{* * *}$ & $2007^{* *}$ & $2006^{*}$ & $2007^{* *}$ \\
\hline No deductible & $10.12^{* * *}$ & $6.22^{* *}$ & $13.94^{* *}$ & $24.81^{* * *}$ \\
Gap coverage (generics) & $8.99^{* * *}$ & $18.23^{* *}$ & $1.12^{* *}$ & 0.50 \\
Gap coverage (brand-name drugs) & $31.10^{* *}$ & $38.76^{* *}$ & $26.53^{* * *}$ & $19.31^{* *}$ \\
Drug tiers & $3.41^{* * *}$ & $4.17^{* *}$ & $-13.11^{* * *}$ & $-19.78^{* * *}$ \\
Constant & $26.26^{* * *}$ & $23.51^{* * *}$ & & \\
\hline R2 (within) & 0.60 & $0.77^{*}$ & \\
$\operatorname{Var}(\alpha)$ & 12.04 & 8.57 & \\
$\operatorname{Var}(\mathrm{u})$ & 8.34 & 8.01 & \\
$\operatorname{Corr}(\alpha, \mathrm{x} \beta)$ & -0.40 & -0.08 & & \\
\hline
\end{tabular}

Notes: See text for definition of plan attributes and explanation of regressions.

${ }^{*}$ denotes $p<.1,{ }^{* *}$ denotes $p<.05$, and ${ }^{* * *}$ denotes $p<.01$ for a two-sided t-test. 
Table 19: Drug bill by 2006 enrollment

\begin{tabular}{lrrrrc}
\hline & & Mean in & Mean change & Median in & Median change \\
& Obs. & \multicolumn{1}{c}{ 2005 } & $2005-2006$ & 2005 & $2005-2006$ \\
\hline Total & 1,318 & 2577.2 & $440.4^{* * *}$ & 1878.8 & $190.8^{* * *}$ \\
\hline No coverage & 83 & 1270.4 & $652.8^{*}$ & 110.7 & 0.0 \\
Automatic & 688 & 2584.0 & $613.1^{* * *}$ & 1979.1 & $276.6^{* * *}$ \\
Private & 248 & 2712.0 & 49.9 & 1659.1 & $146.3^{* *}$ \\
Part D & 299 & 2812.8 & 307.8 & 2034.4 & $120.5^{*}$ \\
\hline Part D, by type of plan: & & & & & \\
$\quad$ Unknown type & 24 & 2574.0 & 454.0 & 2165.5 & 0.0 \\
$\quad$ Standard plan & 99 & 2654.7 & 169.3 & 1898.6 & $120.5^{*}$ \\
$\quad$ No deductible & 146 & 2814.9 & 80.7 & 1934.5 & 30.0 \\
$\quad$ Gap coverage & 30 & 3515.2 & $1753.5^{* * *}$ & 3110.0 & $1256.8^{* * *}$ \\
\hline
\end{tabular}

${ }^{*}$ denotes $p<.1,{ }^{* *}$ denotes $p<.05$, and ${ }^{* * *}$ denotes $p<.01$ for a two-sided t-test. 
Table 20: Parameter estimates

\begin{tabular}{lcccc}
\hline & \multicolumn{2}{c}{ Males } & \multicolumn{2}{c}{ Females } \\
\hline Mortality: & $0.309^{*}$ & $(0.127)$ & -0.083 & $(0.117)$ \\
Non-white & $-0.734^{* *}$ & $(0.094)$ & $-0.706^{* *}$ & $(0.089)$ \\
High education & $1.336^{* *}$ & $(0.061)$ & $1.728^{* *}$ & $(0.057)$ \\
Latent health & & & & \\
\hline Drug bill: & $-0.271^{* *}$ & $(0.301)$ & $-0.683^{* *}$ & $(0.246)$ \\
Non-white & $-1.133^{* *}$ & $(0.209)$ & $-1.232^{* *}$ & $(0.185)$ \\
High education & $6.124^{* *}$ & $(0.175)$ & $6.228^{* *}$ & $(0.150)$ \\
Latent health & & & & \\
\hline SRHS: & $0.370^{* *}$ & $(0.065)$ & $0.465 * *$ & $(0.052)$ \\
Non-white & $-0.914^{* *}$ & $(0.044)$ & $-0.847 * *$ & $(0.039)$ \\
High education & $0.877^{* *}$ & $(0.025)$ & $0.910 * *$ & $(0.022)$ \\
Latent health & & & & \\
\hline Latent robustness: & $0.967^{* *}$ & $(0.004)$ & $0.963 * *$ & $(0.003)$ \\
Correlation $\rho$ & & & & \\
\hline
\end{tabular}

Notes: All equations also include age splines

Parameters significantly different from zero with ${ }^{* *}: p<.01,{ }^{*}: p<.05$ 
Table 21: Simulation results: descriptives

\begin{tabular}{lrrr}
\hline & mean & 5 th & 95th \\
\hline enrollment share: & & & \\
Fully rational & $97.5 \%$ & $81.7 \%$ & $100.0 \%$ \\
Myopic & $81.7 \%$ & $7.8 \%$ & $100.0 \%$ \\
\hline benefit of enrollment: & & \\
Total & $\$ 1,413$ & $\$ 148$ & $\$ 3,989$ \\
Immediate & $\$ 1,116$ & $-\$ 163$ & $\$ 3,813$ \\
Future & $\$ 299$ & $\$ 110$ & $\$ 447$ \\
\hline
\end{tabular}

Table 22: Simulated vs. actual enrollment

\begin{tabular}{lrrrrrr}
\hline Actually & & \multicolumn{2}{c}{ Enrollment share } & \multicolumn{3}{c}{ Benefit of enrollment } \\
enrolled? & Obs. & Fully rational & \multicolumn{1}{c}{ Myopic } & \multicolumn{1}{c}{ Total } & Immediate & Future \\
\hline Total & 653 & $97.5 \%$ & $81.7 \%$ & $\$ 1,413$ & $\$ 1,116$ & $\$ 299$ \\
Yes & 558 & $98.2 \%$ & $85.8 \%$ & $\$ 1,510$ & $\$ 1,217$ & $\$ 295$ \\
No & 95 & $93.4 \%$ & $57.6 \%$ & $\$ 845$ & $\$ 523$ & $\$ 324$ \\
\hline
\end{tabular}


Table 23: Simulation results by individual characteristics

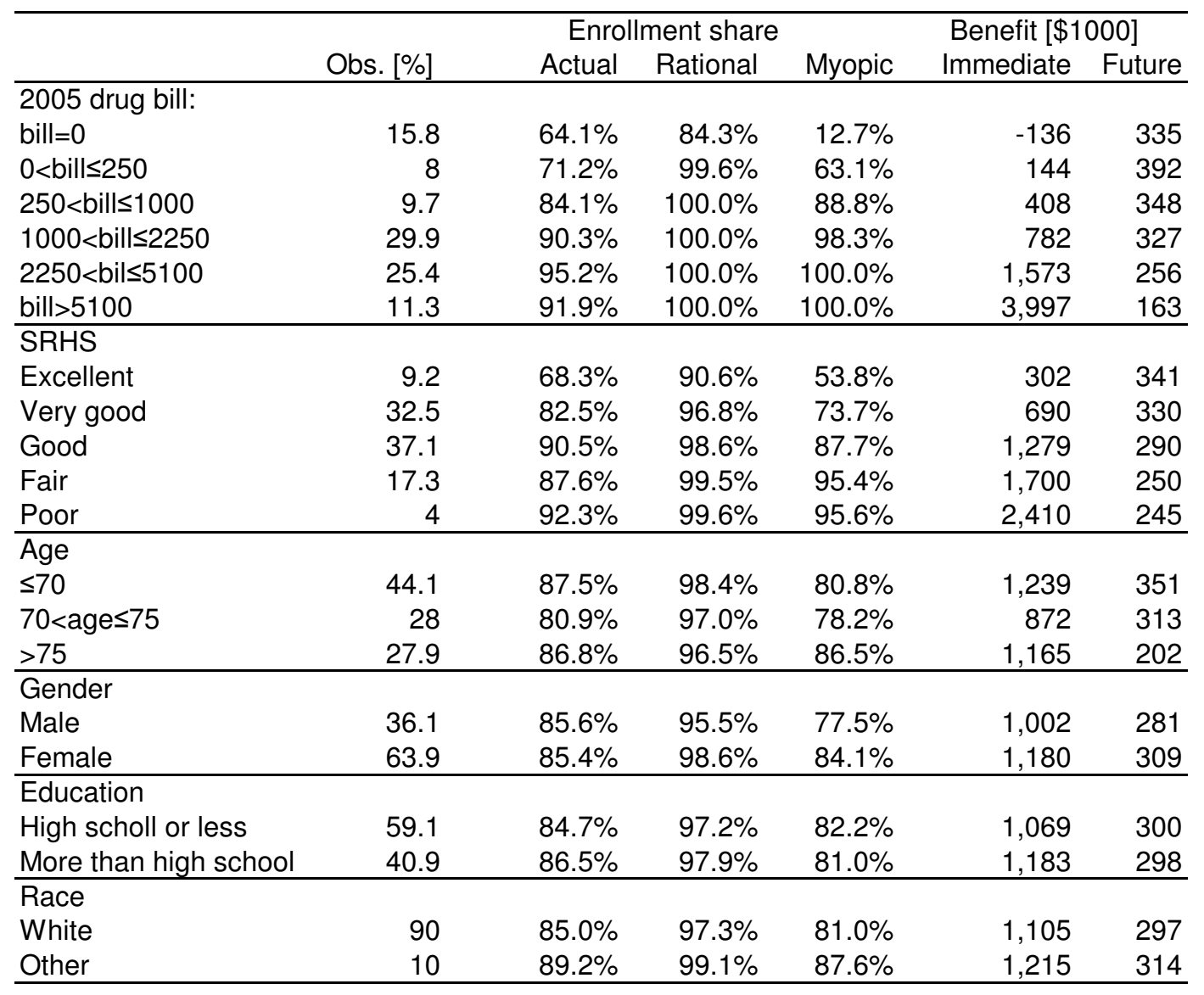


Table 24: Reduced-form regressions: actual and rational enrollment

\begin{tabular}{|c|c|c|c|c|}
\hline \multirow[b]{2}{*}{$0<$ bill $\leq 250$} & \multicolumn{2}{|c|}{$\begin{array}{l}\text { Logit model } \\
\text { actual enrollment }\end{array}$} & \multicolumn{2}{|c|}{$\begin{array}{l}\text { OLS on log odds } \\
\text { rational enrollment }\end{array}$} \\
\hline & 0.241 & $(0.380)$ & $5.827^{* * *}$ & $(0.207)$ \\
\hline $250<$ bill $\leq 1000$ & $1.156^{* * *}$ & $(0.417)$ & $6.730 * * *$ & $(0.105)$ \\
\hline $1000<$ bill $\leq 2250$ & $1.657^{* * *}$ & $(0.323)$ & $7.036 * * *$ & $(0.083)$ \\
\hline $2250<$ bil $\leq 5100$ & $2.473^{* * *}$ & $(0.472)$ & $7.099 * * *$ & $(0.082)$ \\
\hline bill>5100 & 1.920 *** & $(0.548)$ & $7.110 * * *$ & $(0.089)$ \\
\hline SRHS excellent & $-0.775 * *$ & $(0.335)$ & $-0.556^{* * *}$ & $(0.116)$ \\
\hline SRHS fair/poor & -0.499 & $(0.359)$ & $0.082 *$ & $(0.045)$ \\
\hline $70<$ age $\leq 75$ & -0.526 * & $(0.283)$ & $-0.171^{* * *}$ & $(0.046)$ \\
\hline$>75$ & -0.275 & $(0.308)$ & $-0.615^{* * *}$ & $(0.079)$ \\
\hline Female & -0.169 & $(0.255)$ & $0.419 * * *$ & $(0.054)$ \\
\hline More than high school & 0.354 & $(0.252)$ & $0.307 * * *$ & $(0.050)$ \\
\hline Non-White & 0.222 & $(0.426)$ & 0.038 & $(0.070)$ \\
\hline
\end{tabular}

${ }^{1}$ :dependent variable $=\log (P /(1-P))$, where $P$ represents the rational enrollment probability, trimmed at 0.9999 .

Standard errors in parentheses

Standard ${ }^{* * *} / * \star *$ : different from 0 at $10 \% / 5 \% / 1 \%$ significance level. 
Table 25: Logit models for actual enrollment

\begin{tabular}{|c|c|c|c|c|c|}
\hline & $(1)$ & (2) & (3) & (4) & (5) \\
\hline \multirow[t]{2}{*}{ Rational enrollment } & $5.530^{* * *}$ & $3.877^{\star \star \star}$ & -0.289 & -0.656 & -0.297 \\
\hline & $(1.155)$ & $(1.494)$ & (1.873) & (2.002) & $(2.053)$ \\
\hline \multirow[t]{2}{*}{ Immediate benefits } & & 0.468 ** & 0.166 & -0.040 & -0.022 \\
\hline & & $(0.212)$ & $(0.177)$ & $(0.203)$ & $(0.244)$ \\
\hline \multirow[t]{2}{*}{ Future Benefits } & & -1.389 & -0.267 & -3.618 & -1.641 \\
\hline & & $(1.724)$ & $(1.775)$ & $(2.898)$ & $(3.200)$ \\
\hline \multirow[t]{2}{*}{ Myopic enrollment } & & & $1.894^{* * *}$ & $2.160 * * *$ & 0.692 \\
\hline & & & $(0.514)$ & $(0.530)$ & $(1.645)$ \\
\hline \multirow[t]{2}{*}{ SRHS excellent } & & & & -0.757 ** & $-0.767^{* *}$ \\
\hline & & & & $(0.353)$ & $(0.369)$ \\
\hline \multirow[t]{2}{*}{ SRHS fair/poor } & & & & -0.416 & -0.522 \\
\hline & & & & $(0.337)$ & $(0.344)$ \\
\hline \multirow[t]{2}{*}{$70<$ age $<=75$} & & & & $-0.725 * *$ & -0.626 * \\
\hline & & & & $(0.322)$ & $(0.336)$ \\
\hline \multirow[t]{2}{*}{ age $>75$} & & & & $-0.817^{*}$ & -0.536 \\
\hline & & & & $(0.496)$ & $(0.547)$ \\
\hline \multirow[t]{2}{*}{ Female } & & & & -0.089 & -0.122 \\
\hline & & & & $(0.270)$ & $(0.285)$ \\
\hline \multirow[t]{2}{*}{ More than high school } & & & & 0.240 & 0.321 \\
\hline & & & & $(0.254)$ & $(0.286)$ \\
\hline \multirow[t]{2}{*}{ Non-White } & & & & 0.207 & 0.222 \\
\hline & & & & $(0.447)$ & $(0.450)$ \\
\hline \multirow[t]{2}{*}{$0<$ bill $<=250$} & & & & & 0.027 \\
\hline & & & & & $(0.940)$ \\
\hline \multirow[t]{2}{*}{$250<$ bill $<=1000$} & & & & & 0.766 \\
\hline & & & & & $(1.318)$ \\
\hline \multirow[t]{2}{*}{$1000<$ bill $<=2250$} & & & & & 1.145 \\
\hline & & & & & $(1.456)$ \\
\hline \multirow[t]{2}{*}{$2250<$ bill $<=5100$} & & & & & 1.847 \\
\hline & & & & & $(1.522)$ \\
\hline \multirow[t]{2}{*}{ bill>5100 } & & & & & 1.200 \\
\hline & & & & & $(1.708)$ \\
\hline Observations & 653 & 653 & 653 & 653 & 653 \\
\hline Log-Likelihood & -259.4 & -250.6 & -244.0 & -238.5 & -235.0 \\
\hline
\end{tabular}

Standard errors in parentheses

${ }^{* * *} /{ }^{* * *}$ : different from 0 at $10 \% / 5 \% / 1 \%$ significance level. 
Table 26: Dissatisfaction with current Part D plan

\begin{tabular}{lc}
\hline & "poor" or "fair" rating [\%] \\
\hline Overall & 17.6 \\
Premium & 23.5 \\
Gap coverage & 47.2 \\
Deductible & 25.8 \\
Formulary & 19.4 \\
Customer service & 12.7 \\
\hline
\end{tabular}

Table 27: Switching of Part D stand-alone plans

\begin{tabular}{lrr}
\hline & Obs. & Share \\
\hline Enrolled in the same plan in 2006 and... & & \\
.. did not consider switching & 323 & $2545.3 \%$ \\
.. considered switching & 96 & $756.5 \%$ \\
Switched plans & 56 & $441.3 \%$ \\
Not enrolled in 2006 & 46 & $362.5 \%$ \\
\hline Total & 521 & $4105.6 \%$ \\
\hline
\end{tabular}


Table 28: Logit models for plan switching

\begin{tabular}{|c|c|c|c|c|c|}
\hline \multirow{2}{*}{2006 characteristics: } & \multirow[b]{2}{*}{ Premium } & \multicolumn{2}{|c|}{ Considered switching } & \multicolumn{2}{|c|}{ Switched } \\
\hline & & 1.023 & 1.032 & $1.086^{* *}$ & $1.098^{* \star}$ \\
\hline & No deductible & $0.353 * *$ & 0.373 ** & 0.252 ** & 0.264 * \\
\hline & Gap coverage & 0.486 & 0.436 & $0.007 * *$ & 0.006 * \\
\hline \multirow[t]{3}{*}{2006 - 2007 change: } & Premium & 1.062 & 1.068 * & 1.183 ** & $1.201^{* *}$ \\
\hline & No deductible & 0.514 & 0.512 & 0.608 & 0.734 \\
\hline & Gap coverage & 1.640 & 1.498 & 0.808 & 0.790 \\
\hline \multicolumn{2}{|c|}{ Dissatisfaction with plan } & & $3.994 * * *$ & & $5.798 * * *$ \\
\hline \multicolumn{2}{|c|}{ Constant } & 0.319 ** & $0.178^{* \star *}$ & $0.018^{* * *}$ & $0.007^{* * \star}$ \\
\hline \multicolumn{2}{|c|}{ Number of observations } & 197 & 190 & 197 & 190 \\
\hline
\end{tabular}

Notes: Coefficients reported in this table are odds ratios.

${ }^{*}$ denotes $p<.1,{ }^{* *}$ denotes $p<.05$, and ${ }^{* * *}$ denotes $p<.01$ for a two-sided t-test. 
Figure 1: Part D Standard Plan

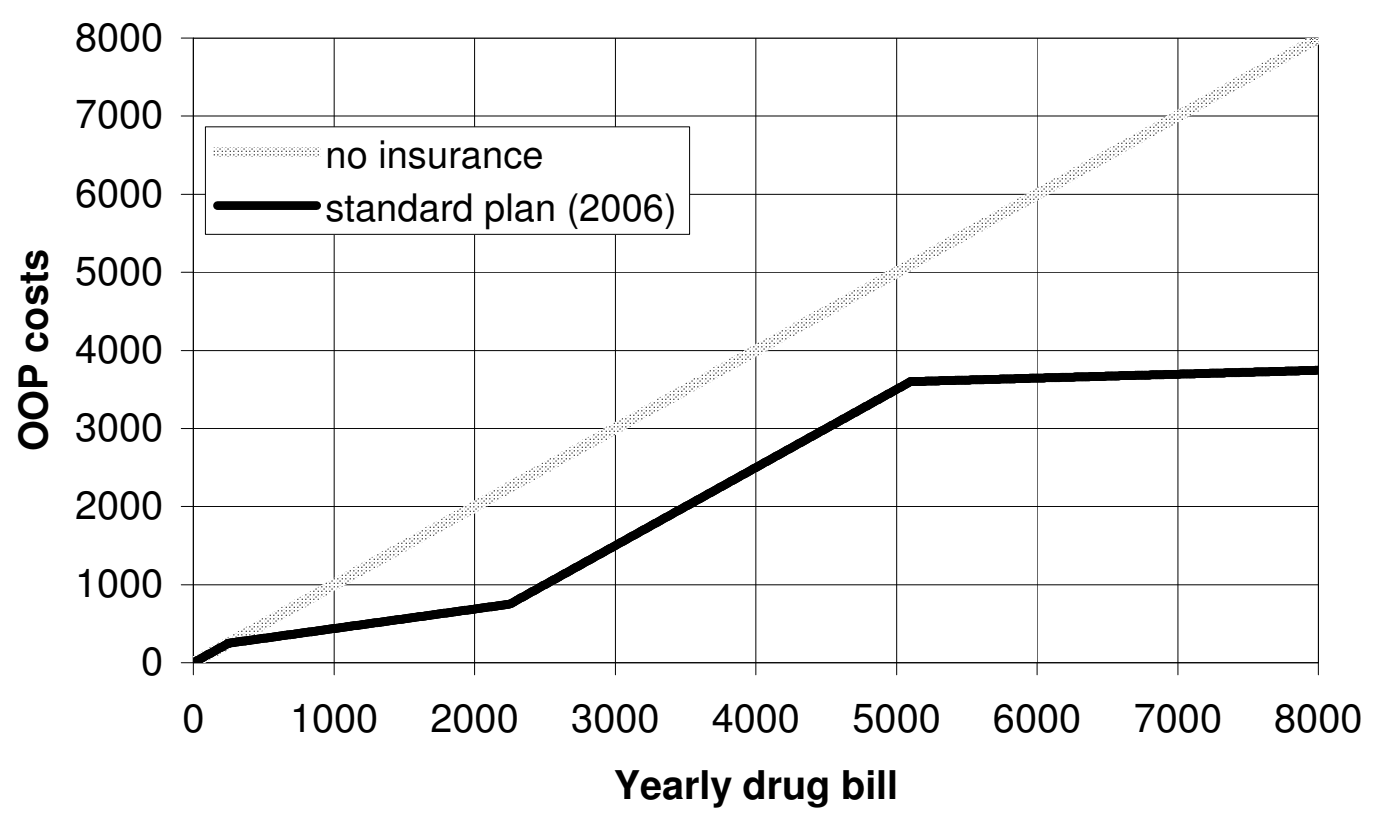

Figure 2: Timing of initial Part $D$ enrollment

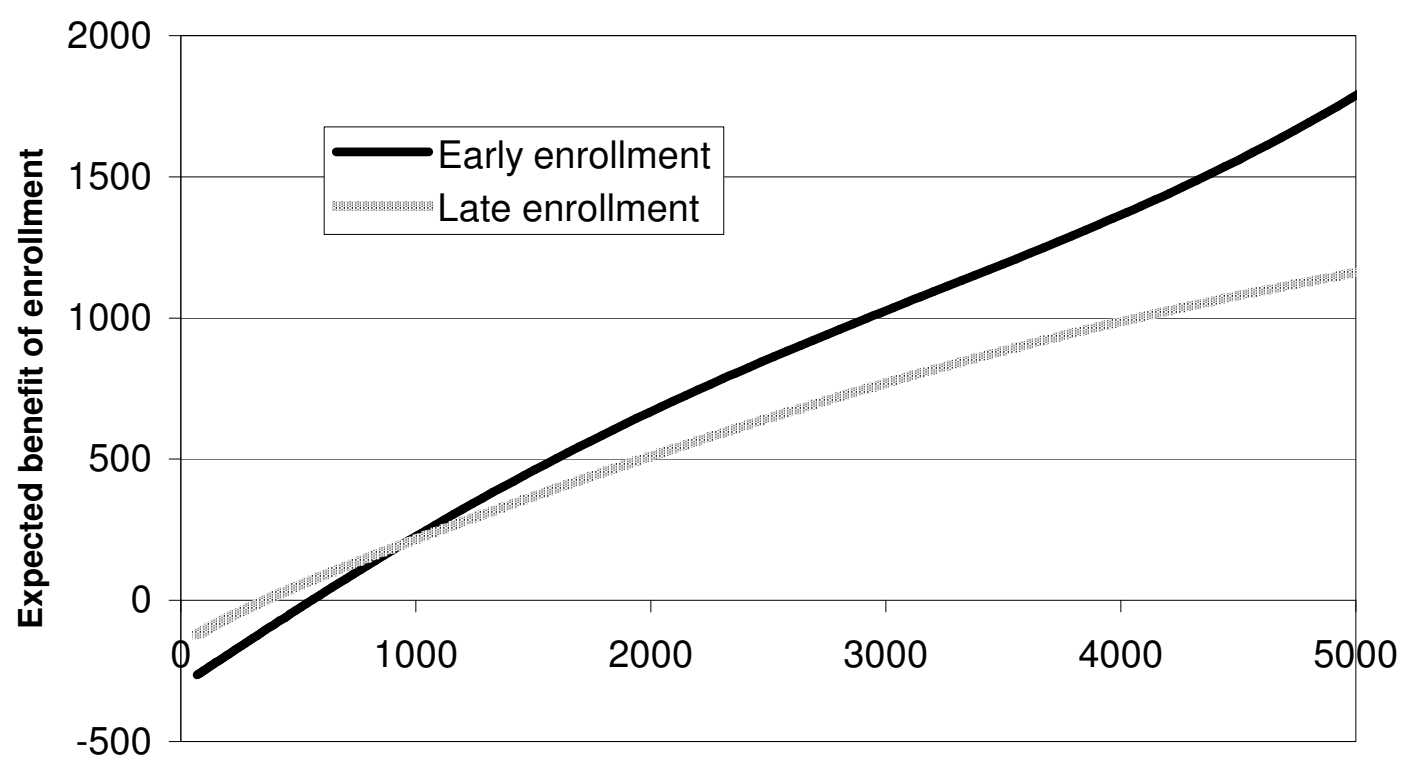

Expected yearly drug bill [\$] 
Figure 3: Distribution of enrollment month

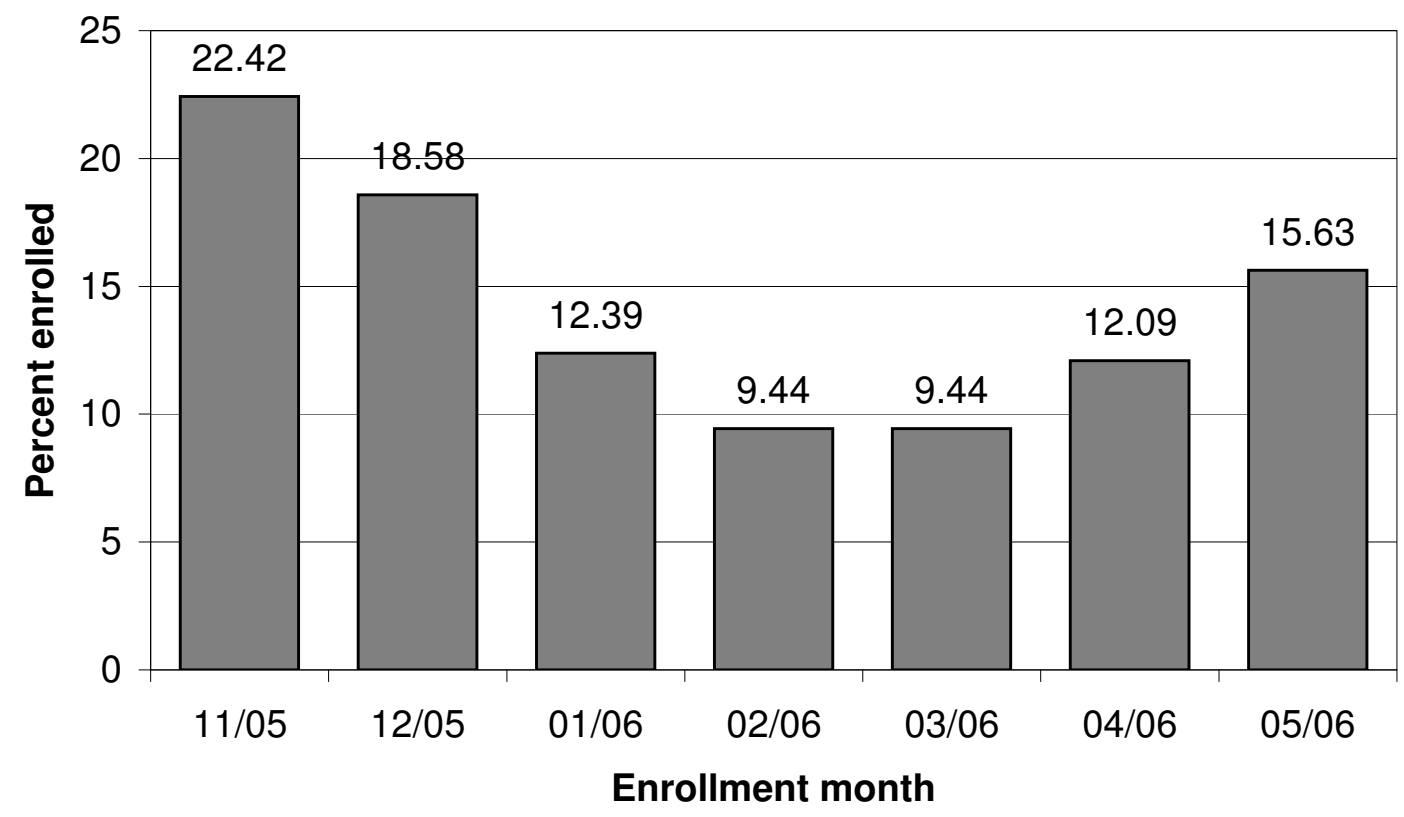

Figure 4: Drug bill distribution by enrollment

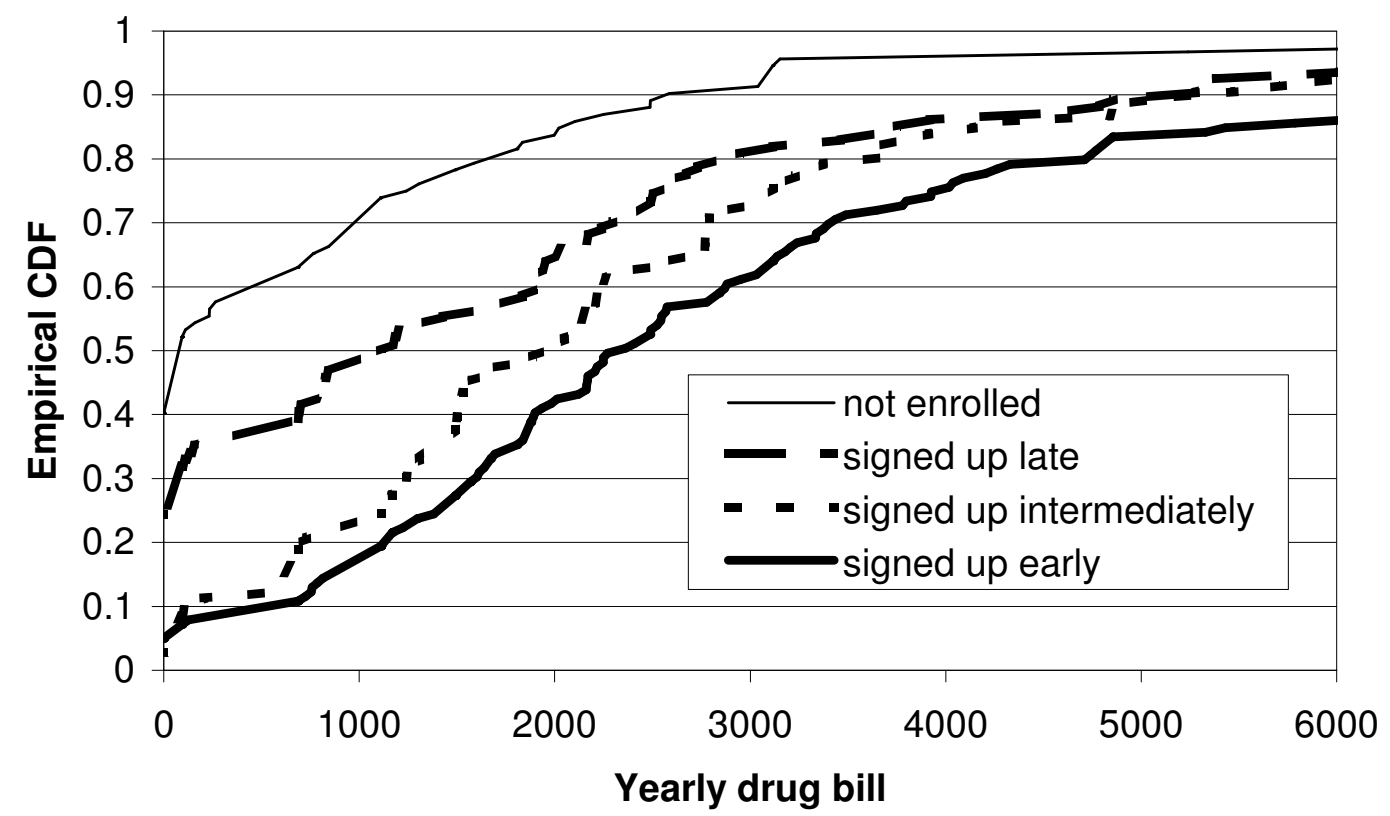


Figure 5: Premiums of Part D plans by coverage type (a) All plans available for 2006

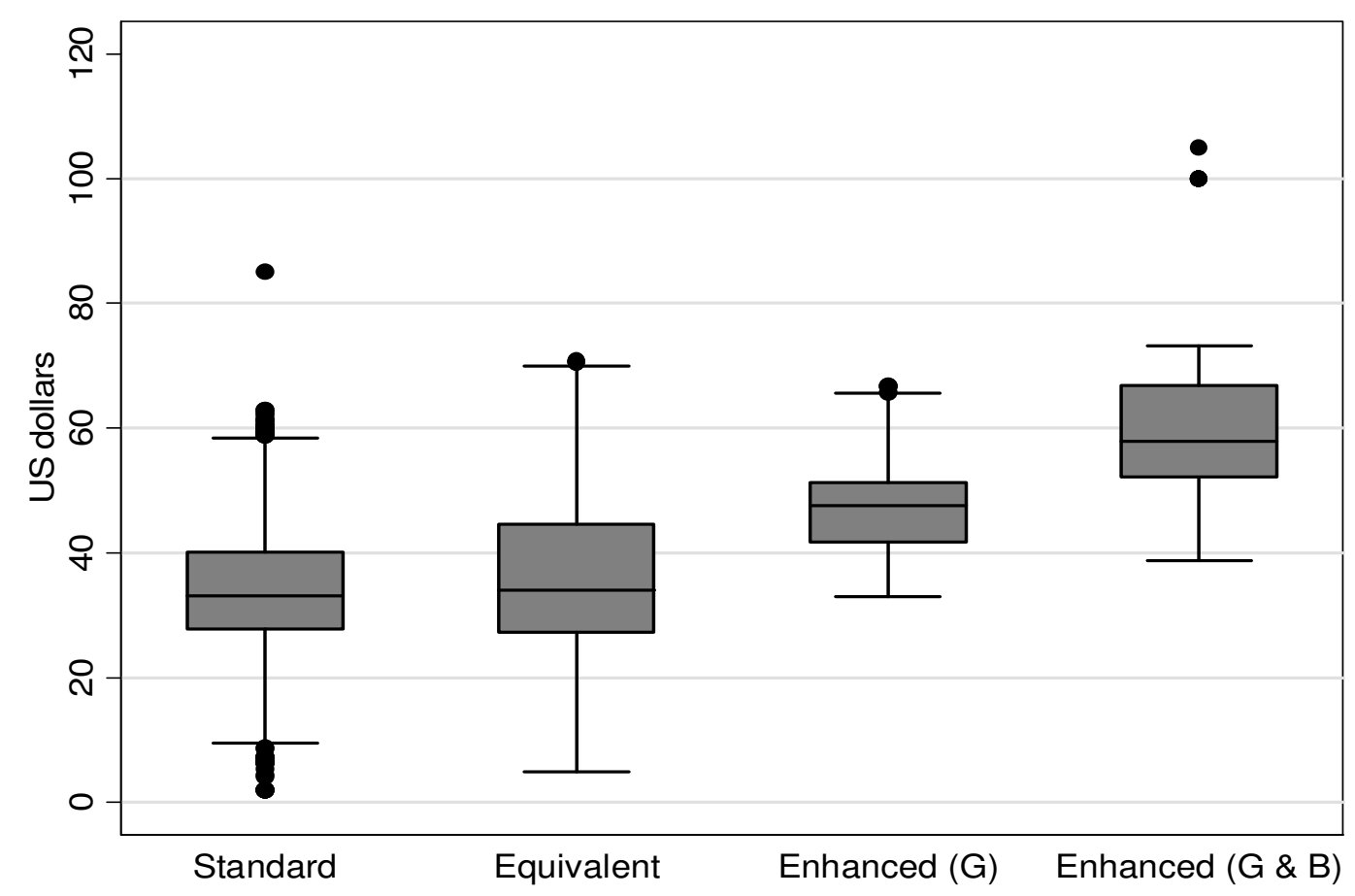

(b) Plans chosen by RPS 2006 respondents

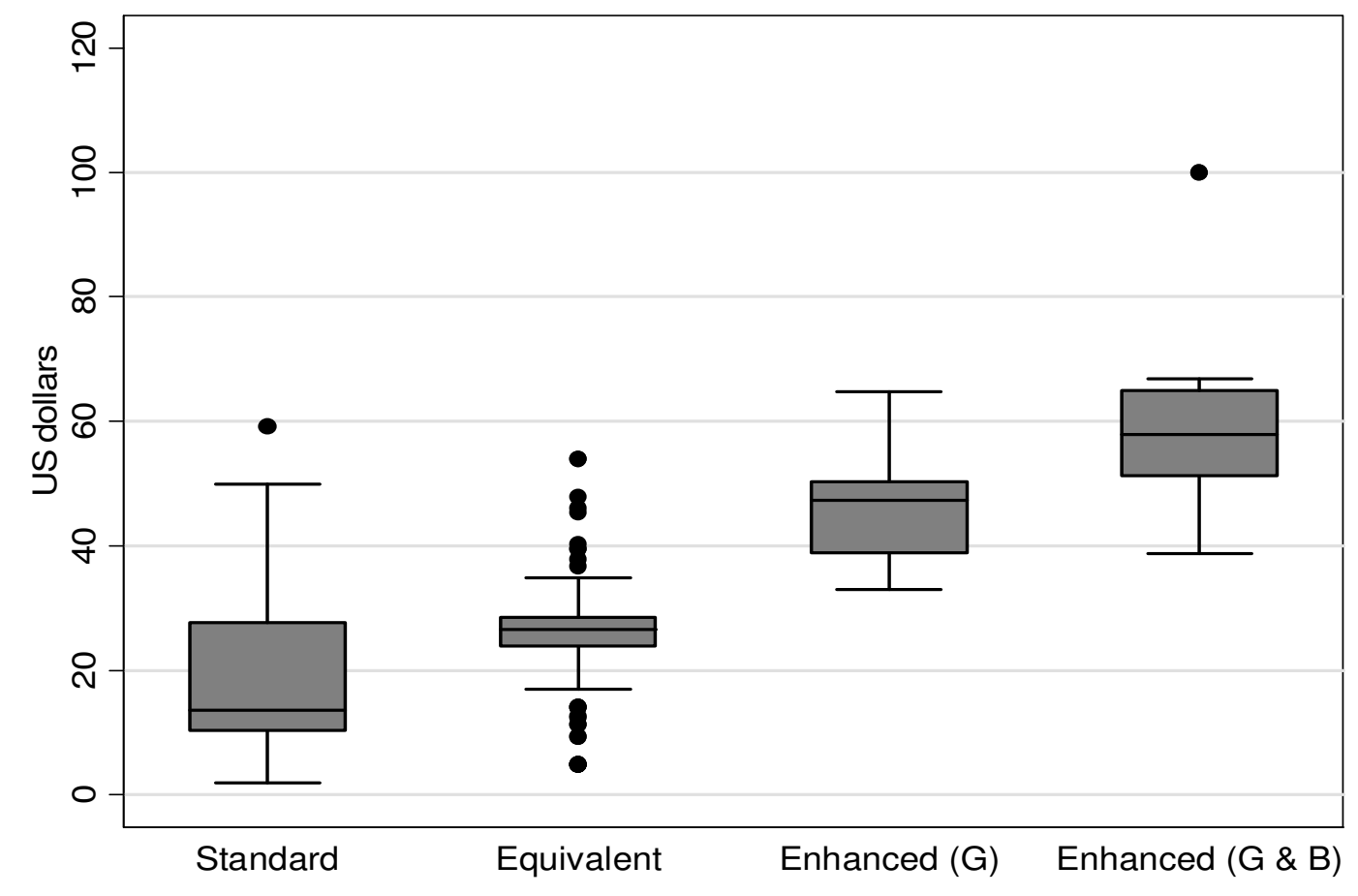


Figure 6: WTP for gap coverage by drug bill (a) 2006 choice

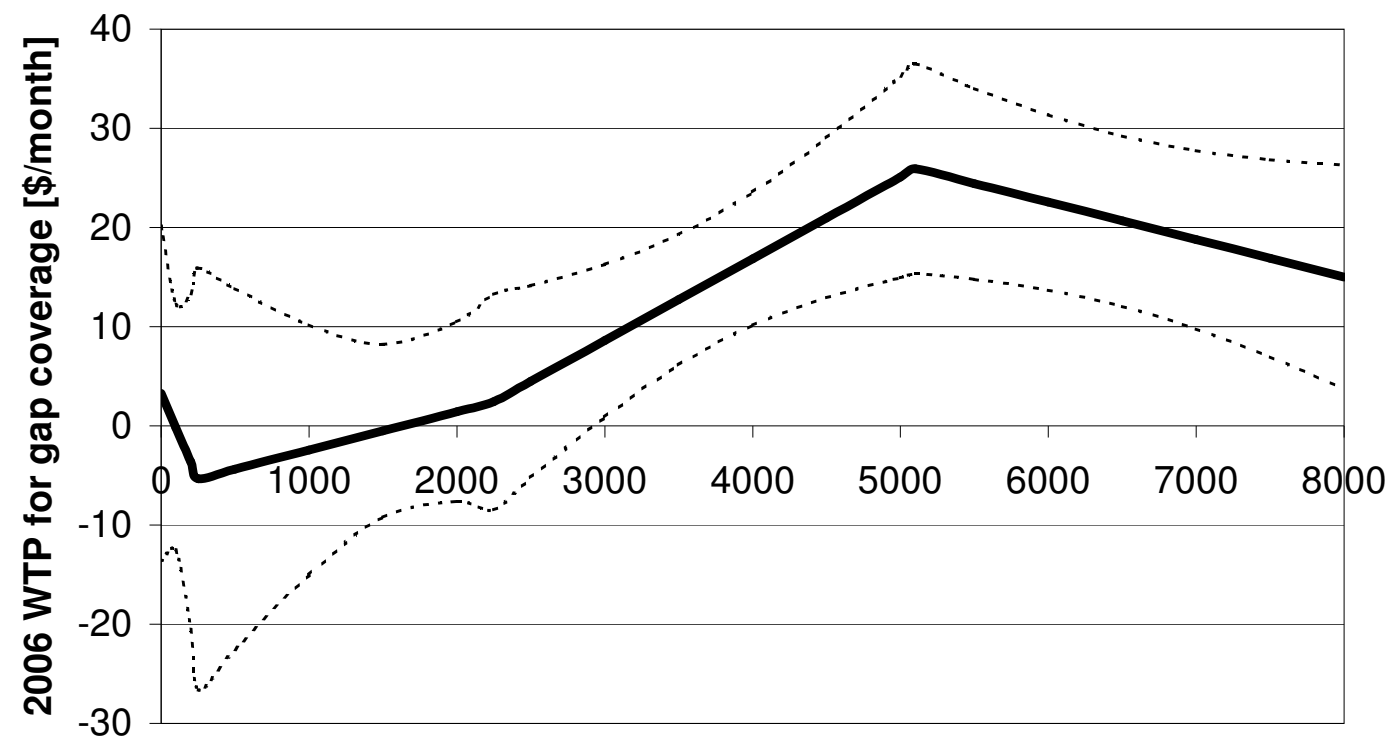

2005 drug bill

(b) 2007 choice

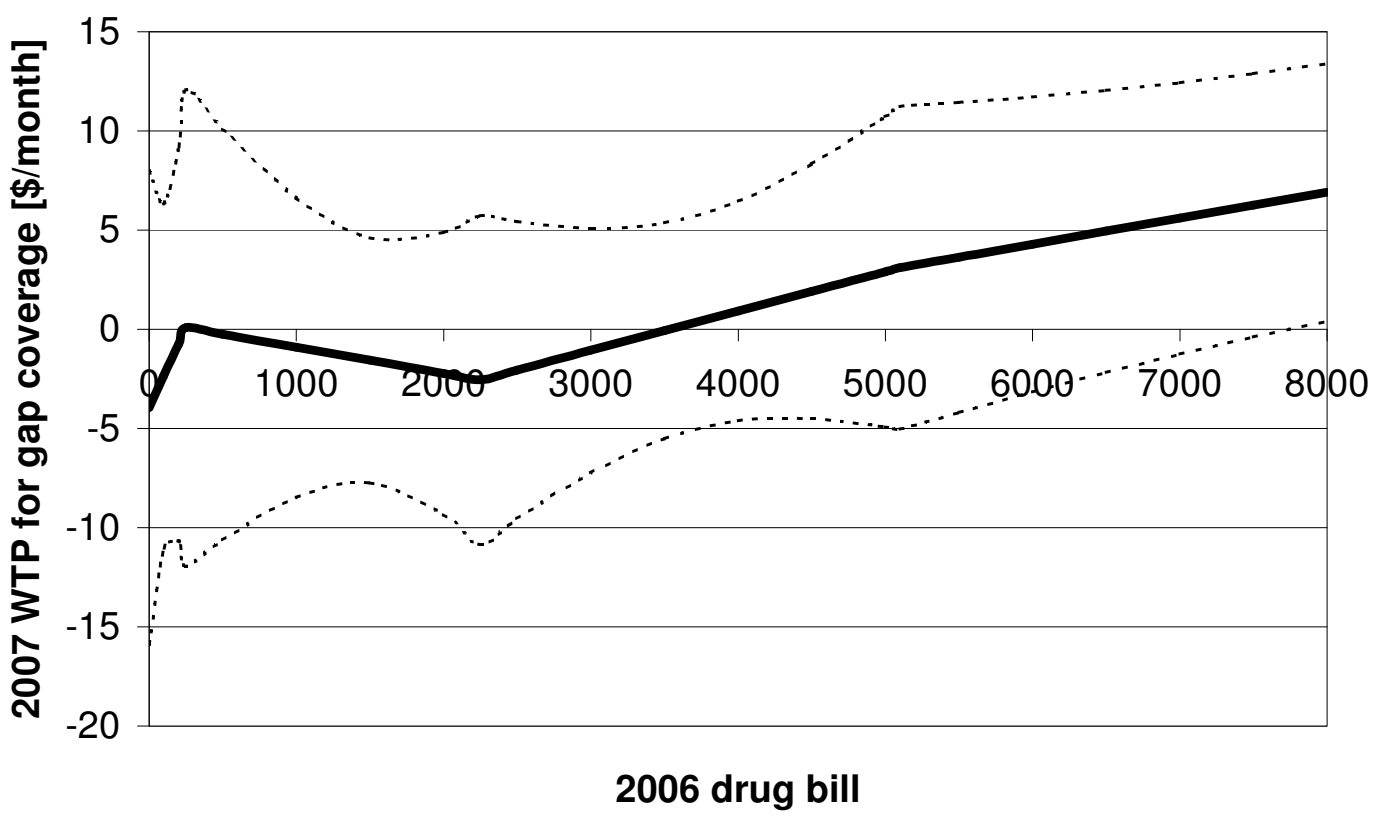

Note: The dotted line corresponds to the $95 \%$ confidence bands. 
Figure 7: Persistence and selectivity: latent robustness by age

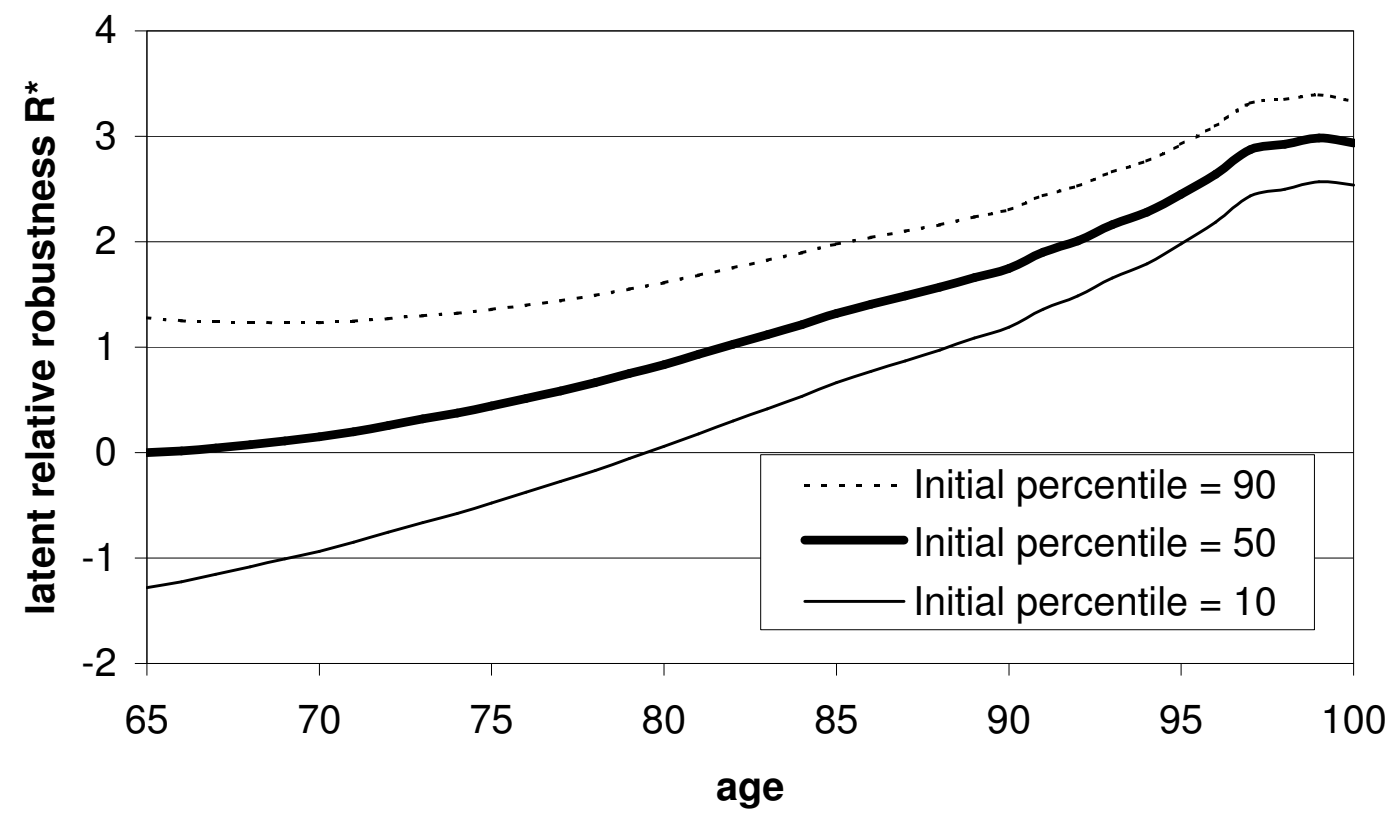

Figure 8: Survival by initial robustness

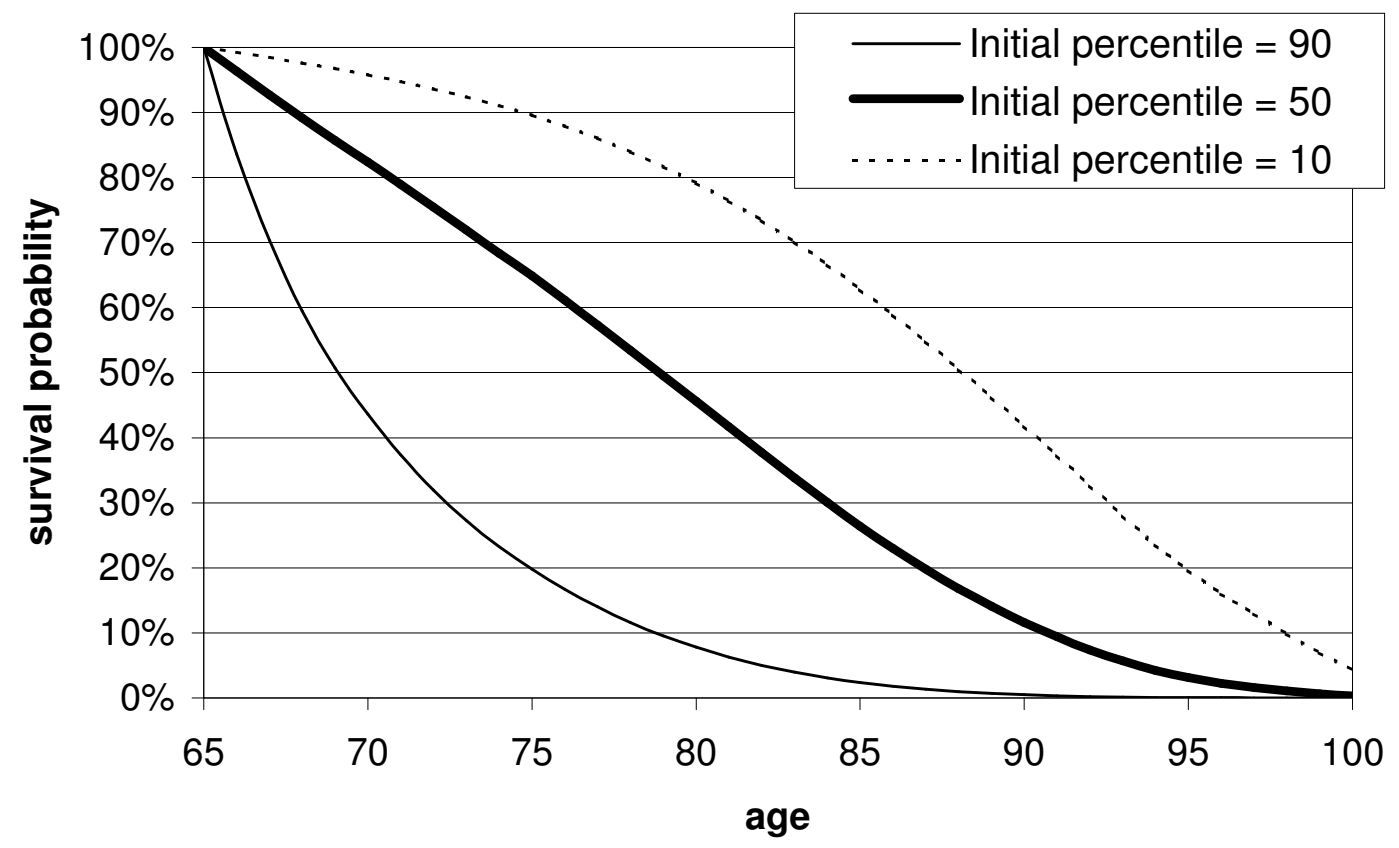


Figure 9: Drug bill by age

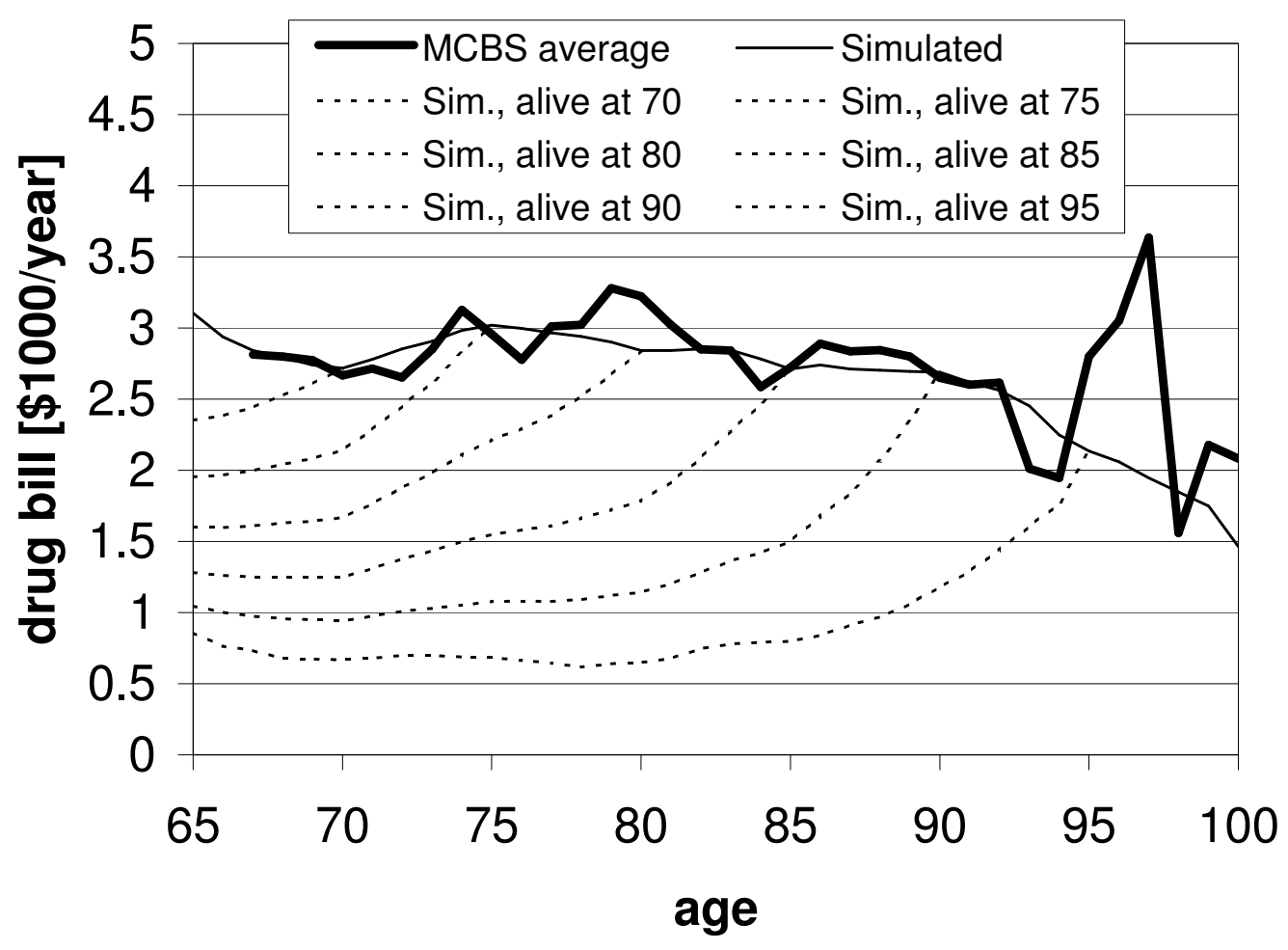


Figure 10: Simulated benefit of enrollment

(a) 65 year old white males with a high school degree or less

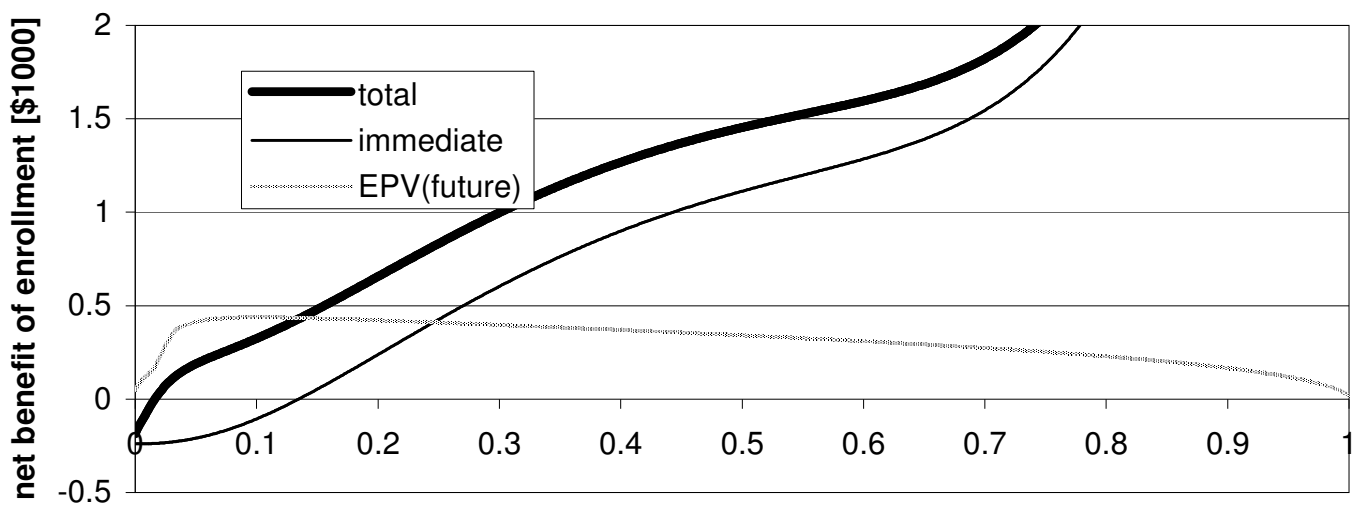

latent health quantile

(b) 65 year old white males with a high school degree or less, zero previous drug bill

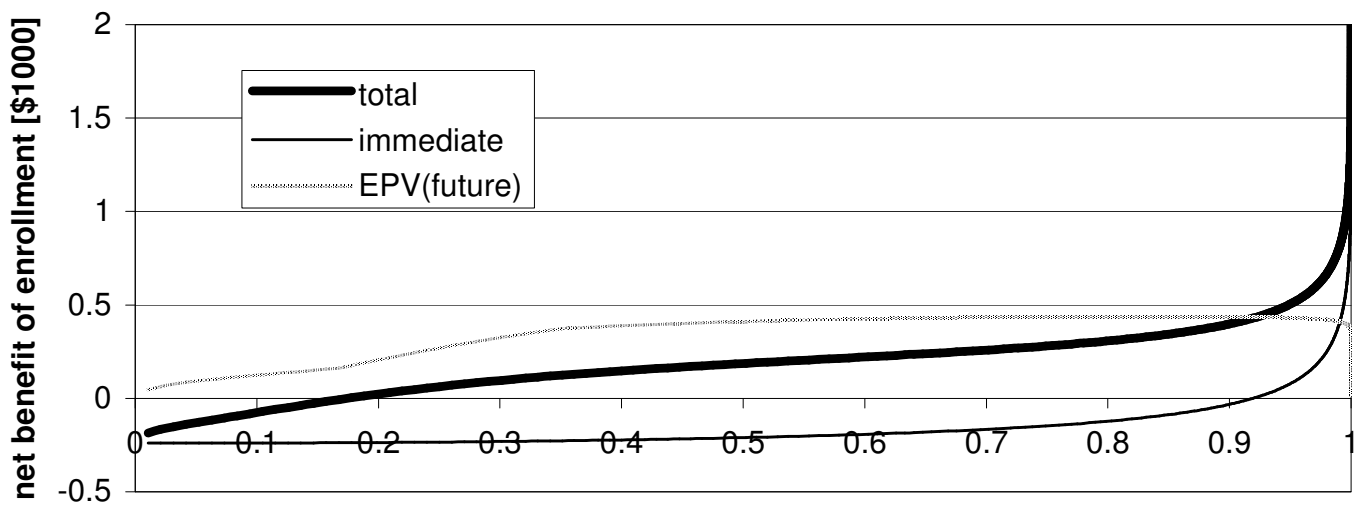

latent health quantile

(c) 85 year old white males with a high school degree or less, zero previous drug bill

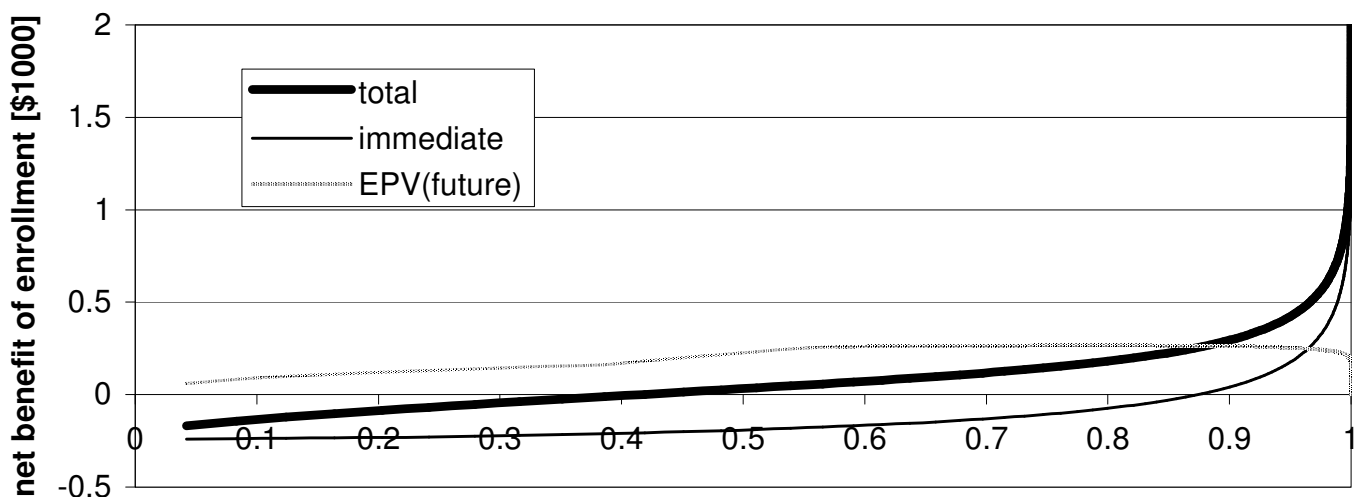

latent health quantile 